\title{
THE RELATION BETWEEN HEATING VALUE OF GAS AND ITS USEFULNESS TO THE CONSUMER
}

\section{A CRITICAL REVIEW OF THE PUBLISHED DATA}

\author{
By E. R. Weaver
}

\begin{abstract}
The introduction, Section I, contains a description of the sources and a discussion of the churacter of the available information which has an important bearing upon the subject treated. The data are divided into two classes, (1) direct observations of the useful effects obtained from the utilization of gases of different qualities in the appliances in common use, and (2) statistical data showing changes in the quantity of gas used which accompanied changes in heating value.
\end{abstract}

Section II contains a summary and some discussion of the data of the first class. Because of the large amount of such material only the briefest summary of such information consistent with clearness has been given. In some cases in which data are not available to the public in published form, and in others in which the reviewer does not agree with the authors upon the interpretation of the data, detailed figures are presented.

Section III contains a summary and discussion of the general significance of the information presented in Section II. There is very general agreement that in all kinds of commercial appliances the potential heat of the gas is used with substantially equal efficiency, whatever the other properties of the gas may be. An explanation is offered for the general applicability of this relation to the results observed with appliances of the most varied character when using gases of any composition within the ordinary limits of commercial supply.

Section IV presents the statistical data bearing upon the subject. It is found that within the limits which could be expected, in view of the numerous conditions which affect the volume of gas used by a community, this volume is inversely proportional to the heating value of the gas supplied. In other words, the amount of potential heat used by a community in the form of gas does not appear to be affected by the heating value of the supply.

Section $\mathrm{V}$ contains a discussion of the statistical data in general and points out the application of the facts established to standards and rates.

\section{CONTENTS}

I. Introduction

1. Character of available data 348

1. Character of available data___. 350

1. Various early investigator gas 352

2. Bureau of Standards, 352

3. R. F. Pierce 355

4. C. N. Cross 362

5. Investigations 365

6. Ges research 365

7. Committee

7. Committee on efficiency and cconomy of gas, Califoruia

8. Recent investigations

9. Detroit testing laboratory 377

10. Efficiency in gas engines 
III. Discussion of direct evidence regarding the usefulness of various qualities of gas . . . .

IV. Data regarding quantity of gas used by customers and its relation to

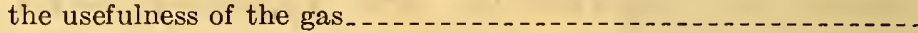

1. Eight Stone \& Webster companies.............

2. California $\ldots \ldots \ldots \ldots$

3. Massachusetts

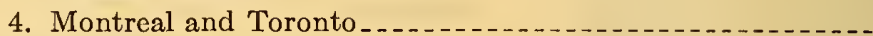

5. Reading, $\mathrm{Pa}_{\ldots}$

6. Providence, R. I

7. Sheboygan, Wis

8. Seattle, Spokane, and Tacoma, Wash......................

9. Philadelphia, $\mathrm{Pa}$

10. New Jersey

11. Rochester, N. Y

12. Selected groups of customers

V. Discussion of changes in volume of gas used before and after a change of heating value

1. Relation of decreased heating value to complaints

2. Relation of relative usefulness of different gases to standards and rates........

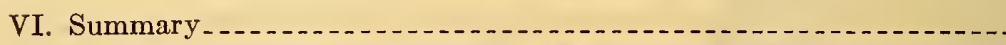

\section{INTRODUCTION}

For many years the question of the relative usefulness of gases of different heating values has been a subject of great interest to the gas industry and one of more or less active controversy. Opinion has been rather sharply divided between (1) those who believe that the available heat delivered to a customer in the form of gas is the useful commodity for which the customer pays and the amount of heat delivered is a measure of the value received, and (2) those who regard the meter readings as a true measure of the service rendered, without much regard to whether the gas metered has a high or a low heating value.

The importance of the subject can not be overestimated. If the second view is an entirely correct one, then there is no reason why each gas company should not distribute gas of whatever heating value it pleases, without any consideration of the rate at which the gas is sold. If the first view is correct, then the heating value of the gas per cubic foot is of as much interest to each customer as the readings of his meter; and the heating value maintained must be regarded as one of two equally important factors, both in the measurement of the service for which the customer pays and in the determination of the rate at which he should pay for such service. The engineering problems of the industry are equally affected. If available heat is essentially what the utility is furnishing, the engineer should determine and adopt the method of manufacture which will deliver at the point of sale the maximum amount of heat per unit 
cost. If the meter reading is the true measure of the company's service, as well as the means of determining how the company's product is distributed among its customers, then the engineer has only to determine and adopt the methods of manufacture and distribution which will deliver some kind of gas at the lowest cost per cubic foot, always, of course, with the reservation that the gas distributed will burn. If neither of these extreme views is entirely correct, but the truth lies somewhere between them, it is of the utmost importance to determine what relation does exist between the quality of a gas supply and its usefulness, primarily as an aid to the engineers of the industry who are responsible for serving the public at minimum cost; secondarily, to assist the gas companies and the State commissions, or other regulatory bodies in arriving at a satisfactory arrangement with respect to service requirements and rates.

This paper is the result of an effort to collect and evaluate the existing data which have a bearing upon the question. Partly because of lack of time, and partly because the evidence of that portion of the data which can ever be made complete (statistics regarding consumption can be selected without end) is so consistent that the conclusions to be drawn from it could not be modified by a few additional observations, no exhaustive search of the literature has been made; but those papers which have been found to contain definite and original data have all been included in the review. Approximately 300 articles, including editorials, which had a bearing upon the subject were scanned, and those which seemed important were carefully read; but most of these contained no original quantitative data and are therefore of little value in this connection. The public service commissions of all the States were asked to supply any data which they might have on file. A similar request was sent to the president of the American Gas Association. The past correspondence of the Bureau of Standards relating to this subject was also reviewed. In order to limit the length of the paper, it was finally decided to use only data which had been published (or had been used in support of published arguments without quotation) and data which had been used before National, State, or municipal regulatory bodies as evidence in hearings on rates or standards.

The review when completed was submitted for criticism to the American Gas Association, which appointed a committee for the purpose. The association printed the text of the paper in full, but without illustrations, and distributed it widely, collecting from executives and engineers among its membership such corrections and opinions as were offered. The reviewer has endeavored to meet all the suggestions presented, and in the few cases of remaining differences of opinion care has been taken to distinguish between the reviewer's opinion and what are unquestioned facts. 
The assistance of the association, especially that of Dr. J. F. Wing, who assembled and presented the opinions of the industry, is gratefully acknowledged.

\section{$\because$ F 1. CHARACTER OF AVAILABLE DATA}

The data available are of two kinds: (1) The direct observation of the useful effect which may be obtained by burning gases of different heating values in representative appliances, and (2) the amount of gas burned by all the customers of a gas company or by a selected group of customers before and after the heating value of the gas has been changed.

A distinction is frequently made between practical and theoretical methods of determining technical facts and relationships. By the practical method is usually meant the most direct observation of the facts in question that can be made; by the theoretical method is meant the observation of facts from which the desired information may be obtained only by the use of a relationship or theory which is known or assumed to hold with more or less accuracy. Unquestionably the practical or direct method is the more valuable when it can be applied, because few of our theories are entirely complete and reliable, and complicating factors are likely to enter which we either overlook or do not know how to allow for. The indirect method, depending upon theory, is justifiable only when the observations upon which it is based can be made more easily or more accurately than the direct ones.

In the present case what we wish to find out is how useful gas of each quality is to the user; how much water he can heat to a temperature comfortable for bathing with a given amount of it; how warm he can keep his living room by burning it; how quickly he can cook his dinner with it; how much light he can get by burning it in a mantle, and the like-all these when employing the appliances in common use.

Facts of this kind are subject to direct, easy, and accurate observation, hence there is but little need for applying a theoretical method to the study of the question. There can be no doubt that data on the amount of gas burned before and after a change of heating value have a highly theoretical relationship to the usefulness of the gas before and after the change. The theory involved is, of course, that the customers get the same service before and after the change. Not only is the application of this theory complicated by the fact that the demand for service is always fluctuating, as shown by the sales of any company which is not changing the quality of the gas, but there is every reason to believe that the theory would be incorrect even though all factors which would cause a change of demand were eliminated except the change of heating value. This is so because 
in many cases the customer can not get the same service when the heating value is reduced; he can not keep a room as warm, or heat water, or bake bread as quickly, unless a change is made in the appliances used.

Hence, we can not regard the data based upon consumption as having anything like the value of direct observations upon the performance of appliances. The emphasis which is here placed upon the difference between the two classes of available data may seem unnecessary in view of the fact which will develop in the discussion that both classes lead to substantially the same conclusion. A distinction should be made, however, because the interpretation of the data on consumption is so uncertain in some cases that their real significance might be in doubt were it not for the positive evidence of almost all of the direct tests.

One other distinction should be made between the two kinds of data. The accurate tests of performance of appliances give definite and reproducible numerical results, of the significance of which there can be little doubt. There is, therefore, little chance for personal judgment or prejudice to enter into their interpretation. On the contrary, personal judgment is unquestionably an important factor in the selection and evaluation of data relating to consumption. Nearly every gas company in the world (except natural-gas companies) has changed the heating value of the gas supplied at least once, and many companies have changed it several times in the past 10 or 12 years. The published data relating to consumption are selected from these companies in the most varied manner. In some cases comparisons are made for whole cities or even a whole State; in some cases they relate to selected customers in groups as small as two or three. Sometimes the data selected cover a period of several years; in other cases the comparison is made between a single month of each of two years which may not be consecutive. Sometimes the comparison is made on the basis of consumption per meter by the same customers; sometimes on the number of customers having a given consumption; sometimes on the total sales of the company. Obviously, with these many ways of and opportunities for selecting data an almost infinite number of possible selections can be made, and only those which appear to their authors to be of unusual significance or importance will appear in the literature.

In order to reduce the element of personal judgment in the selection of data by the reviewer, certain rules have been adhered to. The discussion has been strictly limited to cases which have been made public either by publication or presentation before regulatory bodies. Witbin this group all the direct determinations of relative usefulness which have come to the attention of the bureau have been included, and so have all the statistical studies which covered the community 
under consideration in a reasonably complete manner. The statistics published have been freely supplemented by unpublished data which give more complete or accurate information regarding the communities in question. Most of the small groups of selected customers have been disregarded for reasons which will be stated later.

There are, in addition to the papers containing data upon consumption and direct determinations of useful effects, a good many papers, the authors of which endeavor to deduce from flame temperatures, flame velocities, and the like, what the usefulness of gases of various compositions ought to be. Many of these papers are of great value in giving us a better understanding of the reasons for the various phenomena observed in the utilization of gas; but they are generally quite useless as a guide to the utility of gases because none of the theories are complete enough and in close enough accord with observed facts to deserve serious consideration for this purpose.

\section{DIRECT OBSERVATIONS UPON THE USE OF GAS}

\section{VARIOUS EARLY INVESTIGATORS}

The question of the relative usefulness of gases of different compositions has been an active one for 20 or 30 years. One of the first investigators of the subject seems to have been Thomas Fletcher. Two of Fletcher's papers ${ }^{1}$ give the results of comparative tests of Dowson gas and 18-candlepower coal gas for room heating with an incandescent iron fret, for cooking, and for melting iron. The results given are only approximate. The heating values of the two gases were probably in the ratio of about 3.5 or 4 to 1 . Fletcher found that their value was in the ratio of about $3: 1$ for room heating, $7: 1$ for melting iron rod, and $4: 1$ to $10: 1$ for cooking. Fletcher's other papers on this subject were not accessible to the reviewer, but their results are summarized very briefly by his son, T. W. Fletcher, ${ }^{2}$ who points out that there is nothing new in the finding of the gas research committee of the Institution of Gas Engineers that the usefulness of gas is directly proportional to its heating value, since the same conclusion was reached by his father. The following is a quotation from the article referred to:

I venture to suggest that the numerous investigators in this direction should take the trouble to search the writings and lectures of the late Thomas Fletcher, F. C. S., and they would find that little or no new light is thrown on the subject by the above-named report [the first report of the research committee] and that practically there has been no further advancement since his days. Exhaustive experiments with all grades of gases from undiluted oil gas to blue water gas were conducted by him at various pressures.

His tests proved that, other things being equal, the actual economical results varied very little, whatever the calorific value of the gas, provided only that the burner was constructed on scientific lines and properly adjusted in the first place.

1 Thomas Fletcher, Jour. Gas Lighting, 79, pp. 955-956, 1018; 1902.

T. W. Fletcher, Gas. Jour., 144, p. 315; 1918. 
For several years after Fletcher's experiments interest seems to have centered about the effect of the quality of gas upon the service obtainable from mantle lights. Sainte Claire Deville was a pioneer in this investigation. His first work was done in 1894 and continued and published at intervals thereafter until $1907 .^{3}$ The elaborate researches published as a report of the International Commission on Photometry ${ }^{4}$ led him to "the especially interesting conclusion that the light produced per 1,000 heat units employed is substantially constant * **. The heating value of a gas is an accurate criterion of its value for the purpose of mantle lighting." Further work on various enriched mixtures of coal and water gases confirmed the earlier conclusion. ${ }^{5}$ Deville's work is summarized as follows by Forshaw: ${ }^{\circ}$

M. Sainte Claire Deville investigated a number of different composite gases comprising blue water gas, coal gas, and various mixtures of the two, whose net calorific values varied between 76.8 and 208.8 calories per cubic foot (water gas to cannel gas). He employed an atmospheric burner especially constructed so that the relative proportions of air and gas in the mixture could be accurately measured. He found that the duty of a given gas (defined as candles per cubic foot per hour when the proportion of air admitted with the gas is so adjusted as to give the highest illuminating effect for the particular rate of gas consumption) invariably increased with the rate of consumption up to a certain maximum. Beyond this maximum an increase in the rate of consumption caused no further increase in the duty, which, after remaining constant within a certain limited range of consumption, depending upon the size of the mantle, at length fell off considerably.

Taking in each case this maximum duty as the proper basis of comparison with the different gaseous mixtures examined, he concluded that-

1. The duty obtained for the expenditure of a given number of units of heat per hour remains constant within 15 per cent throughout the whole range of illuminating gas from neat water gas to neat cannel gas.

2. That therefore it must be granted that the specific or normal illuminating duty in the incandescent burner is proportional to the calorific value of the gas.

Deville ${ }^{7}$ later pointed out that his generalization did not necessarily hold accurately in the case of all atmospheric burners in general use because of the necessity of adapting the burner to the gas to be used. As an example he quoted a series of observations made in 1894 upon one burner in which the consumption of gas per carcel changed only about 75 per cent as rapidly as the change of heating value.

In a review of his work presented to the International Photometric Commission Deville ${ }^{8}$ repeats the conclusions already given and adds the following significant statement (p. 344):

\footnotetext{
3 Jour. Gas Lighting, 106, pp. 871-872; 1909.

- Sainte Claire Deville, J. Gasbel., 47, pp. 21-27, 46-51, 75-79, 90-95; 1904.

s Sainte Clairo Deville, J. Gasbel., 51, pp. 1097-1 105, 1128-1131; 1908.

6 Jour. Gas Lighting, 106, p. 865; 1909.

7 Deville, Jour. Gas Lighting, 107, pp. 370-371; 1909.

8 Proc. Am. Gas Inst., 6, Pt. II, pp. 315-362; 1911.
} 
* * * it must be granted that the specific or normal illuminating duty in the incandescent burner is proportional to the calorific power of the gas, and the story of the preponderating part played by the flame temperature must no longer be allowed to circulate.

Russell and White ${ }^{9}$ in experiments with gases ranging from pure hydrogen and blue water gas to Pintsch gas and natural gas reached the following conclusions:

1. The consumer's method of adjusting an incandescent gas burner to give a maximum illuminating power also gives him the greatest efficiency.

2. This method of adjusting is also the proper one when gases are to be tested with incandescent mantles. A test with a fixed consumption for several gases will be unfair to one or all.

3. Under a gas pressure of 2 inches of water, when the burner is adjusted to give maximum illuminating power, the number of candles per cubic foot of gas consumed will increase almost directly with the net calorific value, increasing at the rate of one candle per cubic foot for every 4 calories increase in the net heating value.

White and his coworkers encountered minor irregularities, some of which they did not fully explain. Particularly noteworthy are the relativcly low efficiency of carbon monoxidc when using the Welsbach burner and the high efficiencies of the gases of highcst heating valucs-natural gas, Pintsch gas, and their mixtures with coal gas when using the Humphrey burner.

Edward Allen, ${ }^{10}$ in a scries of tests of mantle lights with gases ranging from about 600 to $685 \mathrm{~B}$. t. u., found that the available light fell off, on the average, 3.6 times as rapidly as the heating value.

Forshaw, ${ }^{11}$ in a series of experiments upon hydrogen and carbon monoxide, reached an opposite conclusion to that of White and his collaborators with regard to the relative efficiencies for mantle lighting of the two gases. He found that "with an ordinary burner carbon monoxide invariably gives a very much higher duty than hydrogen " and decided that there was no very close relation between heating value and mantle candlepower.

Mayer and Schmiedt, ${ }^{12}$ however, in an investigation of the questions involved in mantlc lighting, confirmed the "principle of Deville, that various gases give the same amount of light in the Welsbach burner for the same amount of applied heat" as a "uscful rule." In the course of further experiments, in which he dispensed with a measured air supply, Mayer ${ }^{13}$ found a considerable advantage in the efficiencies of mixtures having a high perccntage of hydrogen. $\mathrm{He}$ criticized the conclusions of Forshaw on the ground that no one burner could be adapted for the favorable use of gases having such

\footnotetext{
$\theta$ Russell and White, Jour. Gas Lighting, 77. pp. 879-881; 1901. See also White, Russell, and Traver, Jour. Gas Lighting, 79, pp. 892-894; 1902. White and Traver, Jour. Gas Lighting, 80, pp. 562-565; 1902.

${ }^{10}$ Edward Allen, Jour. Gas Lighting, 96, pp. 601-603; 1906.

11 Forshaw, Jour. Gas Lighting, 106, pp. 865-872; 1909.

12 Mayer and Schmiedt, J. Gasbel., 51, pp. 1137-1140, 1163-1170; 1908.

${ }^{13}$ Maver, J. Gasbel., 63, pp. 933-939; 1910; Jour. Gas Lighting, 112, 197-199; 1910.
} 
different flame volumes as pure hydrogen and carbon monoxide. The article concludes with the statement:

Deville's proposition is not directly a law; but for mixtures of gases within a certain range of calorific power it becomes a useful rule, which is shown by the author's experiments to be valid, for low-pressure upright incandescent burners with the descriptions of illuminating gas now commonly employed.

The relation between heating value and mantle candlepower was investigated by Bunte, ${ }^{14}$ among several other properties of coal gas and mixed gas in the range between 520 and 630 B. t. u. Bunte's observations also showed substantial'proportionality between the heating value of a gas and the light obtainable by burning it in a mantle.

The Portland Gas \& Coke Co., of Portland, Oreg., appears to have been the first company in this country to go to the trouble and expense of making direct experiments upon the usefulness of gases of different qualities. The work was done in connection with an application of the company for a reduction of the heating value standard, and accompanied plant experiments intended to determine the cost of gases of different qualities. The conclusions drawn from the investigation were presented by Hilmar Papst, general manager of the company, in a paper entitled "Standards of quality and service for oil gas," read before the Pacific Gas Association in September, 1913, a report to the Railroad Commission of Oregon, dated January 23, 1914, and two reports to the Bureau of Standards dated December 15, 1913, and August 20, 1914. Papst's conclusions may be briefly quoted from his report of December 15, 1913:

In order to make the recommendations of greater value $I$ have gone to the expense of operating our old plant along experimental lines. The data, therefore, which I give you on the very low B. t. $u$. gases are the result of actual tests * * *. In this connection the adaptability of the gases of various qualities were experimentally tried out on the various consumers' appliances without any readjustment, and it was practically demonstrated that with slight changes in apertures as good service can be given as at present but necessitating somewhat higher street pressures.

At the same time it was experimentally demonstrated that the consumption in B. t. u. remains substantially the same irrespective of the B. t. u. contents of the gas; for example, the efficiency in heating water from the burner of an ordinary reliable stove in a common kitchen kettle was approximately 47 per cent with gas of 450 and 550 B. t. u.

\section{BUREAU OF STANDARDS, 1913-1917}

In 1913 the Bureau of Standards began an investigation of the general subject of the effect of the quality of gas upon its usefulness. This investigation was continued, with some interruptions, until the spring of 1917. At the start of the investigation the bureau sent out a circular letter to a large number of the leading engineers of the gas

\footnotetext{
- Bunte, Jour. Gas Lighting, 119, pp. 40-43; 1912.
} 
industry asking for data bearing upon the subject. A similar appeal was inserted in one or more of the technical journals. In reply a great many opinions were received, but they were backed by surprisingly little definite information.

Within the range of heating values covered, the experiments made by the bureau during the years 1913 to 1917 constituted probably the most thorough study of the use of gas ever made, not excepting that of the gas research committee of the Institution of Gas Engineers and of the Joint Committee on Efficiency and Economy of Gas, whose reports will be discussed later.

Unfortunately, the research was interrupted by the war when half completed; and before conditions had been restored which would permit the continuation of the work all of those who had had an important part in it had left the bureau and only that portion of the unfinished work dealing with mantle lighting was ever published in any detail.

All of the work was done under the general charge of R. S. McBride. J. C. Dickerman, W. A. Dunkley, and C. E. Reinicker were in charge of various phases, and E. C. Crittenden and A. H. Taylor had charge of the photometric work on mantle lighting.

About half of the work actually completed was done at the Bureau of Standards and half at the plant of the United Gas Improvement Co. in Philadelphia.

The investigation did not merely include direct comparisons of a number of gases under conditions assumed to be otherwise comparable; a detailed study was made of the effect of varying each condition which might influence the result. For example, the tests upon the efficiencies of gases for top-burner cooking included, in addition to the effect of the quality of the gas, a study of the effects of the sizes and types of burners, rates of combustion, pressure and size of orifice (that is, what is the difference in effect between gas delivered through a large orifice at low pressure and the same quantity of gas delivered through a smaller orifice at higher pressure), the adjustment of air shutters, the characteristics of the flames (height, color, etc.), the distance of the utensil above the burner and above the flame tips, and the shape, size, and material of the utensils heated.

In interpreting the results in terms of the usefulness of various gases, comparisons were made in various ways. For example, comparisons were made (1) of the amount of gas required to perform a given operation (for example, to heat water in a cooking utensil at a certain rate), or when burned at a constant rate to maintain the temperature of an oven, of a muffle furnace, or of a platinum crucible in an open flame; (2) of the relative time required to perform a certain operation (for example, to bring water to boiling or to bring an oven to a certain temperature) with gases burning at the same rate; 
(3) of the useful effects continuously available from the combustion of the same volume of gas (for example, the light available from a mantle, the temperature at which a furnace can be maintained, etc.); and (4) of the maximum efficiency obtainable with the appliance under any condition of operation.

The appliances tested included at least 11 top burners of different sizes or designs; three ovens, including the oven of a well-constructed gas range and a portable oven for use above a hot plate; an automatic instantaneous water heater; a tank water heater; a small muffle furnace; and a considerable variety of burners and mantles for incandescent light. Observations were also made of the heating of a platinum crucible with the open flame of a Tirrill burner.

The number of tests necessary for so complete an investigation was, of course, very large. As nearly as can be ascertained from the notes (the earlier notes are somewhat confused) 1,661 efficiency tests were made with top burners, 65 with ovens, 69 with the instantaneous water heater, 59 with the tank water heater, 87 with the muffle furnace, and 74 with the platinum crucible in an open flame.

It is quite impossible in a review of this kind to present and interpret such a mass of data; only the bureau's conclusions and some comment upon the methods of study can, therefore, be given.

The following quotation regarding the tests with top burners is taken from the bureau's "Report to the city of Chicago and Peoples Gas Light \& Coke Co.," dated December 28, 1916, after the completion of practically all the top-burner tests made in Philadelphia as well as Washington. In further references this report will for brevity be called the "Chicago report."

In most domestic operations, whether heating a teakettle, boiling vegetables or cereals, or even in deep-fat frying, the heat reaches the food material by the following stages: (1) Heat liberated by gas combustion, (2) absorption of some of this heat by the material of the dish, (3) absorption of heat by the liquid from the material of the dish, and finally, (4) the absorption of the heat by the food material. In frying, the only difference is that the food takes up the heat directly from the interior surface of the pan.

In either process, as far as the usefulness of the heating effect of the gas is concerned, the main thing is the absorption of heat by the material of the dish. In all heating problems this is the important and most difficult step, and, of the heat taken up by the pan, that which is available for the cooking operation is independent of the kind of gas used. The food material within the pan is absolutely indifferent to the source of heat exterior to the pan, provided such source produces the temperature and quantity of heat required within the pan. The problem *** resolves itself into a study of the conditions which affect the absorption of heat from the burning gas by the metal or material of the vessel. This important stage of heating is most accurately measured for practical purposes by measuring the heat absorbed by water in continuous contact with the material of the container. 
The following comment upon the effect of rate of combustion upon the results of top-burner efficiency tests is quoted from the notes of J. C. Dickerman:

The rate of combustion has a definite influence on the efficiency and is one of the important factors. At low rates, under $5,000 \mathrm{~B}$. t. u. per hour with burners of the usual size, the efficiency is less than between 6,000 and 9,000 B. t. u. per hour. In excess of 10,000 B. t. u. per hour the efficiency falls off, accompanied by marked evidence of increasingly imperfect combustion. Curiously, maximum efficiency is usually accompanied with some incomplete combustion. This is probably explained by the theory that the greatest efficiency is obtained when the gas is burning close to the pan with no large excess of air supply and giving maximum temperature against the pan bottom. Under such conditions the cooling effect of the pan surface, combined with the limited and irregular admixture of the air supply, prevent the complete combustion of all the gas constituents.

When comparing gases of considerable difference in heating value per cubic foot, it is necessary to make the comparisons on the basis of the same B. $t$. u. per hour liberated by the combustion rather than at the same number of cubic feet per hour. The results of the bureau's tests are all compared on the basis of the same B. t. u. per hour.

At the conclusion of 968 efficiency tests on top burners, Dickerman wrote as follows in his notes, under the heading "Top-Burner TestsGeneral Conclusions":

Our tests of the efficiencies of highly enriched or $715 \mathrm{~B}$. t. u. gas, ordinary rich gas of about 650 , and lean water gas of about $550 \mathrm{~B}$. t. u. show under some conditions a slightly higher efficiency for the $550 \mathrm{~B}$. t. u. gas; at other conditions, substantially no differences; and under still other conditions, less efficiency for the 550 gas as compared with richer gas. In other words, efficiency curves will cross. Nowhere is there any distinct evidence that the general efficiency for top-burner cooking of a rich or high candle and heating power gas as compared with a lean or low candle and heating power gas varies in any other proportion than that due to the difference in their B. t. u. value as shown by the calorimeter.

Following the substantial completion of the work done in Philadelphia, which covered a wider range of gases than that done at the bureau by Dickerman, the following general conclusion was drawn with respect to top-burner cooking (Chicago report, p. 18):

The conciusions of the bureau, therefore, with respect to the significance of these results to the gas user are as follows: Manufactured gases, consisting of carbureted water gas or mixtures of the same with coal gas, or coal gas alone, of widely different B. t. u. per cubic foot, can be used with substantially equal efficiency - that is, with the same heat utilized per 1,000 B. t. u. produced-in existing cooking appliances, provided the air shutter, gas orifice, and pressure are in suitable adjustment for each kind of gas.

The following quotation from Dickerman's notes explains the tests on oven heating:

Gas-oven cooking is essentially a process in which the products of combustion of the gas, mixed with some excess of air, circulate through the oven, around the food or its containers, maintaining the temperature necessary for cooking, and finally escape, together with any material evaporated from the food, to the flue 
or outer air. Heat from the burning gas must be supplied at a rate sufficient to maintain the food at the proper cooking temperature, to provide for evaporation and chemical changes, and to maintain the proper draft through the oven. The heat consumed by the food material [mostly evaporation] is naturally a variable * * * but as all this heat comes from the circulating hot air, it must be provided by a corresponding combustion of gas to heat the air mixture to a suitable temperature. Likewise the loss of heat through the walls of the oven will be absolutely the same if maintained at a given temperature, regardless of whether the oven contains food material or is empty. The food is indifferent to the source from which the circulating air mixture is heated.

It is undoubtedly true that inserting a pan or other solid body in the oven interferes somewhat with or modifies the circulation of air through the oven, but this is a variable with the size of the pan and its position in the oven which can not be readily generalized for test purposes. A well-designed oven must provide an even circulation when empty to give the best possible results when used with the great variety of objects and materials likely in domestic cooking.

The Chicago report (p. 19) thus summarizes the results of the tests on oven heating:

The results of these tests have demonstrated conclusively the fact that a given number of heat units per hour in an oven will heat up the oven with the same speed and maintain the same final oven temperature regardless of the B. t. u. per cubic foot of the gas used. A very slight (about 1 per cent) advantage of water gas as compared with coal gas was found in one case in confirmation of the theory explained in section 3 of this report, although the difference found was less than the theory would indicate [the point referred to is the use of total heating valucs rather than the net heating values of the gases in computing efficiencies and the greater amount of water formed from coal gas]. It is evident, therefore, that for any oven cooking operation a given amount of heat will be needed, and that the usefulness of a gas for this purpose is dependent almost wholly upon its total heating value per cubic foot.

The tests on water heaters were not made until after the Chicago report was published, hence the following conclusion was drawn without actual testing:

The bureau had expected to make tests of such appliances [water heaters] with the various gases, but time has not permitted this to be done. However, the definiteness of the results obtained in other tests permits definite conclusions to be drawn for water heaters.

It has been shown in other tests that with proper adjustment of gas rate and air-shutter position the same flame characteristics are secured with the different gases, and the heating efficiency of these flamcs is the same for top-burner cooking. In a water heater practically the same types of flame are used, and the problem is that of a transfer of hcat from the flame to the metal surfaces exactly as was the case in the top-burner cooking tests. The results for top burners can therefore properly be used in predicting the results for water heaters. It is therefore concluded by the burcau that the gases in question will be found useful for water heating substantially in proportion to their total heating valuc as in topburner cooking.

How well the prediction was justified is shown by Figures 1 and 2, which show all the results obtained in the testing of a tank water heater and an instantaneous automatic water heater, respectirely, 
with the exception of a small number of observations at very low rates which make no difference in the results. It will be seen that the results on both heaters show a tendency toward higher efficiencies for the gases of higher heating values; but this tendency is hardly greater than the experimental error. The group of six low results with a gas of relatively low heating value in the lower left-hand corner of Figure 2 forms an exception that is not explained by any data in the laboratory notes. The tendency for the gas of higher heating value to give slightly higher efficiencies is probably again due to the fact that total heating values rather than net were observed and used in the computations.

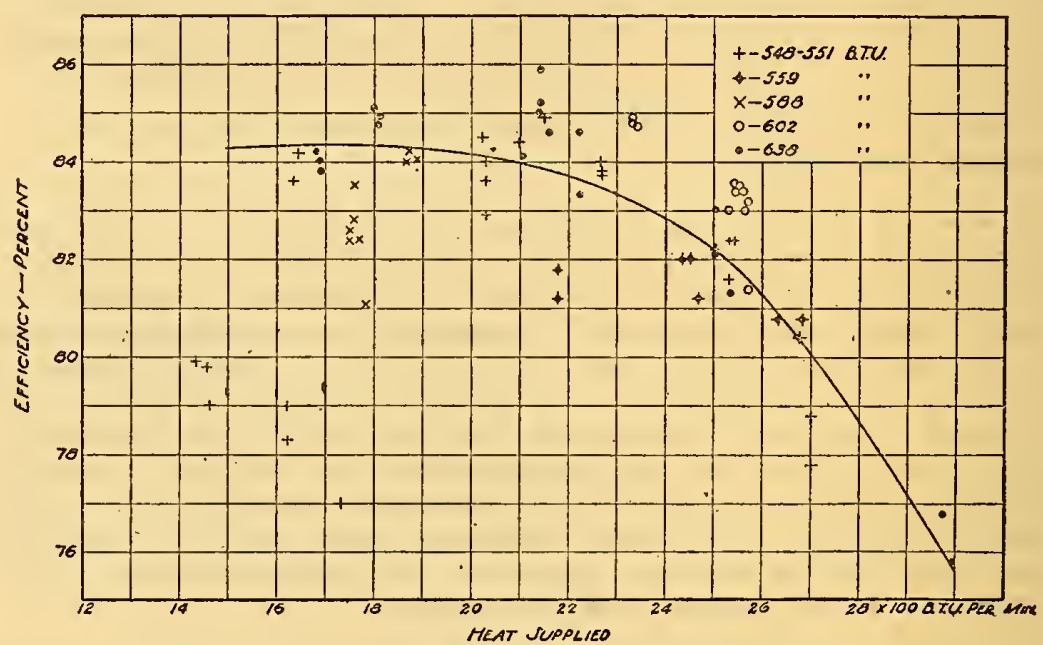

Frg. 1.-Observed efficiencies of a "tank water heater"

The experiments with the muffle furnace and their results are described as follows in the Chicago report (p. 20):

To test the efficiencies of different gases for production of high temperature, a small muffle furnace was constructed and equipped with a thermocouple so placed as to touch the wall of the muffle exposed directly to the impinging flame. A Tirrill burner was used to burn the gas. The position of the air shutter and the distance between the top of the burner tube and the bottom of the muffle were varied, and the position of the flame in relation to the muffle was adjusted so as to obtain with each of the different gases the maximum temperature for several rates of combustion. These temperatures ranged from 1,150 to $1,750^{\circ} \mathrm{F}$. The maximum temperatures obtained when using $550 \mathrm{~B}$. t. u. water gas and 650 B. t. u. mixed gas were practically identical for the same B. t. u. per hour input. Thus, in this type of operation, so far as the tests have been carried, the usefulness of the two qualities of gas appears to be directly proportional to their B. t. u. content. 
The open-flame heating of the platinum crucible is described in Dickerman's notes, as follows:

A small crucible was fitted with a thermocouple, protected from drafts as well as possible while providing for the escape of products of combustion, and heated by means of an adjustable Tirrill burner at various rates of combustion and at three heights of the crucible above the burner. Air-shutter opening and burner position under the crucible were adjusted by trial to obtain the maximum possible temperature for each gas and rate.

As plotted, the maximum temperatures obtainable for the same B. $t$. u. per hour input, whether supplied as 550 B. t. u. lean water gas or as 650 mixed gas, lie so closely on the same curve as to indicate that (within the limits of accuracy of the experiments) there is no difference in the effective usefulness of the gases other than that due directly to the B. t. u. contents as shown by calorimetric test. The curves cross, showing slightly greater efficiency at low rates of consumption for the richer gas and slightly greater efficiency at higher rates for the leaner gas, but the differences are so small as to be within the possible errors of the test.

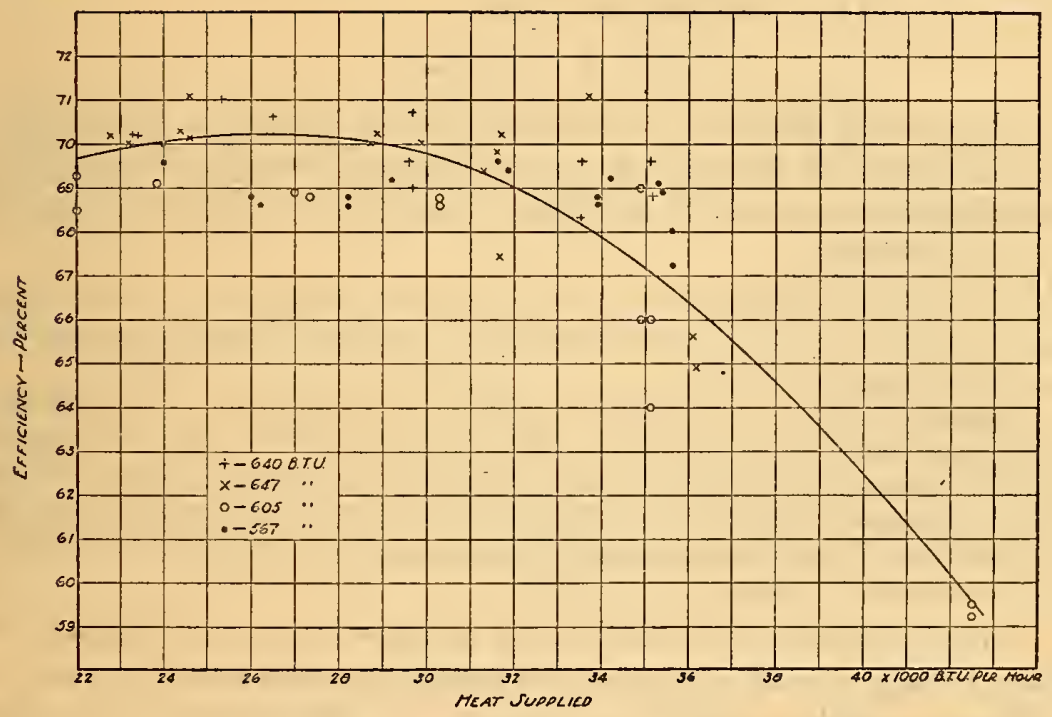

FIG. 2.-Observed efficiencies of an "automatic water heater"

The investigation of mantle lighting was more complete than the other studies. ${ }^{15}$ The general conclusion drawn from the results of this work (Chicago report, p. 15) were as follows:

With uniform gas quality and with good conditions of service in other particulars, the usefulness for mantle lighting of lean water gas compared with rich water gas is slightly higher than in proportion to the heating values as given by the usual calorimeter measurements. Comparing lean coal gas with water gas of the same total heating value, the coal gas is slightly less useful, and this difference is about the same as the difference between the two qualities of water gas. Hence, it may be concluded that the usefulness of a uniform. quality of coal gas of 565 B. t. u. as compared with a uniform supply of water gas of 665 B. t. u. is substantially proportional to their relative heating values.

15 Influence of Quality of Gas and Other Factors on the Efficiency of Gas Mantle Lamps, B. S. Tech Paper No. 110, by R. S. McBride, W. A. Dunkley, E. O. Crittenden, and'A. H. Trylor.

$43360^{\circ}-25 \dagger-2$ 
These conclusions from the laboratory tests are probably applicable without modification to practical cases, since the field inspection of mantles has shown nothing to indicate greater difficulties in commercial use of rich gas than are met in the use of lean gas.

This whole research of the bureau may be summarized by stating that, incomplete as it was, it definitely proved that within the range of commercial gases studied they all could be used with substantially equal efficiency in all of the appliances investigated; these numbered some 25 or 30 and ranged from the water heater and range burner through a series of applications requiring higher temperatures to mantle lighting. Efficiency is here used, of course, in its engineering sense of the ratio of useful work accomplished to the energy available. In no application was the discrepancy large. For all applications, except possibly for mantle lighting, the ratios of value for the several gases appear to have lain between the corresponding ratios of total and net heating values.

\section{R. F. PIERCE}

A conclusion sharply at variance with that of most investigators is reached by $R$. F. Pierce ${ }^{16}$ as to the relation between heating value and usefulness for mantle lighting. The object of Pierce's tests was stated as follows:

This test was planned with a view to demonstrating that calorific value, specific gravity, and gas candlepower do not definitely specify a gas for commercial purposes.

It appears quite obvious that two gases may be identical as regards these particular qualities, yet so entirely different in composition that the resulting flame temperatures will differ greatly. However, the contrary opinion has been so often expressed that it was considered desirable to demonstrate the fact that specifications of these qualities were valueless for conveying any definite idea of the usefulness of the gas to the consumer.

The experiments were made with a single burner and mantle, the burner always being adjusted to produce maximum brightness.

Pierce's results show rather clearly the effect of humidity upon mantle candlepower. At least he was able to derive a formula by the use of which a rather scattered group of observations, plotted with horizontal candlepower per B. t. u. per hour and total B. t. u. per hour as coordinates, may be corrected to much more closely approach a straight line.

Applying this correction formula to his results, Pierce obtained a constant candlepower, under the method of test, with a variation of only about 4 per cent from the mean, whatever the heating value of the gas. Pierce's method of adjustment to maximum candlepower must have led to always filling the mantle with a gas and air mixture so proportioned that the mantle would coincide with the zone of

${ }^{10}$ R. F. Pierce, Am. Gas Light Jour., 103, pp. 1-5; 1915. 
maximum temperature. Since the light emitted by the mantle depends only upon its temperature and was found to be independent of the gas used, the observations constitute a neat demonstration of the fact that the flame temperatures of all the gases used were about the same.

Unfortunately, the data are not presented in such a form that any conclusion may be drawn regarding the relation between the heating value of the gas and the amount required to give this adjustment at which the candlepower will be a maximum. The results without the large humidity correction were plotted with horizontal candlepower per B. t. u. per hour and heating value of the gas as coordinates and the result (Pierce, fig. 5) showed a tendency toward "decreased duty with increased calorific value" which is the caption of the figure. Pierce himself said: "At first glance the data do not seem sufficiently consistent to justify the drawing of a curve assumed to represent average conditions," but he nevertheless drew such a curve and gave its equation with three and four significant figures in the constants. By a happy coincidence this equation agrees exactly (to three significant figures) with that necessary to make the candlepower per cubic foot per hour the same for $480 \mathrm{~B}$. t. u. and 660 B. t. u. gas, hence Pierce felt justified in drawing the conclusion that-

The most interesting feature of this curve is the fact that the decrease in duty with increase in calorific value is exactly counterbalanced by the latter. For example, comparing gases of 480 and 660 B. t. u. per cubic foot, respectively, it is seen that while the duty expressed in horizontal candlepower per $B$. $t$. $u$. with the former $(0.04555)$ is 37.5 per cent greater than that with the latter $(0.03312)$, the B. t. u. per cubic foot of the latter (660) are 37.5 per cent greater than in the former (480). Thus, the cost per candlepower hour of producing light in the incandescent burner is independent of the calorific value of the gas. * * *. In short, as far as incandescent lighting is concerned, it does not make the least difference to the customer whether he pays $\$ 1$ per 1,000 cubic feet for gas of 480 B. t. u. or $\$ 1$ per 1,000 cubic feet for gas of 660 B. t. u.

Another interesting conclusion which Pierce might have drawn from his precise equation but did not is that mantle candlepower would disappear entirely with natural gas of $1,196 \mathrm{~B}$. t. u. per cubic foot. The real significance of Pierce's equation may be best seen by assuming it correct and plotting, with the aid of the much better established relation that the maximum candlepower obtainable from the mantle used was 116.3, the volume of gas of each heating value required to give this maximum illumination. The rather remarkable result is shown in Figure 3. Although all Pierce's results are for maximum candlepower obtainable with the particular gas, he managed, by the use of varied mathematical treatment of the same observations, to draw the conclusions that this candlepower is a constant and that it is a parabolic function of the heat input in B. t. u. per hour. According to this last-mentioned relation heat 
input bears the same kind of relation to the candlepower developed as that found for the relation of the heating value of the gas to candlepower, and Pierce would have been as much justified in drawing the conclusion (from his fig. 8) that the incandescence of the mantle is independent of the heat input (or what amounts to the same thing; of the volume of gas burned) as in drawing his earlier conclusion that it was independent of the calorific value of the gas supply.

Pierce evidently fell a victim to the very common error of representing scattering observations by a series of equations and then drawing conclusions from them as though they were exact mathematical laws. We may therefore safely disregard his theorizing and consider only the relations directly indicated by the data which he

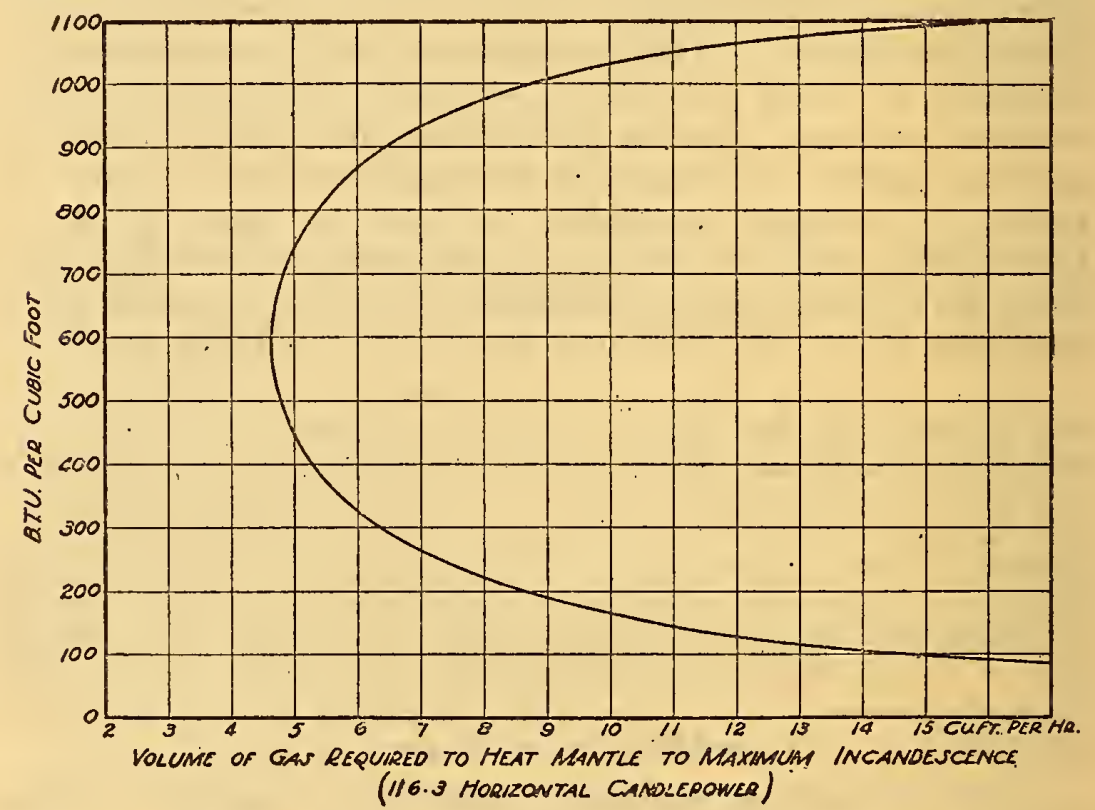

FIG. 3.-Relation resulting from Pierce's equation for "duty" of gases of different heating value

presented. They are: (1) The maximum flame temperatures obtainable with the gases used are practically the same, and (2) the efficiency of the incandescent light is considerably affected by atmospheric humidity. His parabolic relations, especially the one between heat input and candlepower, may correspond roughly to the fact that, in experiments otherwise similar, there is a certain heat input which will correspond to a flame size which brings the zone of highest temperature into contact with the mantle, and greater or less heat will cause the zone of maximum temperature to be outside or inside the mantle, respectively. 
4. C. N. CROSS

About the time the tests at the bureau were completed, C. N. Cross, employed by the Pacific Gas \& Electric Co., carried out a series of careful experiments upon the efficiencies of different gases for top-burner cooking.

The employment of Cross for this purpose seems to have followed preliminary observations made in the laboratory of the company by L. W. Jones ${ }^{17}$ with three different gases. The efficiencies reported by Jones were $24.0,32.12$, and 37.66 per cent for gases of 651,566 , and $562 \mathrm{~B}$. t. u. per cubic foot, respectively. The investigation made by Cross ${ }^{18}$ was carefully planned and controlled, and the results were consistently decisive. Tests with gases of $600,560,540$, and $525 \mathrm{~B}$. t. u. per cubic foot showed a small but negligible advantage in thermal efficiency in favor of the gases of higher heating value.

\section{INVESTIGATIONS IN 1918}

Probably the work most frequently referred to by the advocates of the idea that gases of low heating value are more efficient than those of high heating value is that of W. H. Y. Webber. ${ }^{19}$ The data are not given in a form for easy comparison. They have therefore been rearranged for easy comparison and the observed ratios between the different gases computed by the reviewer. The data given do not include the time required to boil water, which must have been greater for the gases of lower heating value if, as appears from the description of the experiments, the composition of the gas was the only condition changed. (The relative time required for the volumes of the respective gases used to flow through the same orifice is easily computed from the specific gravities, which are stated.) The results are given in Table 1 . It is hard to see how the advocates of a low calorific standard can have interpreted these data as indicating generally higher efficiency for gases of lower heating value.

A short series of tests was made in 1918 by the New Haven Gas Co. in cooperation with the Connecticut Public Utilities Commission. ${ }^{20}$

Two principal series of tests were inade on the efficiencies of ring burners. In test $D$ the same volume of each of eight gases, ranging from 496 to 657 B. t. u. per cubic foot, was used to heat water in the same utensil over the same burner "with the gas cock wide open" and the "air shutter correctly adjusted." The rate at which the gas was burned in these tests is not stated. The increase

${ }_{17}$ Report to United States Fuel Administration of Committee on Meating Value of Artificial Gas. Appendix C, p. 11-12.

${ }^{13}$ C. N. Cross, "A study of the efficiency of utilization of different manufactured oil gases in modern gas stoves," June 11, 1917. Distributed by Pacific Gas \& Electric Co.

10 W. II. Y. Webber, Gas World, 68, p. 173; 1918.

${ }^{20}$ Report transmitted by the Public Utilities Commission, State of Connecticut. 
TABLE 1.-Results of comparisons of various gases by W. H. Y. Webber

[All comparisons are made with the gas of highest heating value as unity]

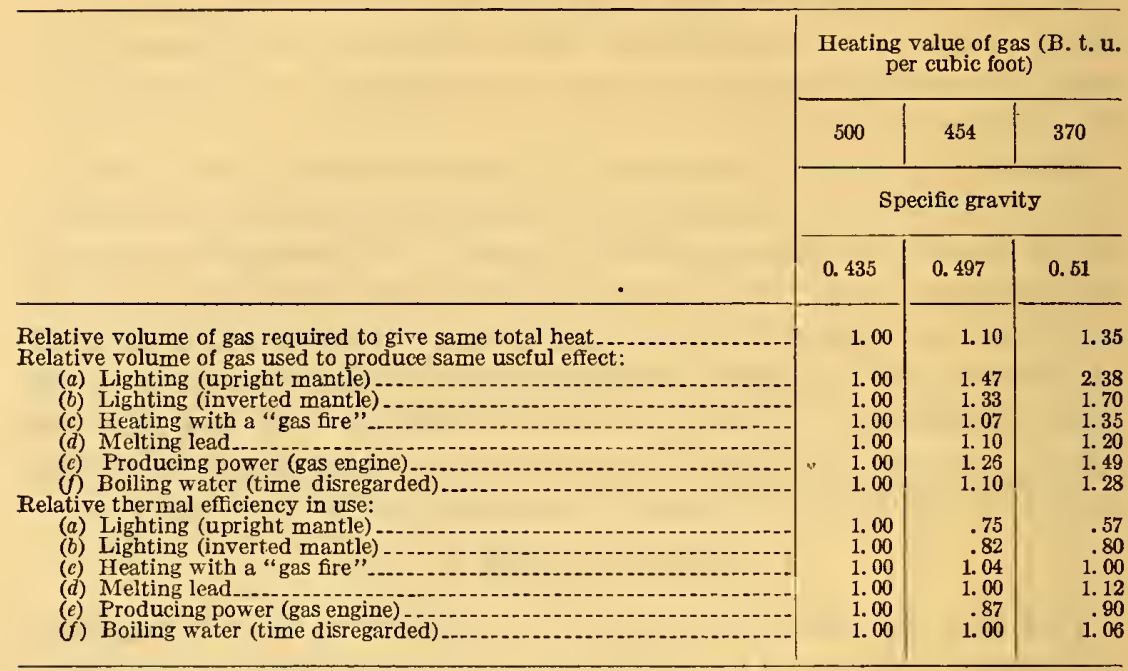

of temperature of the water in the utensil was noted, and the efficiencies (which are inserted in pencil and do not seem to have formed a part of the original report) were computed without considering heat losses, which must have been slightly greater for higher temperatures and rates of consumption.

A second series, test $G$, was made to determine the rate of combustion at which maximum efficiency was obtained when using gas of $560 \mathrm{~B}$. t. u. per cubic foot under conditions otherwise the same as those in series $D$. Plotting the two series of observations we can find the approximate rate at which the gas must have been burned in test $\mathrm{D}$ (the rate at which $560 \mathrm{~B}$. t. u. gas has the same efficiency in the two series). If no condition was changed except those mentioned, we can therefore plot the two series of tests with the same coordinates, efficiency, and B.t. u. per hour The result is given in Figure 4 and shows that for the same service the gases of higher heating value appear to have been a trifle more efficient; but the difference is probably within the limit of error, although it may have been caused by the use of total or gross rather than net heating values.

Part 2 of the report gives the results of incandescent lighting tests on six burners or combinations of burner and mantle. In each case three gases were used, the highest having a heating value between 609 and 618 B.t. u., the lowest between 516 and 520 B. t. u., and the third intermediate. In five of the tests the efficiencies ranged in the same order as the heating value, the maximum difference being 13 per cent in favor of a gas of 618 B. t. u. over one of 508 B. t. u., efficiencies being measured in candles per B. t. u. per 
hour. The sixth test showed the gas of intermediate heating value to have an advantage of one-fourth per cent over the richer and one-half per cent over the poorer gas, a negligible difference. Averaging the six tests we obtain the following figures:

\begin{tabular}{|c|c|c|c|}
\hline & $\begin{array}{l}\text { Average } \\
\text { heating } \\
\text { value } \\
\text { (B.t. u.) }\end{array}$ & $\begin{array}{c}\text { Candles } \\
\text { per } \\
\text { B. t. u. } \\
\text { per hour }\end{array}$ & $\begin{array}{l}\text { Relative } \\
\text { efficiency }\end{array}$ \\
\hline $\begin{array}{l}\text { Rich gas } \\
\text { Intermediate gas } \\
\text { Poor gas }\end{array}$ & $\begin{array}{l}614 \\
557 \\
513\end{array}$ & $\begin{array}{r}0.0395 \\
.0377 \\
.0363\end{array}$ & $\begin{array}{r}1.00 \\
.95 \\
.92\end{array}$ \\
\hline
\end{tabular}

Wibaut and de Leeuw ${ }^{21}$ made a series of tests of efficiencies for cooking purposes by the usual method of heating water in ordinary

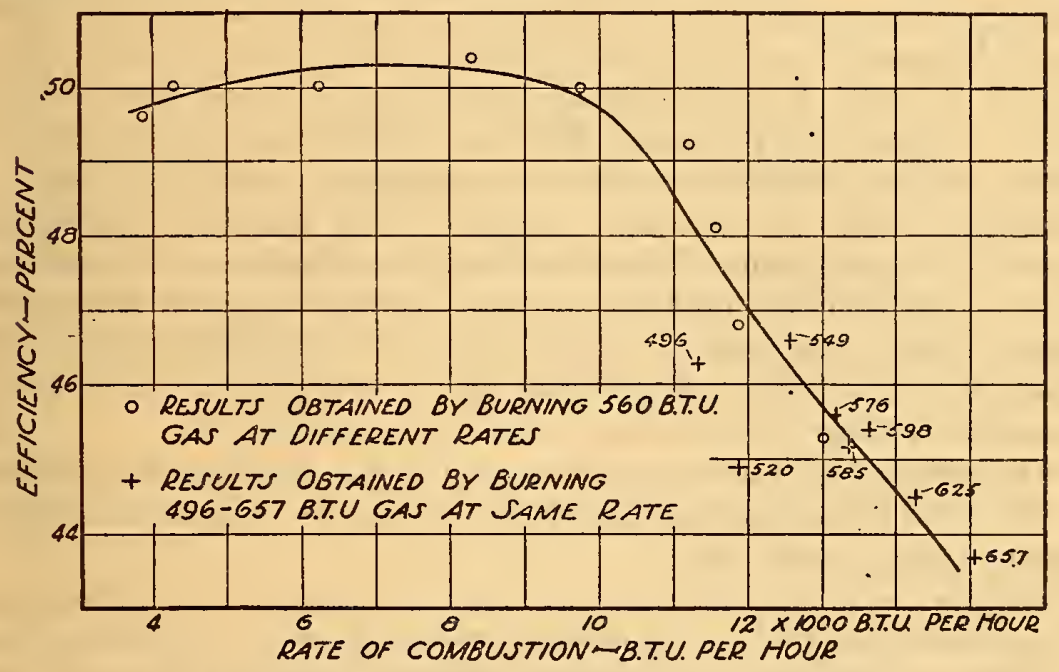

Frg. 4.-Results of top burner tests by New Haven Gas Co.

Numbers attached to points on figure give heating value of gas used

utensils. Their results showed slightly greater efficiencies for the gases of higher heating value. The results are given in Table 2.

TABLE 2.-Wibaut and de Leeuw's results of boiling tests

\begin{tabular}{|c|c|c|}
\hline \multicolumn{2}{|c|}{ Heating value of gas } & \\
\hline $\begin{array}{c}\text { Kilogram } \\
\text { calories per } \\
\text { cubic meter }\end{array}$ & $\begin{array}{c}\text { B. t. u. per } \\
\text { cubic foot }\end{array}$ & Efficiency \\
& & \\
\hline & & Per cent \\
4,200 & 472 & 57.8 \\
3,700 & 415 & 57.8 \\
3,400 & 382 & 56.9 \\
2,300 & 260 & 54.3 \\
\hline
\end{tabular}

21 J. P. Wibaut and H. do Leeuw, Het Gas, 38, pp. 225-228; 1918; Chem. Weekblad, 15, pp. 127S-1279; Chem. Abs., 18, p. 510; 1919. 


\section{GAS RESEARCH COMMITTEE}

Probably the most conclusive, and certainly the most generally accepted investigation of the usefulness of various gases was that carried out in England, over a period of several years, by the gas research committee of the Institution of Gas Engineers. This committee undertook to study economy in the production as well as efficiency in the use of gas. The work assumed a semipublic character because its results were applied to the question of rate and service regulations and were eventually accepted in their entirety by both the gas industry and the governmental authorities having jurisdiction over public-utility service.

This investigation was carried out with the same thoroughness and care as the earlier one at the Bureau of Standards, but the range of heating values to which most attention was paid was entirely different. Whereas most of the work of the bureau was done with gases of 500 to $725 \mathrm{~B}$. t. u., the research committee devoted most of their study to gases of 240 to $550 \mathrm{~B}$. t. u. This is especially fortunate, since, without duplicating efforts to any great extent, the range of thorough study was extended over the entire range of commercial gases. The conclusion of the two investigating bodies was the same-that for all practical applications the value of the gases within the range studied was directly proportional to the heating value; or, in other words, a definite quantity of heat is of the same value to the consumer whatever the volume of the gas containing it.

In introducing the first report of the gas research committee, J. W. Cobb ${ }^{22}$ thus summarized the purpose and results of the experiments which it described:

The work which the research subcommittee set themselves was the determination of the relative efficiencies of different grades of gas in use. We believe, and the belief is firmer than ever to-day, that, although confident statements might be made by individuals on this subject, there was no consensus of opinion on this subject; there was no consensus of opinion possible unless and until careful comparative experiments gave some firmer basis for it than any which was in existence. Our inquiry has been limited, on account of time, to the investigation of gases which might reasonably be regarded as coming in the range of gas-works practice; and the tests have been carried out on what we regarded as representative of existing appliances.

I think we were all rather surprised to find the extent to which the efficiency in use of the gas fire, and even more so the ring burner, was dominated by the number of calories supplied to it and how little it was affected by the grade or composition of the gas.

The first report of the gas research committee ${ }^{23}$ contained the following conclusions (p. 241) with respect to efficiencies of "ring" burners. (The term may be regarded as synonymous with "top" burners or "range" burners as used in the reports of the Bureau of Standards and in the American publications generally.)

22 Gas Jour., 144, pp. 291-292; 1918.

${ }^{23}$ First report of the gas research committee, Gas Jour., 141, pp. 235-251; 1918. 
The results obtained from a particular gas depend upon the number of heat units supplied. Provided suitable adjustments are made, the efficiency is practically independent of composition, inerts, or calorific value. As a matter of practical convenience, to deliver a sufficient number of B. t. $u$. in a reasonable time, without abnormal pressures, the gas used should be of moderately high calorific value.

The conclusions outlined above depend presumably upon the fact that the difference between the temperature of the water (even at its boiling point) and that of the flames of any gas mixture which has been tried is so great that the variations in flame temperature met with in practice are negligible in effect.

The committee deeided that it was so obvious that the same relation would hold with respeet to ovens that it was not necessary to make the test (p. 240). That the conelusion was justified is shown by the bureau's tests of ovens already reported.

The research committee's summary of the experiments upon incandeseent lighting with a low-pressure, upright burner is as follows:

1. For satisfactory lighting with incandescent mantles it is necessary to place the mantle exactly in the zone of active combustion of the gas mixture.

2. Or, since the burner and mantle are in practice fixed, the zone of active combustion must be made to fit the mantle.

3. The above requirement is so stringent that, with all gases which could be proposed as reasonably suitable for public supply, other considerations, such as that of flame temperature, become relatively unimportant.

4. The means of varying the position and character of the zone of active combustion are (a) varying the gas consumption, and (b) varying the degree of aeration.

5. With gases of about $450 \mathrm{~B}$. t. u. gross and below, the control possible to obtain by varying the consumption and aeration was not sufficient to give satisfactory illumination.

6. With the burner used, a gas of about 550 B. t. u. gross maximum to 500 B. t. u. gross minimum gave the best performance, both as regards efficiency and total illumination; but gases of about $600 \mathrm{~B}$. t. u. gross per cubic foot gave inferior results, owing to defective aeration.

7. Gases of low calorific value and high inerts were found to be distinctly inferior, on all grounds, to gases of similar low calorific value but low inerts; that is, consisting mainly of low-grade combustible matter.

8. The effects of inerts up to 20 to 25 per cent were less marked in the case of gases of calorific value 500 to 550 gross, being, in fact, quite negligible.

9. The maximum attainable illumination was found at about $525 \mathrm{~B}$. $t$. $u$. gross.

10. When a reduction in illuminating power and efficiency accompanies a reduction in calorific value or an increase in inert constituents, the result is due immediately to the unsatisfactory size and shape of the flame and its position with respect to the mantle.

11. A gas in which inerts are largely in the form of air does not behave as a poor gas but as an equivalent volume of the original air-free gas.

The eommittee's summary with respeet to the tests on "gas fires" (radiant heaters) was as follows (p. 248): 
1. With each gas fire there is a certain consumption which, for the gas used, gives the maximum radiant efficiency.

2. If a fire is turned down so that less than half the radiants are heated, the fire suffers severely.

3. Existing gas fires vary very considerably in their ability to adapt themselves to gases of different grades.

4. The evidence obtained points so far to the conclusion that a difference in the grade or composition of the gas supplied, within wide limits, does not cause any considerable difference in the radiant efficiency of a gas fire, provided that the mechanical construction of the fire will allow sufficient gas to be passed, so that the same number of B. t. $u$. per hour can be supplied to the radiants.

Soon after issuing the first report the research committee ${ }^{24}$ published a request to the industry that they be furnished with data bearing on the usefulness of different qualities of gas. The subsequent reports of the committee indicated that, as in the case of the similar request by the Bureau of Standards, little or no data of value were submitted in response to the request. Only one report on boiling tests is mentioned as having been received in this way, and regarding this, J. W. Cobb ${ }^{25}$ says, in part:

It is unfortunate that the actual rate of heat supply in B. t. u. per hour for the tests was not also given, as this would have been a much better assurance that the two gases were being tested under comparable conditions than the eye estimate apparently used.

Introducing the second report of the research committee, ${ }^{28}$ the committee explains its tests upon a gas of unusually low heating value in the following words:

The first report of this committee dealt with the results obtained in initiating a systematic survey of the relative efficiency in use of different grades of gas. Such a survey demanded a large number of experiments to be made with many gases, in the first place, on existing appliances without modifications to be followed by other experiments made with appliances modified to meet the varied requirements of different grades of gas ***. A special need of the Nation and the industry at this time has, however, asserted itself emphatically and caused the inquiry to be pushed forward in one particular direction with the object of obtaining badly needed information.

The need of the Nation referred to is, briefly, fuel conservation, and the information necessary was the practicability of using gases of very low heating value made by the complete gasification of the coal by one or another method. The committee availed themselves of an opportunity to use a plant for the production of such a gas by steaming in a vertical retort. Continuing, the committee says:

The results [of plant tests] may be expected to place in our hands very soon definite and quantitative information on the working of this development of gas practice-a thermal and chemical balance sheet of the process-of a kind which should prove of a high degree of usefulness and of a completeness which has

24 Gas Jour., 146, p. 147; 1919.

23 Gas Jour., 147, p. 385; 1919.

26 Gas Jour., 146, pp. 607-620; 1919. 
hitherto been lacking. It is plain, however, that the efficiency of this or any other process of production is dependent upon the efficiency of utilization of the product. The position with reference to the steaming process or to the bluewater-gas process, as providing the possibility of increasing the total heat energy of the coal carried by the gas, is that in either case the calorific power of the gas per cubic foot will be diminished. It was therefore of primary importance to make direct tests on the gas at Uddingston, deliberately made of a lower calorific value than that in common use to-day, in order to determine whether such gas when made was satisfactory and economical in use.

The principal conclusions resulting from this investigation are stated as follows:

Ring burners designed for gas of $500 \mathrm{~B}$. t. u. gross per cubic foot and upward give trouble with lighting back and with inability to deliver heat units at a satisfactory rate when used with a gas of 400 B.t. u. gross, as supplied at Uddingston; both difficulties can be overcome by the simple process of opening-out the nipple orifices to a suitable size and shape ***.

This gas of 400 B. t. u. gross per cubic foot gave as good a thermal efficiency as any other grade with which we have experimented when used with a suitable modification of the burner, which can be easily made.

It follows from the above that the gas of lower calorific value is not so good foot for foot as gas of a higher calorific value, but that the value in this use of different gases is directly proportional to the potential heat units they carry. This is in accordance with the results already published in the first report of the gas investigation committee ***.

Gas of the quality tested at Uddingston, of approximately $400 \mathrm{~B}$. t. u. gross per cubic foot, can be used in ordinary burners for either low or high temperature work if the nipple orifice is increased in area to allow of the delivery of the greater volume of gas required. This being done, the use for low temperature work (for example, in the ring burner) offers no difficulty, and the thermal efficiency is the same as that already found for gas of higher calorific value. With the incandescent lighting burner taken as representing the most stringent requirements of high temperature domestic use, the maximum efficiency under test conditions is a little lower than the best obtainable with gas of a higher calorific value but is much more easily and consistently obtained.

The experiments of the research committee which followed the second report were made with incandescent lighting units and with gas fires. This work is covered in the third report. ${ }^{27}$ The conclusions with respect to mantle lighting (p. 597) are as follows:

Air may be mixed with a straight coal gas of low inerts to the extent of 20 to 30 per cent of the mixture without reducing in the slightest degree the illuminating power and the thermal efficiency attainable with the incandescent mantle burner if heat units are supplied at the equivalent rates. Where nitrogen or carbon dioxide is added to a straight coal gas there is a reduction of theoretical flame temperature which might be expected to reduce the attainable illuminating power and thermal efficiency, but in practice such factors as flame shape and structure assume so much importance that only when the quantity of inerts becomes large, or when a specially arranged series of mixtures is under test, call the falling off in illuminating power be definitely associated with the lowering of theoretical flame temperature. For smaller quantities of inerts and for gas consumptions, in general, any such effect is masked by other influences.

17 Third report of research subcommittee, Gas Jour., 150, pp. 592-599; 1920. 
The third report summarizes the work on radiant heaters, or gas fires, as follows:

A series of comparative tests of radiant eficiency has been made with a typical gas fire, covering a range of calorific values and gas qualities from 150 to 620 B. t. u. gross per cubic foot. The mixtures comprise straight coal gas, coal gas diluted with air, with nitrogen, with carbon dioxide, and with blue water gaseach in a series of mixtures of different proportions; also (as an extreme case) Mond gas was tested.

Excepting for rich gases (requiring a large volume of air per cubic foot for their complete combustion) the addition of air down to 350 gross B. t. u. per cubic foot produces no determinate effect on the radiant efficiency in use (and hence presumably upon the total thermal efficiency also). The inclusion of air among the total inerts when considering thermal efficiency in use is therefore misleading.

Nitrogen may be added to good coal gas to the extent of 20 per cent, thereby reducing the calorific value to $500 \mathrm{~B}$. t. u. gross without affecting the radiant efficiency to any measurable extent.

The fall in radiant efficiency with further dilution is very slow, and even when the calorific value is reduced to $300 \mathrm{~B}$. $t$. u. gross the maximum radiant efficiency only falls from 44 to 40 per cent on the gross calorific value.

This fall is actually less than that experienced with good coal gas (530 B. t. u. gross and upwards), due to imperfect aeration, and is little greater than the variations in radiant efficiency with any one gas which accompany ordinary alterations in the rate of its use. ***.

In conclusion, it is to be pointed out that while inerts have thus been shown to exert measurable effects upon the thermal eficiency of the gas fire, these effects are relatively small, and for any mixture down to $350 \mathrm{~B}$. t. u. gross per cubic foot thermal equivalence in practice may be assumed.

Following a controversy with George Helps respecting the relative merits of low and high grade gases, Isaac Carr ${ }^{28}$ conducted a series of tests with ring burners on gases of 340 to $536 \mathrm{~B}$. t. u. The results are given in tabular form and may be summarized by saying that the effects of the changes of gas quality were somewhat masked by changes of rate, but that a fairly close approach to constant thermal efficiency resulted, with a tendency for the gases of higher heating value to give higher results. In Carr's own words: "It is quite true that these tests were not made by 'a chemist of unquestionable repute in the gas industry' but by members of my staff competent to make ordinary daily gas-works tests, which tests are, in my judgment, sufficiently near the mark to indicate the baneful effect that low-grade gas inflicts upon the consumer both in loss of money and time."

J. H. Dawe ${ }^{29}$ gives two comparative tests on cooking efficiencies with two gases, the utensil being at different distances from the burner in the two tests. The respective volumes of gas required to heat 1 quart of water $80^{\circ} \mathrm{F}$. were 2.92 and 3.32 cubic feet for gases of 593 and $441 \mathrm{~B}$. t. u. in one test and 2.10 and 2.37 cubic feet in the other. The lower thermal efficiency of the gas of higher heating value was attributed by Dawe to an insufficient quantity of primary air, but the

${ }^{28}$ Isaac Carr, Gas Jour., 145, p. 270; 1919.

29 Dawe, Gas Jour., 151, p. 669; 1920. 
discussion of the paper ${ }^{30}$ brought out the fact that the time required for performing the operation had been neglected.

The results of a series of top-burner tests made in 1921 and kindly given to the bureau by J. E. Worsley, chief engineer of the Kansas Public Utilities Commission, show efficiencies in use of manufactured and natural gas. Several different appliances were used. Six of these appear to have been employed with both natural and artificial gas. In most cases two different rates were used with each appliance and each quality of gas, and the thermal efficiencies obtained in bringing a definite amount of water from room temperature to boiling were determined. Taking the average efficiency of each appliance in all tests with each quality of gas, and taking the mean of these to obtain general averages for artificial and for natural gas, we obtain an average efficiency of 35.1 per cent for artificial gas of 517 to 555 B. t. u. and 35.0 per cent for natural gas of 1,000 B. t. u.

\section{COMMITTEE ON EFFICIENCY AND ECONOMY OF GAS, CALIFORNIA}

An investigation ranking in thoroughness with those of the Institution of Gas Engineers and the Bureau of Standards and, like the former, carried out in the main by representatives of the gas industry was that of the Joint Committee on Efficiency and Economy of Gas of the Railroad Commission of California. The committee consisted of 3 representatives of the railroad commission, 2 representatives of the Pacific Coast Gas Association, and 11 representatives of the larger gas companies of the State. The investigation is particularly valuable because it included and correlated studies of the efficiencies of modifications of the manufacturing processes, direct determinations of the relative efficiency of use of various gases, and statistical studies of the use of gas by consumers. Only the results of the direct tests of appliances will be considered at this point. The following quotations will set forth well enough the scope of the experiments and their results:

The laboratory tests have been carried on to determine the relative efficiency of different qualities of gas used in top burners of standard cooking stoves, water being heated to boiling and also evaporated, this being the manner in which the largest proportion of gas is used in the ordinary operations of consumers. Tests have been carried on to determine efficiency of operation of instantaneous and automatic water heaters and ovens. *** The results would indicate the experimental error to be within the limits of plus or minus 0.75 per cent.

Preliminary investigations indicated the importance, for comparative purposes, of maintaining uniform room temperatures, and special care has been taken to eliminate any error from this source. The tests carried on included efficiency tests with gas varying in quality from 500 to $600 \mathrm{~B}$. t. u. per cubic foot. The entire appliance investigation was conducted at San Jose, using gas as manufactured at that plant, tests being made with various qualities of gas, both under normal operation and with the inclusion of inerts. In total some 250 tests were made under various conditions of operation.

${ }^{30}$ Gas Jour., 152, p. 31;. 1920. 
The general results of the tests on efficiency of utilization with the use of top burners and the boiling of water in a teakettle are in summary form set forth in Appendix V, Tables 1, 2, and 3. The results of these tests are such as to convince the committee that from the laboratory standpoint at least the efficiency of utilization of gas, defined as the ratio of heat utilized to the heat content of the gas supplied, is constant within the range of oil gas quality of from 500 to 600 B. t. u. per cubic foot.

Tests on the operation of an oven to which was connected an oven-temperature regulator indicated similar results to those obtained with the top burner; that is, a proportional reduction in the use of gas with an increase in the quality supplied. ${ }^{31}$

For all practical purposes it may be concluded that the use by consumers of gas made by either of the California oil gas processes will vary inversely in proportion to the change in quality of gas supplied within the limits of a delivery to consumers of from 600 to $500 \mathrm{~B}$. t. u. per cubic foot, conditions of uniformity of quality and pressure remaining the same. ${ }^{32}$

The experimental data upon which these conclusions are based are fully set forth in the two "progress reports."

Tests made on the heating of a frying fat are worth noting separately, since they appear to be the only tests of gas for this particular application reported in the literature. "The results from heating Crisco from 100 to $500^{\circ} \mathrm{F}$. with different qualities of gas tended, if at all, to show a lower efficiency with lower heat content gas." "33

\section{RECENT INVESTIGATIONS}

In a paper which is, in general, an argument in favor of gases of low heating value, George Keillor ${ }^{34}$ asserts that gases of low heating value can be used with greater efficiency than can gases of high heating value. Fortunately, he gives the evidence on which his assertion is based, and a comparison of the figures given shows at once that there is an appreciable increase in efficiency in the use of gas of low heating value only if the time required for the operation is left out of account. In practically all domestic burners some thermal efficiency has been sacrificed to speed, and the use of less heat per unit time, whether accomplished by turning down the burner or reducing the heating value of the gas supplied, is accompanied by a loss of time and a gain in efficiency. If we compare Keillor's observations upon the same appliance by plotting the observed thermal efficiency against rate of heat supplied or against time required to perform a given operation, it is at once apparent that the gases of lower heating value were not more efficient, but rather the contrary. From Keillor's description of his experiments it is a little uncertain just which results were obtained with the same

\footnotetext{
31 Quotations from p. 18 of Second Progress Report of the Joint Committee on Efficiency and Economy of Gas; 1922.

32 Quotation from second progress report, p. 25.

${ }^{23}$ Quotation from p. 36 of First Progress Report of the Joint Committee on Efficiency and Economy of Gas; 1921.

${ }^{34}$ Gas Jour., 158, pp. 93-96; 1922.
} 
appliances and are therefore comparable. The results represented in Figures 5 and 6 are certainly comparable and those in Figure 7 are probably so, although they occur in Keillor's table under slightly different captions. For the other results given the range of heating values is too small to be of any significance in comparison with the wide differences in the rates of combustion employed. Keillor's apparent misinterpretation of his results in his eagerness to make his point did not escape his countrymen..$^{35}$

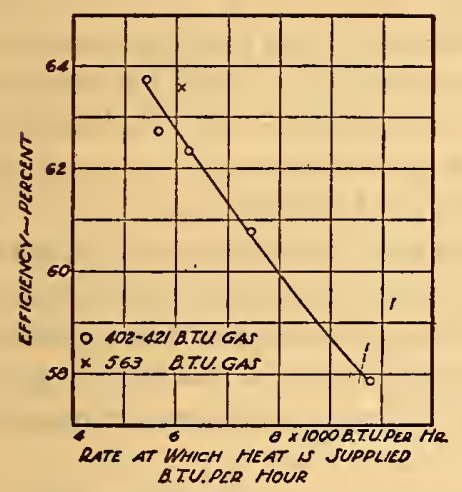

Fig. 5. - Keillor's observations with "new type boiling ring B" Gas. Jour., 158, p_ 96; Table 1

The observations of G. E. Whitwell (unpublished but frequently referred to in the literature) appear to fall in the same class. They have generally been interpreted as showing much greater efficiency for gases of lower heating value, but such is the case only when the time required to perform a given operation is neglected. This statement is based upon the memory of members of the bureau who examined the original data several years ago and upon certain memoranda and correspondence written at that time. A request was made to Whitwell for the privilege of examining the data for the purpose of this review, but they are unfortunately no longer available. It should be stated that Whitwell himself did not apparently construe his laboratory experiments as indicating different efficiencies for different gases when employed under the same conditions, as indicated by the following quotation from his letter of May 21, 1924.

85 See W. C. Goodchild, Gas Jour., 158, p. 329; 1922. 
This investigation soon led to the information, since that time published by yourselves and the California committee, that little, if any, substantiation of thermal advantage in the use of gases of lower heating value could be obtained by boiling tests, if the boiling tests were to be conducted on any basis of constant B. t. u. input per unit of time.

Whitwell does not, however, regard "boiling tests," either his own or those of others, as of much significance in connection with the determination of what gas is most valuable to the consumer.

The first investigation of thermal efficiencies by the Bureau of Standards, while it included a few tests on natural gas and on gases of very low heating value, including pure carbon monoxide and hydrogen, covered in a thorough manner only the range of gas qualities at that time under serious consideration as public-utility standards. Hence, when the question of the use of by-product gas in Baltimore arose, the bureau took advantage of an opportunity to cooperate with the Public Service Commission of Maryland and the Consolidated Gas, Electric Light \& Power Co., of Baltimore, in a new study of efficiencies. The investigation covered the performance of gases from 300 to $600 \mathrm{~B}$. t. u. when used for top-burner cooking. ${ }^{36}$ The results obtained confirmed the former work of the bureau as far as relative efficiencies were concerned. The conclusions drawn were summarized as follows (p. 88):

1. Irrespective of the heating value of the gas, the efficiency (ratio of heat absorbed to heat contained in the gas burned) obtained with any one burner is very nearly constant, provided the burner is adjusted to consume the same number of B. t. u. per hour with each gas. Thus, to heat a given quantity of water to the same temperature in the same time required 2 cubic feet of $300 \mathrm{~B}$. t. u. gas to 1 cubic foot of 600 B. t. u. gas. In other words, the quantity of gas required varied inversely with the heating value of the gas.

O. L. Kowalke and L. E. Biemiller ${ }^{37}$ give the following table (Table 3) showing the amount of heat, supplied by gases of various heating values, required to heat water to boiling and maintain it at the boiling temperature for 20 minutes. It is quite evident that if the small difference in the amount of heat required is significant, and not experimental error, the gas of highest heating value was the most efficient. Some earlier experiments of Kowalke ${ }^{38}$ in which potatoes, carefully seasoned to taste, were cooked until soft seem to have been given an altogether undue amount of attention. Such "practical" tests merely substitute an inaccurate method of measurement of efficiency for an accurate one.

${ }^{36}$ Relative Usefulness of Gases of Different Heating Value and Adjustments of Burners for Changes in Heating Value and Specific Gravity, by W. M. Berry, I. V. Brumbaugh, J. H. Eiseman, G. F. Moulton, and G. B. Shawn, B. S. Tech, Paper No. 222, 17, pp. 15-91; 1922.

37 "Volumes of gases of various heating values required to boil water in kettles of various sizes." Paper presented before the gas section of the Wisconsin Utilities Association; 1923.

38 Testimony before Illinois Commerce Commission, Mar. 6 and 23, 1922. 
TABLE 3.-Observations of Kowalke and Biemiller

[Each value shown is the average of three determinations]

\begin{tabular}{|c|c|c|c|c|c|c|c|c|c|}
\hline \multirow{2}{*}{ B. t. u. of gas used } & \multicolumn{3}{|c|}{ Kettle No. 1} & \multicolumn{3}{|c|}{ Kettle No. 2} & \multicolumn{3}{|c|}{ Kettle No. 3} \\
\hline & Heat & Boil & Total & Heat & Boil & Total & Heat & Boil & Total \\
\hline 580 & $\begin{array}{r}\text { B.t.u. } \\
1,035 \\
1,027 \\
1,021 \\
1,015 \\
979\end{array}$ & $\begin{array}{r}\text { B. } t . u \text {. } \\
698 \\
731 \\
728 \\
727 \\
703\end{array}$ & $\begin{array}{l}\text { B.t.u. } \\
1,733 \\
1,758 \\
1,749 \\
1,742 \\
1,682\end{array}$ & $\begin{array}{r}\text { B. t. } u . \\
1,063 \\
1,033 \\
1,017 \\
1,002 \\
986\end{array}$ & $\begin{array}{r}\text { B.t. } u \text {. } \\
445 \\
459 \\
442 \\
491 \\
445\end{array}$ & $\begin{array}{l}\text { B.t.u. } \\
1,508 \\
1,492 \\
1,459 \\
1,493 \\
1,431\end{array}$ & $\begin{array}{r}\text { B.t. } u . \\
582 \\
566 \\
578 \\
567 \\
570\end{array}$ & $\begin{array}{r}\text { B. } t . u \text {. } \\
393 \\
394 \\
431 \\
416 \\
401\end{array}$ & $\begin{array}{r}\text { B.t. } u . \\
975 \\
960 \\
1,009 \\
983 \\
971\end{array}$ \\
\hline
\end{tabular}

Heat $=$ period of heating during which water is brought up to boil.

Boil $=20$-minute period during which water is kept "just at a boil."

Water Kettle No. $1-2$ pounds.

$\left\{\begin{array}{l}\text { Kettle No. } 1-2 \text { pounds. } \\ \text { Kettle No. } 2-2 \text { pounds. }\end{array}\right.$

A very recent direct determination of the relative usefulness of various gases was conducted in the Municipal Testing Laboratories of St. Paul, Minn. The data obtained in this investigation were furnished to the bureau through the kindness of V. H. Roehrich, director of the Municipal Testing Laboratory, and J. H. McDonald, commissioner of public utilities. The study includes a rather thorough series of tests on top burners with gases from 545 to $607 \mathrm{~B}$. t. u. per cubic foot and a series of observations on mantle candlepower with gases of 606 and $557 \mathrm{~B}$. t. u. per cubic foot. The results of the boiling tests are summarized by Roehrich in the following words:

These tests show that when the heating value is dropped a given percentage the careful user will be compelled to use practically that same percentage more gas; that is, a pro rata loss is incurred by the consumer.

The boiling tests show even greater loss than a pro rata loss for both a given time and a given evaporation.

The observations on mantle lighting were plotted by the observer to show the relation of total candlepower and of candlepower per cubic foot to rate of consumption, and average curves were drawn. The reviewer has replotted in Figure 8 the second set of curves to show more directly the relation between candlepower per heat unit and rate of consumption. It is seen that as far as these tests with a single appliance and two gases are concerned the gas of lower heating value is less efficient and, since the peak of the curve is sharper, it has a smaller range of adjustment for good service.

\section{DETROIT TESTING LABORATORY}

During 1924 the Detroit Testing Laboratory conducted tests upon the relative efficiencies in use of 530 and $600 \mathrm{~B}$. t. u. gases. These tests formed the basis of the Report of the Detroit Testing Laboratory to the Common Council of the City of Detroit, dated November, 192t, and their significance has been the subject of thorough discussion between the Detroit laboratory and the Bureau of Standards during $43360^{\circ}-25 \dagger-3$ 
a period of about four months. In the course of the discussion the Bureau of Standards was permitted to examine the original records of a portion of the tests.

This brief review is a summary of the results disclosed by the original records. The data used are the data actually observed and recorded by the Detroit laboratory and unaffected by any theory or assumption or opinion whatever. The basis of comparison between the gases here employed is that chosen by the Detroit laboratory (all comparative tests are made with the same mechanical setting of all appliance adjustments for each gas). All questions of judgment are eliminated by using general averages, mechanically arrived at, and merely pointing out their significance.

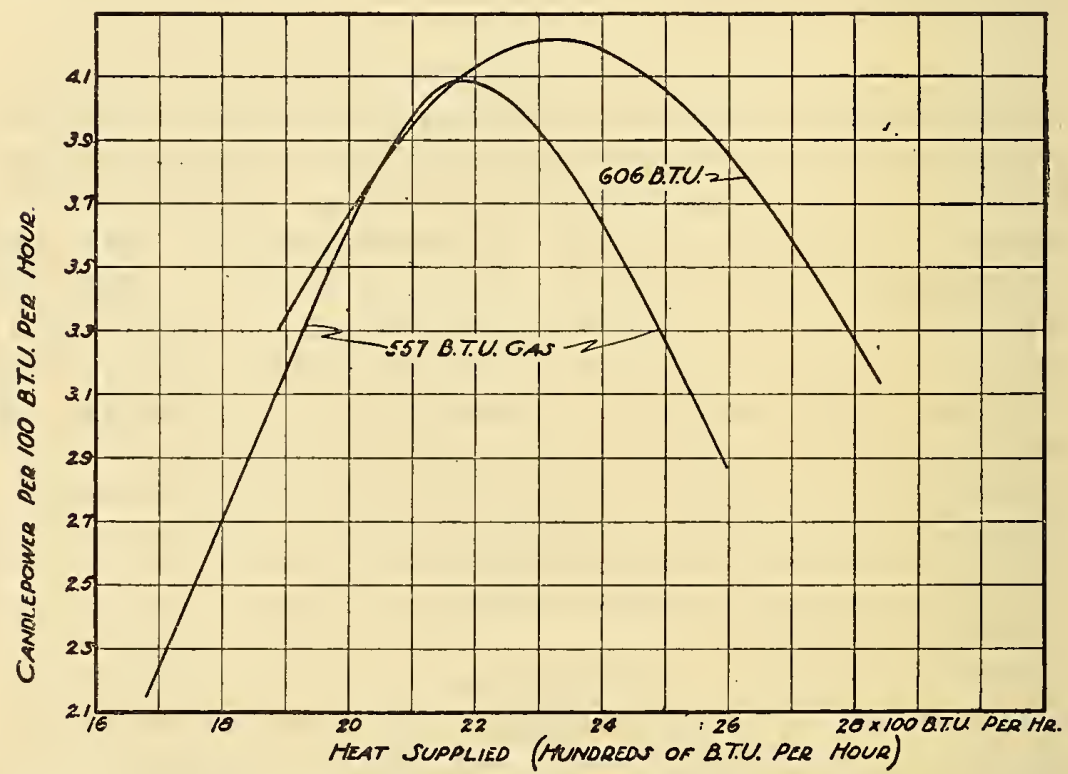

FIG. 8.-Relative mantle lighting tests with two gases of different heating value by St. Paul Municipal Laboratory

In the principal series of tests 4.17 pounds of water was heated in a kettle over the "top burner" of a gas range. The temperature interval through which the water was heated varied somewhat, but it was usually from about 70 to $210^{\circ} \mathrm{F}$. All results have been corrected (in the same way by both laboratories) to show the amount of gas required to heat from 70 to $212^{\circ}$. The heating of 4.17 pounds of water over this temperature range is therefore referred to as the "standard test." The results of these tests are shown graphically in Figures 9, 10, and 11 .

Taking the general average of the results of all these tests, 2.36 cubic feet of gas of $600 \mathrm{~B}$. t. u. perform the service represented by the standard test in 526 seconds. The same service is performed by 2.64 
cubic feet of $530 \mathrm{~B}$. t. u. gas, but 570 seconds is required. If both gases cost 79 cents per thousand cubic feet (the figure assumed in the Detroit report), the test costs 0.186 cent when performed with 600 B. t. u. gas and 0.209 cent with $530 \mathrm{~B}$. t. u. gas. To do the same work at the same cost, $530 \mathrm{~B}$. t. u. gas would have to be sold at 70 cents per thousand cubic feet, and even then, on the basis of comparison chosen by the Detroit laboratory, much time would be wasted with the $530 \mathrm{~B}$. t. u. gas. If the two gases were sold at the same price per million B. t. u. (the price being that of the $600 \mathrm{~B}$. t. u. gas at 79 cents per thousand), the $600 \mathrm{~B}$. t. u. gas would cost 0.186 cent for the standard test and the $530 \mathrm{~B}$. t. u. gas 0.184 cent. This makes a dif-

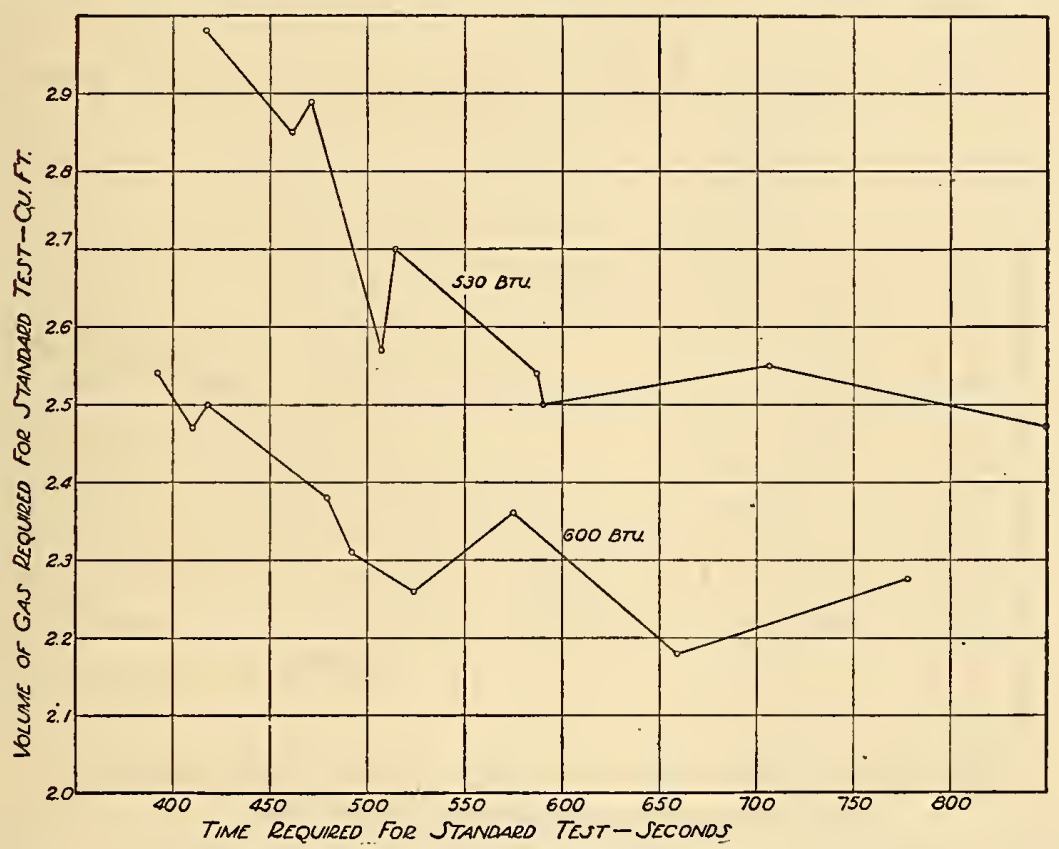

FIG. 9.-Top burner tests made by Detroit Testing Laboratory with air shutter wide open

ference of 1 cent in 430 operations requiring a total of 63 hours with $600 \mathrm{~B}$. t. u. gas or 68 hours with $530 \mathrm{~B}$. t. u. gas. Thus an actual loss of five hours is involved in saving 1 cent.

The test data show that many of the settings of the burner were utterly improper for both gases, because they caused a dangerous condition of incomplete combustion which would be at once recognized and eliminated by any experienced representative of a gas or appliance company. If we eliminate the tests made under such conditions from the average and use only the tests made under conditions approaching those of practical usage (those with the air shutter wide open and two-thirds open), we find the following relations:

With both gases at 79 cents per thousand cubic feet, the operation involved in the standard test costs 0.185 cent with $600 \mathrm{~B}$. t. u. gas aud 
0.210 cent with 530 B. t. u. gas. It would cost the same with both gases if the $600 \mathrm{~B}$. t. u. gas were sold at 79 cents per thousand and the $530 \mathrm{~B}$. t. u. gas at 70 cents per thousand, and it would still require 10 per cent more time with the gas of lower heating value. If the gases were sold at the same price per million B. t. u., the operation would cost 0.185 cent and 0.184 cent with 600 and $530 \mathrm{~B}$. t. u. gases, respectively. To save 1 cent with the $530 \mathrm{~B}$. t. u. gas would then require about 1,100 operations requiring 178 hours of actual time, while the same result would be achieved in 161 hours with 600 B. t. u. gas, a sacrifice of 17 hours for 1 cent.

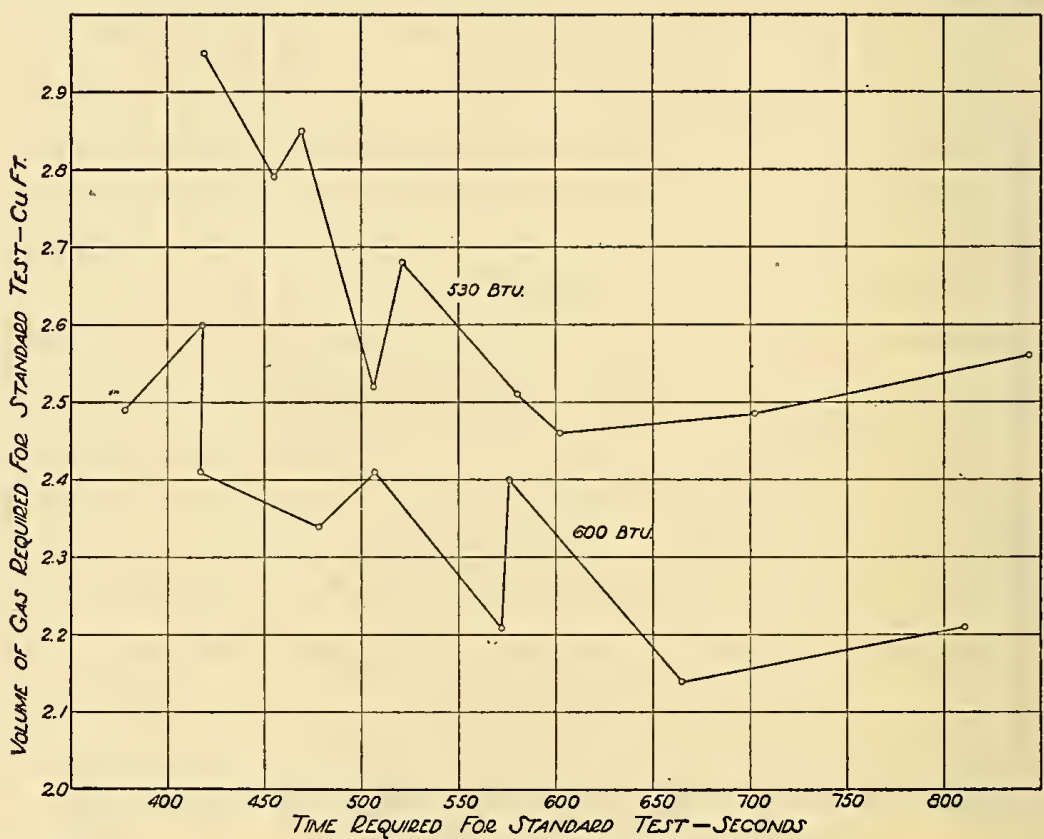

Fig. 10.-Top burner tests made by Detroit Testing Laboratory with air shutter two-thirds open

An oven was heated with 600 B. t. u. gas burned at one rate and with $530 \mathrm{~B}$. t. u. gas burned at two different rates, one which supplied heat more rapidly and one in which the same volume of gas was burned per unit time but which supplied heat less rapidly than the 600 B. t. u. gas. The observed time-temperature curves were somewhat irregular. Averaging the quantity of gas necessary to heat the oven to each of 9 evenly distributed temperatures in the upper part of the range of oven temperatures employed in practice, we find that the volume of $530 \mathrm{~B}$. t. u. gas was, in the two tests, 17 and 14 per cent greater than the volume of $600 \mathrm{~B}$. t. u. gas required to accomplish the same purpose. The same amount of heat was required to produce 
the same effect when burning the $600 \mathrm{~B}$. t. u. gas and when burning the $530 \mathrm{~B}$. t. u. gas at a higher rate. When the two gases were burned at the same rate in cubic feet per hour, about 4 per cent more heat was required from the $530 \mathrm{~B}$. t. u. gas. The observed data are shown graphically in Figure 12. As noted on the figure, the data for the lower portion of the curves relating to $530 \mathrm{~B}$. t. u. gas were not available to the bureau except in the form of a printed figure from which they were taken by enlargement and measurement.

Under every one of the many test conditions employed the volume of $530 \mathrm{~B}$. t. u. gas required to produce a given result was greater than

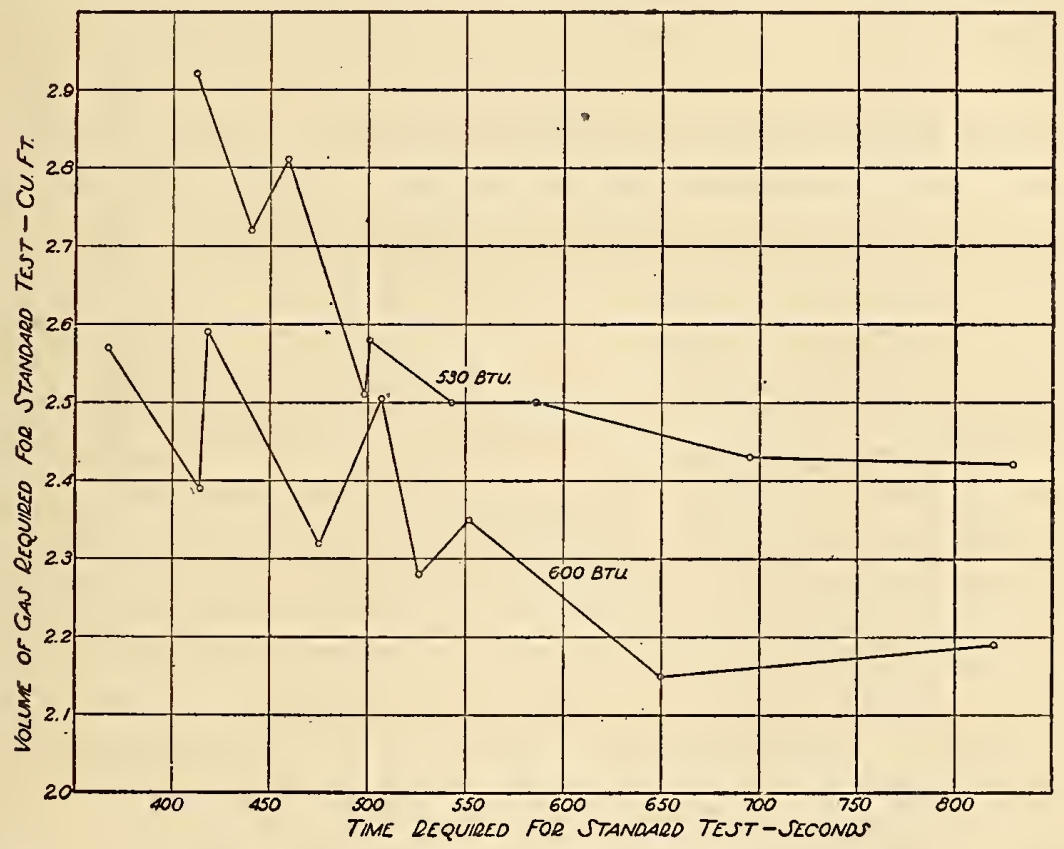

FIG. 11.-Top burner tests made by Detroit Testing Laboratory with air shutter one-third open

the volume of $600 \mathrm{~B}$. t. u. gas required for the same purpose. In no case was there an important difference in the amount of heat required to produce the same result. In so far as these statements differ from the conclusions of the Detroit Testing Laboratory the difference is caused by unnecessary assumptions introduced by the Detroit laboratory, the most important of which are clearly shown by the experimental data themselves to be contrary to fact.

As evidence of the statements here made there will be sent to those interested, upon request, a detailed criticism of the report of the Detroit Testing Laboratory, together with comments upon the same written by both laboratories. 


\section{EFFICIENCY IN GAS ENGINES}

In considering the use of gas for producing power in gas engines we will depart from our rule of considering only those opinions which are accompanied by the evidence upon which they are based, for the reason that no direct comparative tests of gases of various compositions have been found. There are many available reports of efficiency tests of gas engines, of course. It is common engineering practice to make measurements of the power produced by any large or unusual

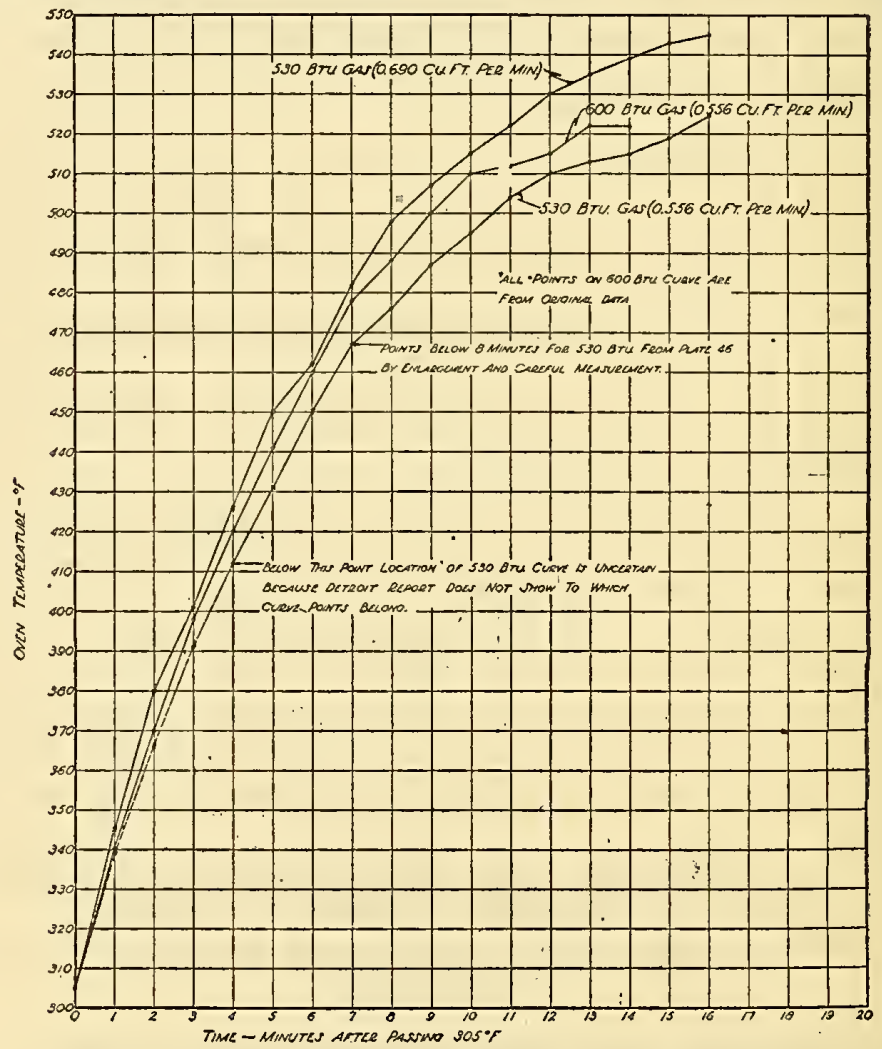

Fig. 12.-Oven tests made by Detroit Testing Laboratory

installation, and the general statement is probably justified that thermal efficiencies are much the same when using fuels throughout the range from gasoline and kerosene to blast-furnace gas. General statements regarding efficiencies by engineers who are familiar with this field are therefore probably more significant than general opinions regarding the efficiency of other appliances would be. Sir Dugald Clerk, ${ }^{39}$ a leading authority on internal-combustion engines, in discussing the first report of the research committee of the Institution of Gas Engineers, said: 
In fact, we have actually to add to the coke-oven gas a certain proportion of cold exhaust gases $* * *$ so as to lower the flame temperature in the cylinder and so reduce the liability to preignition. I am pointing this out because I want to say that, so far as we are concerned, what we want is a certain number of heat units for our money. We do not mind inerts so long as we do not pay for them, but we do not want to pay for heat units whereas we are getting nitrogen and oxygen, which we can obtain from the atmosphere without paying for them.

The following quotation from W. A. Tookey ${ }^{40}$ is a part of the same discussion:

We can work, as we have worked, engines with natural gas approaching 1,000 B. t. u., as well as with a blast furnace gas, which, as you know, contains about 100 B. t. u. And, speaking generally, we obtain in gas engines, small, as well as large, the same efficiencies with very slight variations $* * *$. When $I$ use the word "efficiency" I mean the'same number of B, t, u. per H. P. hour.

\section{DISCUSSION OF DIRECT EVIDENCE REGARDING THE USEFULNESS OF VARIOUS QUALITIES OF GAS}

The direct evidence regarding the usefulness of various qualities of gas which has been summarized in Section II can lead to but one possible conclusion. For all ordinary purposes the value of commercial gases is directly proportional to their heating value. The proof rests upon several thousand careful determinations made by not less than 50 observers taking part in more than a score of independent investigations of the subject. The evidence that in any part of the range of commercial gases there is any considerable advantage in thermal efficiency for the gases of lower heating value is entirely negligible. Only a fraction of 1 per cent of all the observations on the subject indicate anything of the sort, and these few, almost without exception, were made in isolated groups of such small number that the investigator had no opportunity to study his sources of possible error, which are numerous in work of this kind. Even the results obtained by the two or three observers (Webber, Keillor, and Whitwell) who are most frequently quoted as authority for the view that the gases of lower heating value are the more efficient show the contrary when the time factor is considered. Indeed, the evidence of somewhat greater efficiency for the gases of higher heating value is much stronger than the evidence of less efficiency, at least when the gross or total heat value is the basis of comparison.

The applications directly studied include, in the approximate order of increasing temperatures, use with automatic and circulating water heaters, a great number and variety of top burners, thermostatically controlled, portable and ordinary ovens, muffe and open flame crucible heaters, radiant space heaters, and all sorts of incandescent burners and mantles. For all these purposes the same siniple rule

10 W. A. Tookey, Gas Jour., 144, p. 295; 1918. 
holds. It should be possible, therefore, to give a general explanation of the reason why the efficiency in use is not more dependent upon properties of the gas other than the heating value.

The key to the problem lies in the fact that when any of the commercial combustible gases is burned with air under favorable conditions the hottest part of the flame has about the same temperature for each gas. In a few applications all the heat of the gas is directly utilized. In all others there is an incomplete transfer of the heat of combustion from the flame to some object to be heated, and the efficiency of the transfer depends upon bringing the zone of maximum flame tempertaure into the most favorable position with respect to the object. When this is done-that is, when the appliance is correctly adjusted-the rate of heat transfer from the flame to the object will remain the same provided the total amount of heat supplied to the region of transfer is the same. In some applications, most notably the cutting and welding of metals with a blowtorch, the region of transfer is small and the amount of heat dissipated is large, so that it is necessary to supply heat at a very rapid rate to a small area. In this case the gas which reacts most rapidly (hydrogen and some of the hydrocarbons) is most valuable; and the possibility of supplying heat more rapidly to a given area probably makes hydrogen of a little more value for many purposes than in proportion to the heat it produces (which is the net value). However, the existing data indicate that this advantage of hydrogen is seldom great enough to make the rapidly burning gas of as great relative usefulness per unit volume as would correspond to its total heating value, and the ratio of usefulness of gases for most purposes therefore seems to lie between the ratios of their total and net heating values.

The possibility of using the greater reaction velocity of hydrogen is limited in many appliances by the danger of flash back; this is especially true in the case of radiant heaters and incandescent lights where this property of hydrogen might otherwise prove important. Because of the danger of flash back we are frequently limited to an air mixture which gives less than maximum efficiency, and the greater reaction velocity of hydrogen is therefore of no avail.

The correctness of the above explanation rests upon that of the statement that "when any of the commercial combustible gases is burned with air under favorable conditions the hottest part of the flame has about the same temperature for each gas." There are in the literature several discussions of this subject based upon more or less theoretical grounds involving the relations between flame velocities, specific heats, the potential heat per unit volume of the gas-air mixtures in correct proportion for compiete reaction, dissociation at high temperature, etc. Few, if any, of these discussions 
are complete; and in view of the uncertain accuracy of some of the important data, such as the specific heats of gases at high temperature, we are justified in avoiding the complication and uncertainty of a theoretical discussion by considering only directly observed facts. The behavior of the mantle light is of the utmost importance in this connection, because the mantle will glow with maximum brightness when it coincides with the hottest part of the flame, and the brightness of the mantle affords a delicate measure of the relative temperatures of the combustion zone under various conditions. The observations of the efficiency of gas when used for mantle lighting, therefore, have this significance in connection with the behavior of other appliances. The mantle light should be the first appliance to show the effect of flame temperature upon the efficiency with which the same total heat is applied, and when no such effect appears we would naturally expect that it would not appear in other appliances less sensitive to the conditions of application of the heat evolved. As a matter of fact, it does not appear in any of the many classes of appliances which have been investigated, except the blowtorch, and we may safely conclude that it will appear in few, if any, of the great variety of industrial applications which have not been directly studied. This is well brought out by Pierce, ${ }^{41}$ who says:

The efficiency of the most important processes involving the uses of gaseous fuel is a function of flame temperature, and the higher the temperature involved in the process the more greatly is the efficiency influenced by the flame temperature. We are perhaps justified in assuming that the relations of flame temperature to efficiency in the incandescent gas lamp and in other high-temperature appliances, such as broilers, furnaces for the heat treatment of metals, metalmelting furnaces, etc., are sufficiently similar to justify us in taking the relation in the former as at least an index of the relation in the latter group. In the case of bake ovens, water heaters, and appliances for processes involving comparatively low temperatures the efficiency is favorably affected by increased flame temperature but to a very much smaller degree than in high-temperature operations.

C. M. Walter, ${ }^{42}$ engineer in charge of the Industrial Research Laboratory of the Birmingham (England) Corporation Gas Department, gives the following more detailed classification of industrial apparatus on the basis of the factors which affect their efficiency. His discussion of practical difficulties is certainly not favorable to gases of particularly low heating value.

1. Heating appliances employing atmospheric burners of the ring and bar types and other forms of the open-flame type burners in which the transfer of heat is affected by flame contact with a metallic or heat-conducting vessel without the employment of a fire-brick combustion chamber, including such apparatus as vats, boilers, white-metal melting pots, and some forms of soldering-iron stoves, all of which require both primary and secondary air for the combustion of the gas.

41 R. F. Pierce, Am. Gas Light Jour., 103, pp. 1-5; 1915.

42 C. M. Walter, Gas Jour., 153, pp. 464-465; 1921. 
2. Furnaces employing open-flame type burners in which the heating is effected in a similar manner as in (1), but in which the degree of primary aeration is increased (and the flame temperature thus raised) by increasing the velocity of mixture prior to combustion by the employment of (a) gas under pressure, $(b)$ low-pressure gas with air under pressure, $(c)$ both gas and air under pressure, or $(d)$ air-gas mixtures under pressure, which burners require both primary and secondary air for the combustion of the gas but a greater proportion of primary air than in the case of (1). In the above types of apparatus the heating efficiency is largely dependent on the temperature of the flame produced.

3. Heating apparatus employing burners of the open-flamc type used for such work as japanning stoves, core-drying ovens, drying stoves, and hot-air chambers in the case of which the heating effect is dependent on the total B.t.u.'s, supplied and in which the heating efficiency is not necessarily dependent on flame temperature.

4. Furnaces employing burners used in connection with high-temperature furnaces in which the combustion takes place in combustion chambers composed of refractory materials; for example, metal-melting, forging, hardening, and annealing furnaces, and welding and reheating apparatus employing burners using gas under pressure, gas with air under pressure, gas and air both under pressure or air-gas mixtures under pressure.

5. Furnaces employing simple forms of atmospheric burners producing large well-aerated flames as are required for annealing, reheating, and any such work requiring moderatcly high temperatures and a nonoxydizing atmosphere in the furnace, and also certain types of low-temperature, metal-melting furnaces.

It will be generally found that all forms of heating apparatus ordinarily used will fall under one of the above classifications or a combination of one or more * * *. With regard to apparatus classified under (1), where it is generally found that the temperature head available for heat transfer is comparatively high, the calorific value of the gas employed does not materially affect the working efficiency, provided that modifications and adjustments of the apparatus are carricd out to mect the new requirements brought about by the change in form of the flame produced. This also applies generally to apparatus coming under the next three headings with the exception of high-pressure gas systcms employed in connection with the heating of combustion chambers where the primary aeration is carried out at the expense of the kinetic engergy in the gas itself. With such apparatus it will be found that if the calorifie value of the gas used is reduced difficulties will be experienced in maintaining the flame temperature originally obtained unless the mixture velocity is increased. In other words, modifications in the design of the injectors or combustion chambers, to enable the B.t.u. equivalent of a lower grade gas to be utilized, will not result in maintaining the original efficiencies unless the velocity of the mixture is increased.

The difficulty referred to in obtaining sufficient concentration of combustion and therefore high-flame temperature with the atmospheric form of burner with a lower grade gas manifests itself to a much greater extent in the case of apparatus that comes under classification (5). As in certain manufacturing districts furnaces falling within this category are likely to constitute a large percentage of the industrial load, special attention must be given both as to the effects of variations in the thermal concentration of the gas supplied for such apparatus and, secondly, as to the possibilities of modifying the designs to enable same to be used with gas of higher or lower calorific value as other requirements (such as the cost of production) may demand.

During certain periods of the war, when it became necessary to reduce the calorific value of gas supplied, the difficulties which presented themselves were mainly in connection with furnaces of this type, with the result that a consider- 
able amount of experimental work had to be carried out with a view to ascertaining to what extent such reduction in calorific value was possible without materially affecting the output of manufacturing concerns employing such heating apparatus and also to determine as far as possible the efficiencies obtained with a gas of higher calorific value. With a drop of $50 \mathrm{~B}$. t. u.'s in calorific value the effect on the working efficiency of furnaces of this type was particularly marked.

Substitution of larger nipples, to enable the B. t. u. equivalent of the lowergrade gas to be consumed, was attended with considerable prolongation of the heating operation, a lower concentration of combustion, lower available temperature head for heat transfer, and consequent lower thermal efficiency. Modifications in the dimensions of combustion chambers and the employment of more efficient form of injectors were attended with but slight increases in efficiency, but where it was found possible to increase the mixture velocity, either by increasing the pressure of gas at the injector or of the air by a pressure-raising device, the difficulties referred to were removed, provided that the $B$. $t . u$. equivalent of the gas of lower calorific value was employed for the heating operation.

It would appear, therefore, that if from a consideration of manufacturing costs it should be found advisable to supply a gas of lower calorific value, most careful attention must be given in regard to the corresponding effects on the working efficiencies of apparatus as referred to above.

Conclusive as the direct observations upon the usefulness of the different gases would seem to be, the applicability of the observations to the problem of determining the effect upon the average consumer of a change of the heating value of the gas is sometimes questioned. The objections are based primarily upon the idea that the observed consumption of gases of different heating values does not indicate a constant demand for potential heat, and, the tacit assumption being made that the average consumer will always require the same service, the inference is drawn that potential heat is not equally useful in the different gases. The data upon the relation between quantity of gas used by the consumers and the heating value of the gas will be considered in the next section. Here we will examine only two points that are sometimes raised rather as explanations for the supposed difference in the usefulness to the consumer of the different gases than as evidence that such a difference exists. These explanations are:

1. That the direct determinations of efficiency are all made with appliances which have been adjusted to make them comparable, while the consumers' appliances have all sorts of adjustments.

2. That the consumer will waste more of a gas of high heating value than one of low heating value.

Although the first of these criticisms of the value of actual observation of the efficiency of appliances might apply to a limited series of tests in which a single setting of burner adjustments was employed, it certainly does not apply to such comprehensire studies as those made by the Institution of Gas Engineers or the Bureau of Stand- 
ards, in which all sorts of adjustments were used. These studies have clearly shown that whether adjustments are such as to give high efficiencies or low efficiencies, whether they result in dangerously incomplete combustion or give a needlessly large factor of safety from this hazard, it is found that the same type of flame gives the same service with substantially the same thermal efficiencies whatever the gas used. This is true whether the type of flame is judged by appearance or by the more accurate criterion of the ratio of the volume of primary air to that required for complete combustion.

A little consideration will show that the settings of the adjustable features of the appliance (usually orifice and air shutter, but sometimes the position of the burner also), will in general, be made to give the same effect regardless of the gas used. These adjustments are originally made either by the gas company or by the dealer installing the appliance, and the proper adjustment is always determined either by the appearance of the flame and of the object to which heat is applied, or by a more accurate determination of the result obtained. If the adjustment of the appliance is at any time changed by the user, it is because he desires a different effect, and that effect may safely be assumed to be independent of the heating value of the gas, of which the user generally knows nothing. These considerations all lead to the fact that adjustments in practice are made to produce the same result, if the result desired is obtainable, whatever the gas used; and this is the condition of equal efficiency in the application of the various gases.

It must be recognized that maximum thermal efficiency is secured with a given gas and a given appliance only when the gas is burned at such a rate that the zone of highest temperature is brought into proper position with respect to the object to be heated. Frequently it is possible to save a good deal of time by burning the gas faster than this most efficient rate with no great loss of efficiency, and for this reason many appliances, domestic and industrial alike, have been so adjusted that, when they are turned on full, the rate for maximum efficiency is considerably exceeded. Hence by reducing either the pressure at which the gas is supplied or the heating value the range of heat supply possible is cut down, and the customer is prevented, unless he changes the appliance, from using the upper and thermally less efficient rate of consumption, however desirable it might be to sacrifice a little heat for the sake of saving time. In this sense, and in this sense only, is the customer prevented from wasting gas by reducing the heating value.

The following discussion of this question of waste by consumers occurs in the report of the Bureau of Standards previously referred to as the Chicago Report: ${ }^{43}$

${ }^{4}$ Report to the City of Chicago and Peoples Gas Light \& Coke Co., p. 21; 1916. 
It is claimed by some that lean gas has an advantage as compared with rich gas in that less waste of heat results from its use. The bureau does not believe that any considerable weight should be placed upon this claim for the following reasons:

In general, burners must be adjusted to give a certain maximum rate of heat supply per hour when fully turned on, for the possible speed of the operations desired would be less with a reduced rate. It is clear that the present adjustments have resulted largely because the experience and preferences of the gas users make these adjustments most satisfactory, all things being considered. If smaller burners or lower rates of gas burning were desired, it is to be expected that natural development of appliances and the occasional adjustment of appliances would have already produced these changes.

It seems necessary to conclude, therefore, that any change in gas quality will sooner or later bring about readjustment of appliances, changes in pressure of gas, and other changes in the conditions of supply, so that eventually the average rate of burning for any sort of operation would again give substantially the same B. t. u. per hour as now prevails.

If this be true, the waste of heat when a gas burner is kept in operation needlessly will be the same with the new (lower heating value) gas as now. Or, if the burner is kept turned on full when half turned on would serve, the two gases would again be on a par. Furthermore, it is improbable that the operator of gas appliances would turn off the gas more with one than with the other gas; the heat waste would, therefore, be the same in the two cases when the maximum rate of heat supply is the same.

There are, no doubt, some appliances which are now used at too high rates of gas burning and which will not be readjusted for the new gas. In these cases some decrease in waste might be expected. On the other hand, there are appliances now in use at satisfactory adjustments that can not be promptly changed to suit the new supply; in these cases the speed of service which is now possible will not be attainable under the new conditions. ***.

Even if it were true that reducing the average heat set free per minute in domestic burners would result in an enforced saving to careless users, at the same time giving slower service, it is not clear that a saving to careless users which entails poorer service and no saving to careful users can be considered an advantage.

Both questions-the adjustment of appliances for testing purposes and waste by consumers-are discussed as follows by the gas research committee of the Institution of Gas Engineers ${ }^{44}$ in reply to criticism of their first report:

Protest must be made against the practice of testing hot-plate burners "full on" as representing the best performance consumers can obtain. It is not necessarily or usually so. Broadly speaking, the amount of heat transmitted through a metallic partition depends upon the mean temperature difference between the two sides, the thickness and nature of the metal, the cleanliness or otherwise of its surfaces, upon the time of heating, and upon the area exposed to the source of heat. In other words, a given vessel under stipulated conditions of use is capable of transmitting a certain limited number of B. t. u. per hour to its contents. No matter how efficient a burner may be as regards heat production, if the rate of heat supply exceeds the rate of heat transmission (plus sufficient heat to make good certain well known and unavodiable losses due to radiation, loss of sensible heat of products of combustion, etc.) the excess will

" Gas Jour., 145, p. 167; 1919. 
be lost with a corresponding loss of efficiency $* * *$. Sufficient attention is not usully given to this point, especially with small vessels, with the result that very low efficiencies are reported from time to time. In this respect we agree with the contention that the burner and vessel should be reasonably proportioned to one another, and we believe that in our tests this has been done. Careless consumers, by the use of a burner too large for the vessel to be heated or by an excessive supply of gas to an otherwise suitable burner, cause flames to pass beyond the base of the vessel. While the actual speed of heating may be increased to a certain point by this means, the efficiency upon B. t. u. supplied invariably falls.

While admitting that the foregoing conditions represent practical usage in many cases, they show an unfortunate disregard of conditions essential to economy, and it would be unwise to adhere to them in an efficiency investigation merely because they represent (bad) practice. On actual cooker hot plates results have been obtained only slightly inferior to those given in the report, and, while efficiencies of 20 to 25 per cent are not uncommon, their lowness is due to easily avoidable causes.

It is probable that the gas industry would, in general, resent the testing of appliances under conditions of bad adjustment and the publication of the results as those the consumer might expect to receive in service. Indeed, the principal criticism brought against the work of the research committee in the British gas journals was that they used appliances which were representative of those in service rather than representative of good practice.

The criticism is most clearly set forth in an editorial in the Gas Journal, ${ }^{45}$ as follows:

The legislature has recognized as a fundamental right that gas should be allowed in its testing to have those appliances which will develop its maximum efficiency $* * *$. The same principle that is recognized by the legislature should be followed in testing the uses of gas in present-day appliances. One can not expect to correctly gauge the efficiency of any gas if the appliances in which it is used are not themselves efficient. It is not the indifferent ones that should be regarded as representative of the consumers' appliances but those which incorporate in them the maximum progress in invention and which are the standard toward and from which (in the upward direction) the gas industry is working. The committee have to investigate gas composition in relation to use; but the gas composition refers to the future not to the past. It is therefore the duty of the committee to prosecute their reference with due heed to the character of the gas appliances by means of which the gas is to be consumed. The users of good gas fires and other heaters do not want the gas supplied to them to be curtailed in any manner through any criterion set by inferior gasusing appliances, any more than users of inverted burners desire the gas supplied to them to be the gas that the users of flat-flame burners would prefer, and which is uneconomical in different senses for both.

Substantially the same criticism occurs in another editorial ${ }^{46}$ and in discussion by W. B. Davidson, ${ }^{47} \mathrm{~S}$. B. Langlands, ${ }^{48}$ and T. W. Fletcher. ${ }^{49}$

48 Gas Jour., 144, p. 164; 1918

46 Gas. Jour., 145, p. 158; 1919.

47 W. B. Davidson, Gas Jour., 144, p. 295; 1918.

48 S. B. Langlands, Gas Jour., 144, p. 297; 1918.

10 T. W. Fletcher, Gas Jour., 144, p. 315; 1918. 
It would be interesting to see the comment which would result from a proposal to curtail the gas supplied to all consumers to accommodate those who, through neglect or ignorance, have the worstadjusted appliances. If the adjustment of appliances is so bad in any city that it should be seriously considered as a factor in determining the kind of gas to manufacture, should not the gas company readjust the appliances?

The sale of gas in England has been on the heat-unit basis for several years. The change from the basis of sale by volume was made as the direct result of the investigations of the gas research committee, and this investigation has apparently been accepted as authoritative and final by the entire industry. The perusal of more than 100 articles of all descriptions which deal with the reports of the research committee and the "therm" basis for selling gas has failed to disclose a single expression of opinion showing that anyone in the British gas industry objects to the sale of gas on the heat-unit basis because it does not represent the value received by the consumer.

This is in striking contrast to American opinion, which is still strongly divided upon the subject. Even so strong an advocate of gases of low heating value as George Helps, in discussing the first report of the research committee and his own fourteen years of research work on gas utilization, ends with the following statement: ${ }^{50}$

One B. t. u. is as good as another, and the only thing that we as gas makers have to consider is the question of distribution and the adoption of approved appliances. Gas will be required in ever-increasing quantities, and the gas to make is that which contains the greatest number of B.t. u.'s for 1d. at the consumers' appliances.

\section{DATA REGARDING QUANTITY OF GAS USED BY CUSTOMERS AND ITS RELATION TO THE USEFULNESS OF THE GAS}

The assumption has been frequently made that the demand for "gas service" in a given community is so constant that the effect upon the average customer of a change of heating value may be judged from the amount of gas used. The Bureau of Standards once made this assumption and proposed to the Railroad Commission of Oregon and the Portland Gas \& Coke Co., in connection with the company's application for a change of standard, that the experiment be tried of actually delivering gases of different qualities over certain experimental periods and observing the resultant effect upon sales. To this the gas company vigorously objected in the following words:

It has been the experience of all gas companics that there will occur periods when the sale per consumer will fluctuate, due to weather conditions, financial

so George Helps, Gas Jour., 14, p. 295; 1918. 
depression, greater economy in utilization, the purchase and installation of additional appliances, the growth of a community, etc., all of which factors are so involved and complicated that it will be impossible to judge at the end of the trial period whether or not a loss in earnings is directly traceable to a change in the quality of gas.

The company was certainly right; there are so many factors other than a change in the quality of gas which might affect the amount of gas used that it is out of the question to judge from total sales the effect of the change of quality, unless in some way the effects of the other factors can be partially eliminated. In the cases we shall consider various methods have been adopted for eliminating the other variables as far as possible. Before discussing the actual data it will probably be well to enumerate some, at least, of these complicating factors and the most feasible ways of compensating for them. Since most of our data relate to periods of reduction rather than increase of heating value, we will consider only reductions of heating value in this discussion.

We will at the start divide the variables into two classes-those which always tend to prevent the volume of gas used from increasing when the quality is reduced and those which may operate in either direction. In the first class we have the following facts to consider.

1. The volume of gas used in many appliances can not be readily increased by the consumer to supply heat at the same rate unless, as is not usually the case, changes of pressure and specific gravity permit the delivery of the same quantity of potential heat. This is especially true of some mantle lights and room heaters, which are ordinarily used with the supply cock wide open, and the period of operation of which is likely to be independent of moderate variations in the quantity of light or heat produced. It is to some extent true of water heaters, including both the automatic and storage types. This assumes, of course, that the orifices are not enlarged to deliver a greater volume of gas.

2. In most cases of a reduction of heating value the gas company has voluntarily or through necessity made a house-to-house inspection and readjustment of consumers' appliances. This inevitably results in the correction of bad conditions of all sorts, the instruction of consumers in the careful use of gas, and in the general elimination of waste. In some cases the readjustment has been accompanied by a systematic campaign for economy in the use of gas. Such activities on the part of the gas company are of great service to its customers, and their cost is a legitimate service charge for which the company should receive a return as for any other part of the cost of doing business, but it has nothing to do directly with the value of the gas itself, nor does one such service justify the company in charging a higher rate for the heat sold for an indefinite period thereafter. 
3. Many of the changes, the effects of which will be discussed were made in cities in which gas was to a large extent used for lighting, much of it open-flame lighting. When the heating value and openflame candlepower were reduced, the customers were forced to use the more efficient mantle lights (to their advantage, of eourse) or to substitute eleetricity. Both of these changes have been going on extensively in all the older eities; both result in a reduction of the quantity of gas used, and both are aecelerated by a reduction of heating value.

4. The reduction of heating value may have retarded the expansion of the use of gas for other purposes to some extent, especially by the larger industrial eonsumers who would figure the eost of available heat rather closely. In some instances an increase in rate per thousand cubic feet also accompanied the reduction of quality. In none of the eases eited is it shown that a decrease in rate per thousand cubic feet was put into effeet when the heating value was reduced, and a reduction of heating value without a proportional reduction of nominal rate is in effect an increase in the rate at which heat is sold. Although the eustomers did not generally know that they were paying a higher rate for heat, their demand may have been affeeted to some extent, for there is a tendency for customers to keep a uniform bill. A great many families have rather definite and none too adequate budgets. The monthly service bills are carefully scrutinized, and if there is any indication of an increase the family decide to be more careful in the use of that particular service.

Among the factors which affeet the amount of gas used, sometimes in one direction and sometimes in the other, the following should be mentioned:

1. Weather conditions, of eourse, greatly affect the use of gas, and the effect is not always easy to predict even in direction. In the colder parts of the country, for example, houses are heated during the winter by coal-burning furnaces which also supply hot water for all purposes. In the autumn before the furnaces are lighted and in the spring just after they are allowed to go out a considerable amount of gas is used for heating. Cold weather in late fall or early spring will therefore cause the use of the coal-burning appliances, with a diminished use of gas, for both water and space heating. Very severe eold weather in the winter, on the other hand, and unseasonably eold weather in early fall and late spring will much increase the demand for gas for house heating, while changes of temperature during the summer will have little, if any, effect upon the amount of gas used.

2. During the war and in eases of mining or railroad strikes the supply of coal has been frequently interfered with and has unques$43360^{\circ}-25 \dagger-4$ 
tionably greatly affected the demands of both domestic and industrial consumers for gas.

3. Industrial conditions (including both the use of gas in industry and the effect of financial depression, low wages, and unemployment upon the expenditures of domestic consumers) have a decided effect upon the amount of gas used.

4. The amount of gas used is constantly changing as new uses and new equipment are introduced. The extent of such changes is dependent upon the growth and prosperity of the community, upon the activity of the commercial department of the gas company, and, to some extent, especially in communities provided with cheap hydroelectric power, upon the activities of the competitors of the gas company.

5. Numerous other factors enter the problem at times. Among those mentioned in the literature are the domestic canning of an exceptional fruit crop, home brewing, and daylight saving.

It should be noted that with the exception of the second factor of the first group, which is likely to attend a change of heating value but is not caused by it, all these effects which we can anticipaie are caused by changes in the available market for gas service and not by changes in the efficiency with which gas is utilized. If, therefore, it should appear that a reduction of heating value of the gas supply has resulted in a reduction of the amount of heat used by the community served, careful consideration should be given to the extent to which the gas company's market has been destroyed before any conclusion is drawn as to the efficiency with which gas is used by the remaining customers.

An apparently good illustration of the difficulty of correctly interpreting data relating to this matter is furnished by the case of 23 customers in Denver selected by the manager of the local gas company for study. ${ }^{51}$ Details of the consumption of this group were kindly supplied to the Bureau of Standards by F. C. Weber. The volume of gas used monthly by each customer is given in Table 4 .

The aggregate volume used by this group decreased annually as the heating value decreased. Not unnaturally the conclusion was at first drawn that this change of consumption resulted from the more efficient utilization of heat for the same service. If we examine the records in detail, however, we find in the case of each of six customers, Nos. $3,4,6,17,21$, and 23 , a reduction in the use of gas so great that it can not possibly be accounted for by any change in the efficiency of utilization; it is perfectly clear that gas service was not required by these customers in 1922 to the same extent as in 1920 . There is no customer whose use of gas indicates a corresponding increase in the service required, with the possible exception of No. 5.

51 This is the group discussed by Floyd Parsons in the Gas Age Record, 52, p. 773-774; 1923. 
If we omit from the averages those customers whose service requirements thus showed an altogether abnormal change, the consumption by the remainder is very nearly in inverse proportion to the heating value. We therefore find that, in this case at least, the reduction in the amount of heat used can not have been caused by its more efficient use. If the reduced consumption was in any way caused by the change of heating value, which is by no means certain, it must be that high price or unsatisfactory service caused the use of gas for certain purposes to be discontinued.

TABLE 4.-Volume of gas used by 23 selected customers in Denver, 1920-1922

[Consumption by months-hundreds cubic feet]

\begin{tabular}{|c|c|c|c|c|c|c|c|c|c|c|c|c|c|c|c|c|c|c|c|c|c|}
\hline \multirow{2}{*}{$\begin{array}{l}\text { Year and } \\
\text { month }\end{array}$} & \multicolumn{20}{|c|}{ Customer's No.-- } & \multirow{2}{*}{$\begin{array}{l}\text { Average } \\
\text { monthly } \\
\text { B.t.u. }\end{array}$} \\
\hline & 1 & 2 & 34 & 4 & 5 & 6 & 78 & \begin{tabular}{l|l}
8 & 9
\end{tabular} & \begin{tabular}{l|l}
9 & 10
\end{tabular} & 11 & 1213 & 1314 & 415 & 16 & \begin{tabular}{l|l}
17 & 1
\end{tabular} & 181 & $192 x$ & 2021 & 2122 & 23 & \\
\hline 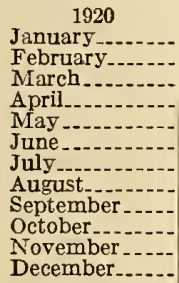 & \begin{tabular}{r|}
17 \\
8 \\
8 \\
11 \\
10 \\
9 \\
5 \\
8 \\
13 \\
8 \\
13 \\
9
\end{tabular} & $\begin{array}{l}21 \\
18 \\
16 \\
15 \\
18 \\
21 \\
21 \\
20 \\
15 \\
18 \\
14 \\
16\end{array}$ & \begin{tabular}{r|r}
19 & \\
15 & \\
16 & 2 \\
13 & \\
13 & \\
16 & \\
16 & 2 \\
23 & \\
15 & \\
22 & \\
19 & 2
\end{tabular} & \begin{tabular}{l|}
23 \\
28 \\
25 \\
30 \\
16 \\
16 \\
23 \\
21 \\
16 \\
19 \\
19 \\
20
\end{tabular} & \begin{tabular}{r|}
9 \\
15 \\
23 \\
22 \\
17 \\
30 \\
27 \\
24 \\
31 \\
24 \\
28 \\
11
\end{tabular} & $\begin{array}{r}21 \\
19 \\
18 \\
21 \\
17 \\
14 \\
16 \\
17 \\
18 \\
9 \\
0 \\
11\end{array}$ & $\begin{array}{rl}8 & 1 \\
7 & \\
6 & 1 \\
10 & 1 \\
7 & 1 \\
7 & 1 \\
8 & 1 \\
8 & \\
7 & 1 \\
12 & 1 \\
9 & 1 \\
11 & 2\end{array}$ & \begin{tabular}{r|r}
13 & 2 \\
8 & 1 \\
18 & 3 \\
13 & 2 \\
11 & 3 \\
10 & 1 \\
13 & 1 \\
6 & 2 \\
12 & 2 \\
12 & 2 \\
13 & 2 \\
21 & 1
\end{tabular} & $\begin{array}{ll}26 & 26 \\
19 & 19 \\
30 & 22 \\
23 & 20 \\
37 & 24 \\
13 & 32 \\
19 & 30 \\
29 & 28 \\
22 & 31 \\
29 & 24 \\
23 & 22 \\
18 & 20\end{array}$ & $\begin{array}{r}8 \\
91 \\
21 \\
26 \\
26 \\
37 \\
20 \\
20 \\
18 \\
6 \\
3 \\
3 \\
12 \\
27 \\
27 \\
37 \\
14\end{array}$ & $\begin{array}{ll}16 & 2 \\
17 & 1 \\
14 & 2 \\
15 & 1 \\
13 & 12 \\
15 & 18 \\
18 & 1 \\
23 & 1 \\
26 & 2 \\
27 & 18 \\
15 & 1 \\
14 & 2\end{array}$ & $\begin{array}{rr}22 & 8 \\
10 & 14 \\
26 & 18 \\
13 & 16 \\
12 & 13 \\
18 & 18 \\
19 & 26 \\
19 & 27 \\
21 & 32 \\
18 & 29 \\
19 & 15 \\
24 & 25\end{array}$ & $\begin{array}{ll}8 & 29 \\
4 & 18 \\
8 & 20 \\
6 & 21 \\
3 & 21 \\
8 & 24 \\
6 & 29 \\
7 & 24 \\
2 & 22 \\
9 & 27 \\
5 & 33 \\
5 & 31\end{array}$ & $\begin{array}{l}26 \\
14 \\
30 \\
28 \\
27 \\
21 \\
30 \\
29 \\
25 \\
19 \\
23 \\
24\end{array}$ & $\begin{array}{l}46 \\
45 \\
44 \\
44 \\
36 \\
25 \\
29 \\
17 \\
31\end{array}$ & $\begin{array}{l}24 \\
32 \\
33 \\
29 \\
32 \\
28 \\
25 \\
23 \\
23 \\
13 \\
28 \\
31\end{array}$ & $\begin{array}{ll}17 & 1 \\
16 & 1 \\
22 & 1 \\
38 & 1 \\
35 & 3 \\
24 & 1 \\
21 & 1 \\
18 & 1 \\
29 & 2 \\
23 & 1 \\
34 & 2 \\
29 & 2\end{array}$ & \begin{tabular}{l|l}
11 & 2 \\
13 & 2 \\
10 & 2 \\
12 & 26 \\
38 & 2 \\
16 & 2 \\
13 & 2 \\
19 & 22 \\
21 & 2
\end{tabular} & \begin{tabular}{l|l}
29 & 47 \\
28 & 45 \\
29 & 55 \\
26 & 47 \\
28 & 43 \\
23 & 45 \\
28 & 57 \\
29 & 53 \\
29 & 57 \\
26 & 55 \\
30 & 36 \\
29 & 46
\end{tabular} & \begin{tabular}{r|r|}
7 & 98 \\
5 & 71 \\
5 & 67 \\
7 & 16 \\
3 & 3 \\
5 & 6 \\
7 & 8 \\
7 & 9 \\
5 & 12 \\
6 & 15 \\
6 & 24 \\
6 & 34
\end{tabular} & 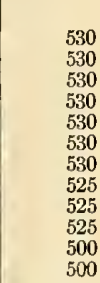 \\
\hline Tot & 119 & 2131 & 19427 & 2732 & 2611 & 1811 & 0015 & 5028 & 88298 & 82522 & 21322 & 221240 & 299 & 2964 & 4033 & 32130 & 30621 & 1432 & & 63 & 524 \\
\hline 1 & $\begin{array}{r}11 \\
19 \\
19 \\
15 \\
20 \\
12 \\
8 \\
16 \\
17 \\
12 \\
8 \\
12\end{array}$ & $\begin{array}{l}20 \\
15 \\
14 \\
14 \\
16 \\
17 \\
12 \\
13 \\
14 \\
14 \\
12 \\
21\end{array}$ & \begin{tabular}{r|r}
15 & 2 \\
15 & 1 \\
15 & 2 \\
14 & 2 \\
14 & 1 \\
13 & \\
6 & \\
12 & 1 \\
16 & 2 \\
18 & 2 \\
20 & 1
\end{tabular} & \begin{tabular}{l|}
21 \\
19 \\
21 \\
20 \\
19 \\
18 \\
18 \\
12 \\
19 \\
22 \\
22 \\
19
\end{tabular} & $\begin{array}{r}18 \\
16 \\
18 \\
43 \\
45 \\
52 \\
37 \\
-54 \\
52 \\
40 \\
38\end{array}$ & $\begin{array}{r}19 \\
12 \\
9 \\
9 \\
7 \\
3 \\
1 \\
6 \\
4 \\
8 \\
8 \\
5\end{array}$ & \begin{tabular}{r|l}
10 & 1 \\
9 & 1 \\
12 & 1 \\
4 & 1 \\
2 & 1 \\
5 & \\
5 & 1 \\
11 & 1 \\
12 & 1 \\
7 & 1 \\
7 & 1 \\
8 &
\end{tabular} & & \begin{tabular}{l|l}
21 & 22 \\
17 & 17 \\
19 & 23 \\
22 & 27 \\
22 & 33 \\
26 & 39 \\
21 & 33 \\
22 & 34 \\
25 & 38 \\
19 & 29 \\
16 & 24 \\
31 & 27
\end{tabular} & $\begin{array}{l}11 \\
14 \\
12 \\
17 \\
24 \\
22 \\
18 \\
19 \\
19 \\
24 \\
24 \\
23 \\
22 \\
2\end{array}$ & \begin{tabular}{l|l}
18 & 2 \\
16 & 2 \\
22 & 2 \\
25 & 2 \\
25 & 2 \\
25 & 2 \\
25 & 2 \\
23 & 2 \\
22 & 2 \\
26 & 2 \\
25 & 2 \\
22 & 2
\end{tabular} & \begin{tabular}{l|l}
21 & 30 \\
21 & 30 \\
22 & 14 \\
22 & 29 \\
20 & 27 \\
23 & 27 \\
21 & 23 \\
21 & 23 \\
25 & 29 \\
20 & 31 \\
21 & 26 \\
22 & 31
\end{tabular} & $\begin{array}{ll}0 & 38 \\
0 & 30 \\
4 & 33 \\
9 & 31 \\
7 & 30 \\
7 . & 31 \\
3 & 34 \\
3 & 34 \\
9 & 25 \\
1 & 46 \\
6 & 30 \\
1 & 28\end{array}$ & $\begin{array}{l}26 \\
26 \\
25 \\
25 \\
21 \\
22 \\
17 \\
21 \\
27 \\
24 \\
28 \\
22\end{array}$ & \begin{tabular}{r|r}
30 \\
37 \\
36 & \\
11 & \\
18 & 3 \\
31 & \\
2 & \\
9 & \\
14 & \\
16 & \\
6 & \\
16 &
\end{tabular} & \begin{tabular}{l|l}
27 & \\
20 & \\
24 & \\
24 & 1 \\
32 & \\
27 & \\
20 & 2 \\
25 & 2 \\
21 & 3 \\
18 & \\
20 & \\
31 &
\end{tabular} & \begin{tabular}{l|l}
16 \\
19 \\
24 \\
15 \\
27 \\
27 \\
22
\end{tabular} & \begin{tabular}{r|r}
19 & 2 \\
21 & 2 \\
19 & 10 \\
16 & \\
14 & 10 \\
14 & \\
13 & 1 \\
8 & 1 \\
18 & 1 \\
18 & 10
\end{tabular} & \begin{tabular}{r|r}
30 & 47 \\
30 & 50 \\
27 & 56 \\
25 & 50 \\
10 & 45 \\
7 & 48 \\
10 & 54 \\
9 & 68 \\
11 & 53 \\
11 & 47 \\
13 & 44 \\
16 & 48
\end{tabular} & $\begin{array}{rr}7 & 30 \\
0 & 27 \\
6 & 27 \\
0 & 23 \\
5 & 25 \\
8 & 3 \\
4 & 5 \\
8 & 21 \\
3 & 11 \\
7 & 7 \\
4 & 5 \\
8 & 8\end{array}$ & . \\
\hline Total_ & 160 & 1821 & 17423 & 2304 & 413 & 91 & & & 61 & 02 & 278 & 150 & 0.390 & 3042 & 22628 & 28 & & 200199 & 0 & 2 & $14=0$ \\
\hline cem & $\begin{array}{l}12 \\
10 \\
11 \\
11 \\
13 \\
11\end{array}$ & $\begin{array}{l}20 \\
22 \\
15 \\
26 \\
21 \\
22 \\
21 \\
27 \\
21 \\
19 \\
23 \\
22\end{array}$ & \begin{tabular}{r|r}
19 & \\
15 & 2 \\
16 & 19 \\
16 & 1 \\
1 & 2 \\
3 & 1 \\
2 & 3
\end{tabular} & \begin{tabular}{r|}
23 \\
22 \\
17 \\
3 \\
1 \\
1 \\
2 \\
2 \\
3 \\
3 \\
3 \\
3
\end{tabular} & $\begin{array}{l}42 \\
41 \\
44 \\
47 \\
41 \\
37 \\
36 \\
11 \\
35 \\
54 \\
33 \\
-.\end{array}$ & \begin{tabular}{r|r}
4 & \\
9 \\
5 \\
3 \\
5 \\
6 \\
10 & \\
4 & \\
3 & \\
6 & \\
2
\end{tabular} & \begin{tabular}{r|r}
7 & 1 \\
4 & 1 \\
6 & \\
4 & \\
1 & 1 \\
2 & 1 \\
3 & 1 \\
7 & 1 \\
10 & 1
\end{tabular} & \begin{tabular}{r|r}
13 & 2 \\
13 & 2 \\
8 & 3 \\
4 & 2 \\
15 & 2 \\
11 & 2 \\
12 & 1
\end{tabular} & \begin{tabular}{l|l}
29 & 23 \\
28 & 22 \\
32 & 25 \\
28 & 22 \\
25 & 28 \\
22 & 38 \\
19 & 35 \\
10 & 40 \\
18 & 39
\end{tabular} & $\begin{array}{r}24 \\
20 \\
21 \\
20 \\
24 \\
19 \\
20 \\
9 \\
12 \\
17 \\
14 \\
18\end{array}$ & \begin{tabular}{l|l}
23 & 21 \\
21 & 21 \\
22 & 25 \\
22 & 24 \\
24 & 18 \\
24 & 20 \\
16 & 19 \\
17 & 18 \\
21 & 23 \\
18 & 19 \\
14 & 21 \\
19 & 22
\end{tabular} & $\begin{array}{ll}21 & 26 \\
21 & -- \\
25 & - \\
24 & 35 \\
18 & 36 \\
20 & 33 \\
19 & 37 \\
18 & 41 \\
23 & 55 \\
19 & 42 \\
21 & 36 \\
22 & 23\end{array}$ & 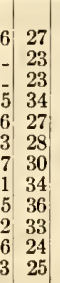 & $\begin{array}{l}32 \\
21 \\
32 \\
13 \\
23 \\
25 \\
19 \\
22 \\
29 \\
27 \\
25 \\
45\end{array}$ & \begin{tabular}{r|r}
18 \\
15 \\
19 \\
15 \\
15 \\
5 \\
4 \\
5 \\
9 \\
7 \\
9 \\
9 & 2 \\
19 & 2
\end{tabular} & $\begin{array}{l}19 \\
19 \\
11 \\
24 \\
22 \\
19 \\
23\end{array}$ & $\begin{array}{rr}46 & 1 \\
19 & \\
41 & 1 \\
36 & 1 \\
41 & 1 \\
33 & \\
20 & \\
35 & 1 \\
31 & \\
31 & 1 \\
37 & 2 \\
6 & 2\end{array}$ & $\begin{array}{rr}16 & 12 \\
9 & 12 \\
13 & 14 \\
19 & 9 \\
12 & 10 \\
8 & 6 \\
7 & 1 \\
15 & 1 \\
9 & 4 \\
18 & 14 \\
23 & 17 \\
21 & 13\end{array}$ & $\begin{array}{rl}12 & 51 \\
17 & 43 \\
14 & 48 \\
9 & 44 \\
10 & 53 \\
6 & 68 \\
1 & 60 \\
1 & 62 \\
4 & 57 \\
14 & 62 \\
17 & 50 \\
13 & 46\end{array}$ & \begin{tabular}{rr|}
1 & 11 \\
3 & 6 \\
8 & 12 \\
4 & 13 \\
3 & 9 \\
8 & 11 \\
0 & 10 \\
2 & 9 \\
7 & 5 \\
2 & 6 \\
0 & 5 \\
6 & 5
\end{tabular} & \\
\hline & & & $97 \mid 8$ & & & & & & & & & & & & & & & & & & \\
\hline
\end{tabular}

1 Average.

With the many conditions which affect the consumption of gas it is surprising that the relation between heating ralue and the volume used is not more completely masked than it is in the data which will be presented. 
In all the data to be considered we will be concerned with the ratio between the percentage change in the volume of gas used and the percentage change in the heating value of the gas when the volume used is corrected so far as possible by the elimination of such disturbing factors as seasonal variations and the regular development of the gas business.

We will therefore agree upon a symbol, $R$, to represent this ratio. Let us represent by $H$ the heating value of the gas before the change, by $h$ an increase, and by $-h$ a decrease in the heating value; by $V$ the volume of gas used by the community or group under consideration and by $v$ the increase in the volume used which accompanies the change of heating value.

Then $R=-\frac{H v}{h(V+v)}$ represents the proportional change of consumption accompanying the change of heating value; if the amount of heat used does not change, $R=1$; if the volume of gas used does not change, $R=0$. The meaning of $R$ may be made clear by numerical examples. Assume that while $600 \mathrm{~B}$. t. u. gas is distributed the average consumption is 2,000 cubic feet per meter per month. The heating value is changed to $500 \mathrm{~B}$. t. u., and the volume used increases to 2,400 cubic feet per meter per month. In this case $H=600, h=$ $-100, V=2,000$, and $v=400$. Substituting these values in the formula we find $R=1.00$. This may be expressed in words by stating that the change of consumption which accompanied the change of heating value is 100 per cent of that required to maintain an unchanged demand for potential heat. If after the change of heating value the consumption averages 2,200 cubic feet per meter,

$$
R=\frac{600 \times 200}{100 \times 2200}=0.55
$$

That is, the change of consumption is only 55 per cent of that which would correspond to inverse proportionality between heating value and volume used.

In order to show graphically the relations which exist between data on consumption and on heating value two devices will be used. The first of these applies where only one locality is under consideration and consists in plotting not the directly observed quantity (for example, volume of gas used per meter) but the ratio to the corresponding quantity at some other time, usually the preceding year. In this way we eliminate regular seasonal variations and any constant tendency for gas sales to increase from year to year.

In order to permit the reader to become familiar with the kind of results to be expected from this method of study some ideal curves are plotted in Figure 13. In this figure curve $A$ represents a constant increase in the volume of gas used. Curve $B$ represents a slightly different constant rate of increase in the volume used annually, 
together with a perfectly regular seasonal variation. Now, let us make the hypothesis that the amount of gas used is inversely proportional to the heating value and see how the changes of heating value represented by the curve labeled "heating value" will affect

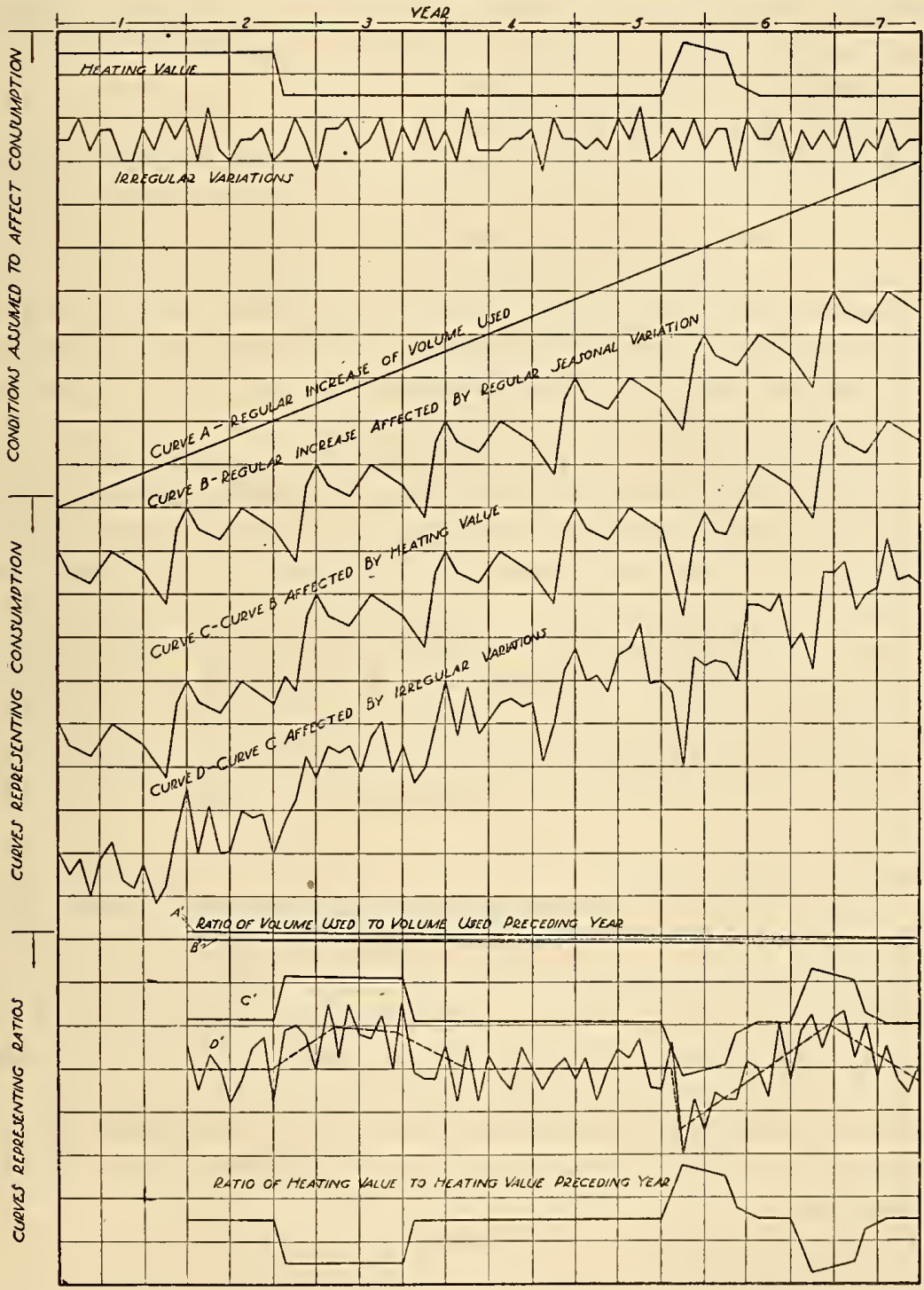

Frg. 13.-Ideal curves to illustrate treatment of statistical data by plotting ratio of heating value and volume used to the corresponding quantity during the preceding year

curve $B$. The resultant is shown by curve $C$. Let us now suppose that the volume used is affected irregularly by influences no greater than that of the heating value so distributed that they do not materi- 
ally affect the amount of gas used in any one year. The magnitude and time of these assumed variations are shown by the curve labeled "irregular variations." The resultant is curve $D$. In obtaining this curve no displacement of the relative position of points on curve $C$ was made grcater than 60 pcr cent of that corresponding to the maximum assumed change of heating value, but the effect of the change in heating value is entirely obscured.

If we now plot the ratio of the volume used during each month to the volume used during the corresponding month of the preceding year for each of the cases represented, we obtain curves $A^{\prime}, B^{\prime}, C^{\prime}$, and $D^{\prime}$, representing the same data as $A, B, C$, and $D$, respectively. $A^{\prime}$ and $B^{\prime}$ are practically horizontal straight lines differing slightly in position because of the difierence in the general rate of annual increase assumed. These two curves are shown in their correct relative positions; curves $C^{\prime}$ and $D^{\prime}$ are given their correct shapes, but their positions on the page are arbitrary.

It will be noted that the effect of a single change in the amount of gas used appears twice on the ratio curves, first in the comparison between the year in which the change occurs with the preceding year, and, second, in the comparison with the year which follows the change.

The heavy broken line drawn through curve $D^{\prime}$ represents approximately the line which would probably be drawn by an observer as representing the tendency of the curve; and it shows at once the direction and the approximate time and magnitude of the change which has taken place, points which could not be judged at all from curve $D$.

The data with which we have to deal in practice are always of the character represented by curve $D$; that is, they always combine with the effects which may be caused by changes of heating value, the effect of the general development of the industry, seasonal changes, and irregular effects from sources of unknown nature and magnitude. The principal difference between actual data and the case assumed in $D$ is that in actual practice the unknown variables, while less numerous than those assumed, are also much less regular and frequently of much greater magnitude and are correspondingly harder to interpret.

The second method of compensating for variables is to make a comparison between two localities which may be assumed to be subject to much the same influences. This comparison is most readily made by determining the ratio between the heating values of the gas supplied and also between the volumes of gas used. This method eliminates all variables which are common to the two localities, but it may not eliminate the effect of local conditions as well as the first method of study. 
Whatever the method of treating the data, whether we use observed data directly or whether we use ratios of different periods of time or different localities, when we plot corresponding curves representing heating value and consumption on corresponding scales we should expect to find one curve the mirror image of the other if a change of heating value causes a proportional change of consumption in the opposite direction. The mirror image will usually be distorted by the effect of the factors other than heating value which affect consumption. Probably the best way to visualize the relation we should expect to find is to think of the outline of a mountain range and its reflection in a lake considerably distorted by waves.

\section{EIGHT STONE \& WEBSTER COMPANIES}

The use of these methods of comparison and the diverse character of the changes in the volume of gas used in different cities will be

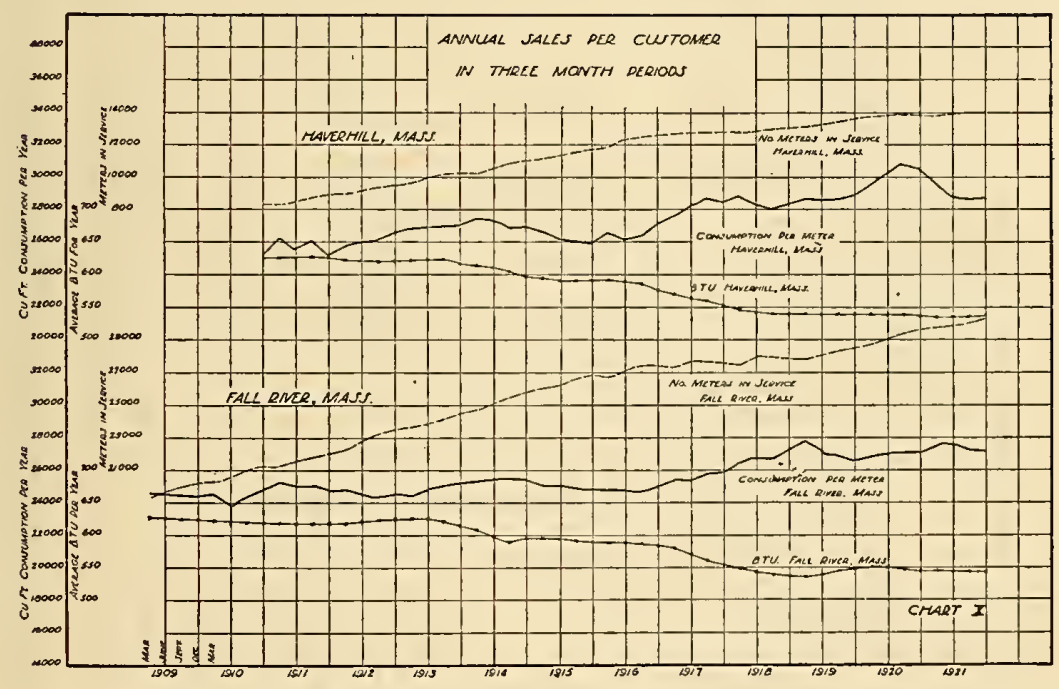

FIG. 14.-Heating value and volume of gas used in Haverhill and Fall River, Mass.

illustrated by data from Haverhill and Fall River, Mass.; New London, Conn.; Pawtucket, R. I.; Columbus, Ga.; Paducah, Ky.; Keokuk, Iowa; and Bellingham, Wash., data for which were made available through the courtesy of G. E. Whitwell and H. P. Geissler, who prepared the curves of which Figures 14 to 17 are tracings; and Stone \& Webster, who supplied, in tabular form, most of the data from which these curves were constructed. All the companies concerned are under the management of Stone \& Webster. These figures constitute a portion of a "Compilation of data, statements, reports, and decisions relative to calorific standards for gas service," prepared by Whitwell. The curves for New London, Columbus, Keokuk, 


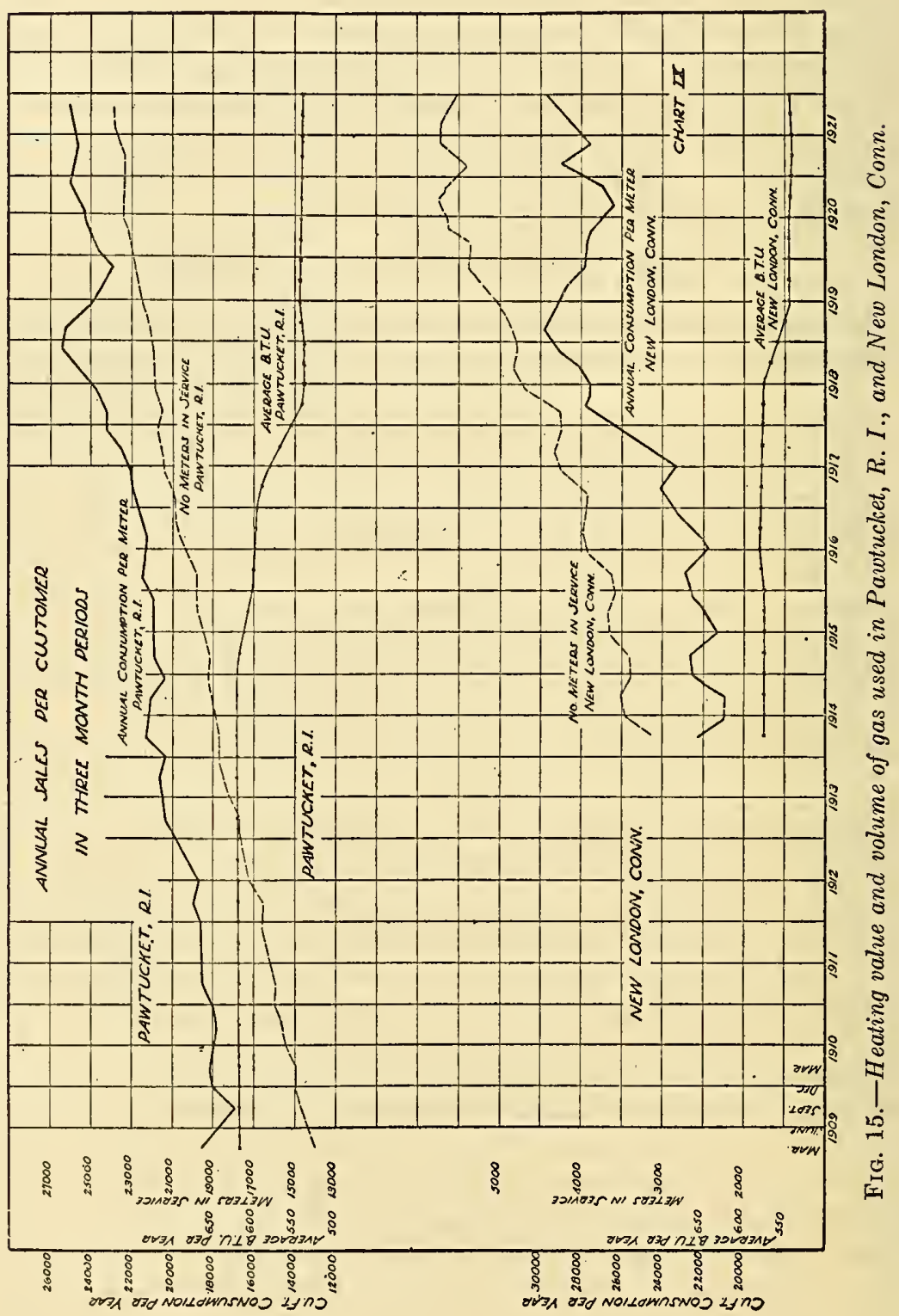




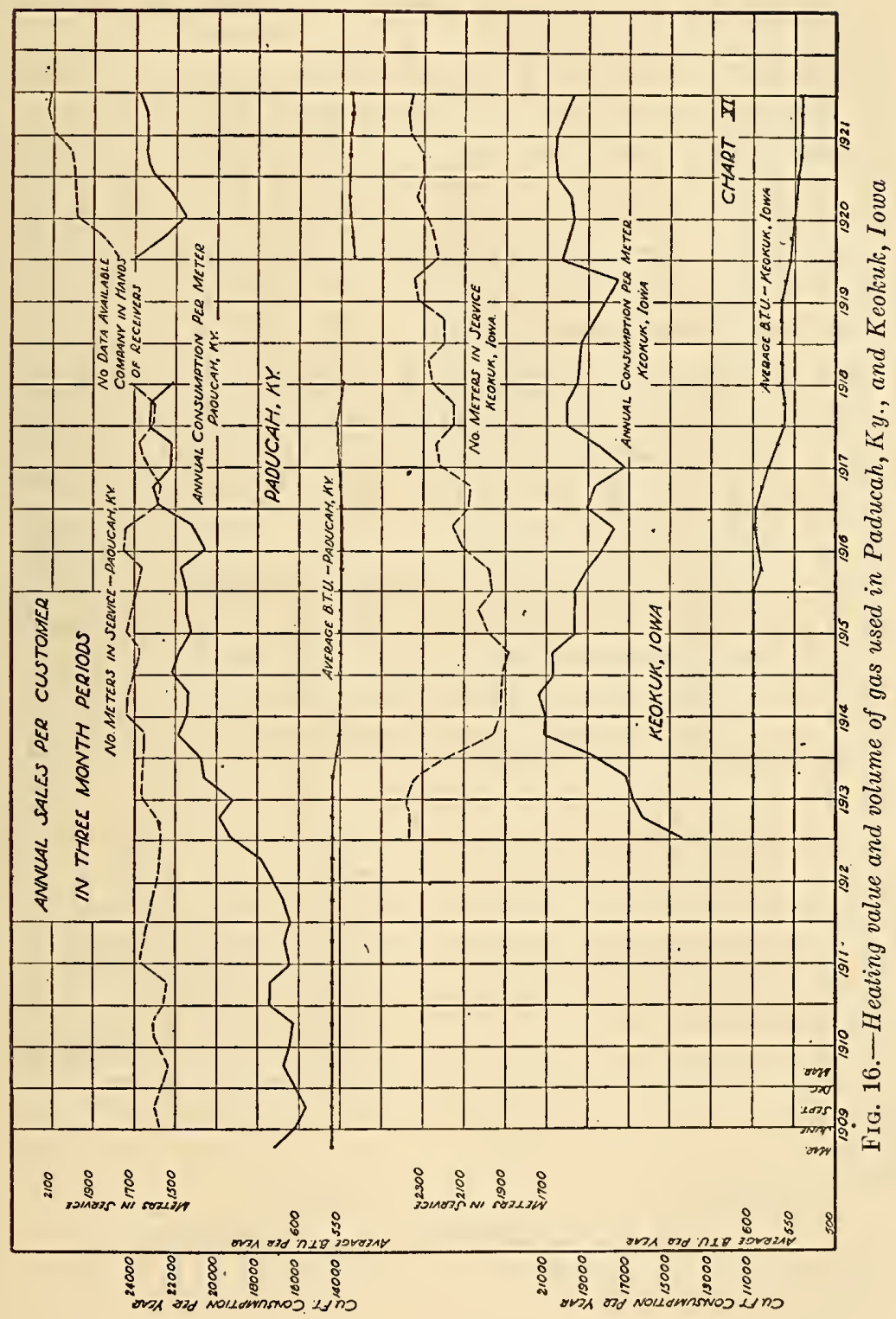




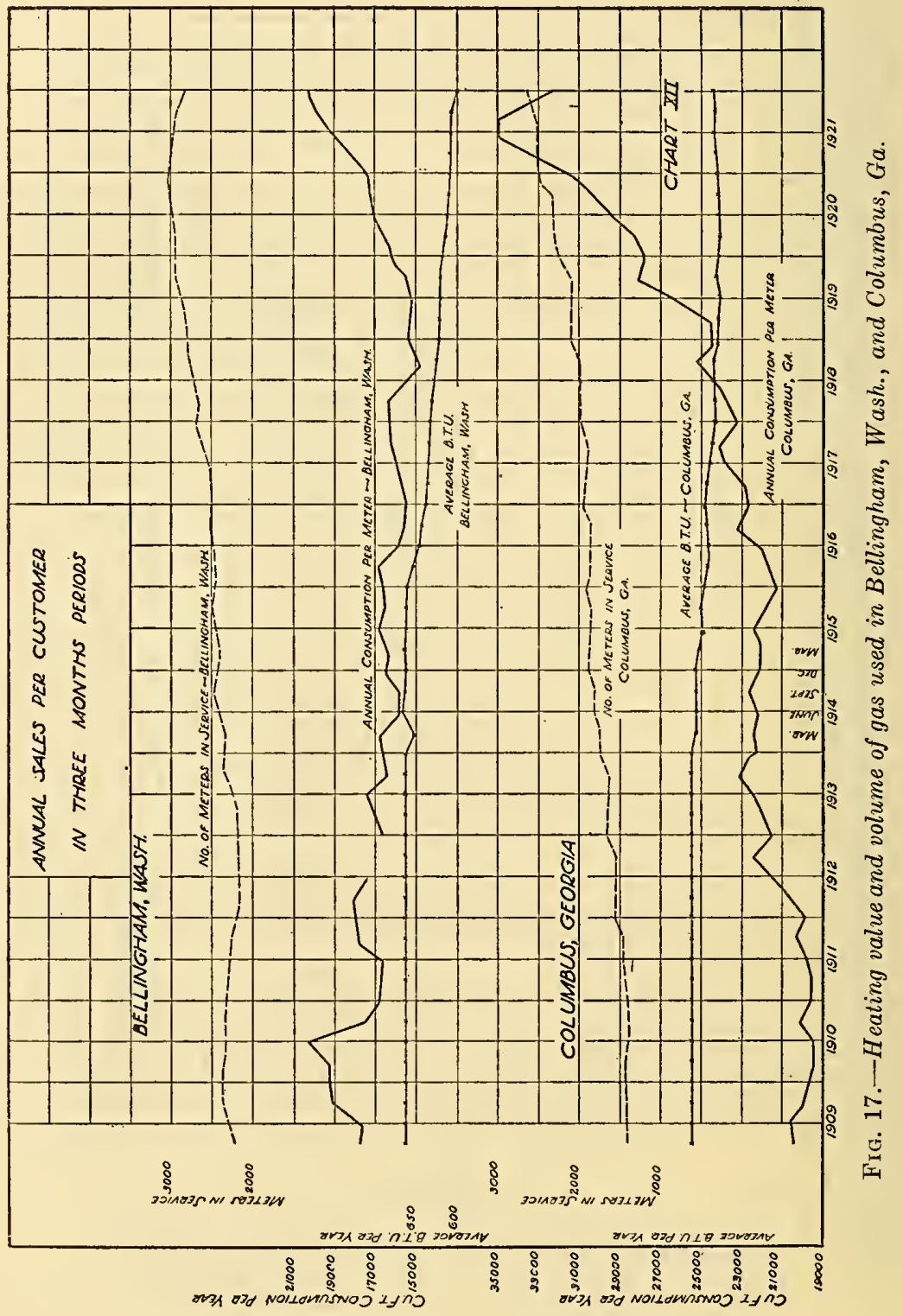


Paducah, and Bellingham are principally of interest as showing the large variations in the use of gas which take place when there is no important change of heating value, and the fact that such changes, while having general tendencies in common, vary greatly in detail. In general, the companies showed a decrease in gas sales per meter during the early part of the World War, or at least a smaller rate of increase, a decided increase during the latter part of the war, and a definite and rather sudden break downward at some time after the armistice. In New London, which was a military and naval station of importance and the leading industry of which is the making of foundry and machine shop products, and in Pawtucket, which also has important metal-working industries, the principal breaks occurred immediately after the armistice. Haverhill, which manufactures shoes, reached its maximum later, during the period of free spending following the war, and broke only during the depression of 1920 . Fall River, which manufactures cotton goods, showed two breaks, one at the time of the armistice and one in 1920. Columbus, Ga., also a center of cotton manufacture had by far its greatest increase af ter the war, and was the last of the cities to show a downward break. Columbus was near a cantonment and was probably considerably affected by demobilization. Bellingham is unusual in showing a slight but fairly steady decrease in the use of gas during a period of nearly 10 years when most other communities had an equally constant increase. New London, Keokuk, and Columbus show prominent seasonal variations; the Massachusetts cities almost none. Paducah and Keokuk have strikingly individual curves, caused, no doubt, by unusual local conditions.

In spite of the varied character of these curves and the fact that their forms are without doubt principally determined by economic conditions, an inspection shows a strong tendency for the curves representing heating value and consumption to form mirror images. In almost every case of a decided reduction of heating value there is a corresponding increase in the slope of the curve representing the volume of gas used.

Another striking thing about these curves is that in nearly every case the volume of gas used rises and falls with the waves of industrial prosperity and depression; but, like ocean waves on an irregular shore line, these surges reach different places at different times. The result of this is that when we try to compare two cities (or as will be shown later, in at least one case, two parts of the same city) for the purpose of eliminating the effects of changes of economic conditions by compensation, we get a series of relative rariations of shorter duration than the general economic conditions of which they are the resultant. 
The three cities which appear most promising for such a comparison because of general similarity of industry and geographical location are Haverhill, Fall River, and Pawtucket. New London can not well be compared with these three because of the different character of its industrial and military activities. The three comparisons are given in Figures 18, 19, and 20. Each figure shows the ratio of heating value and volume of gas used per meter in one city to the same in another city for each period of three months. It is evident that the use of gas in Pawtucket, which started with a low consumption, was increasing much faster than in the other cities. In order to prevent as much as possible the interference of this continuous relative change from obscuring such relations as may exist, a device which is familiar to every draftsman has been adopted and the whole curve representing volume used has been rotated about a

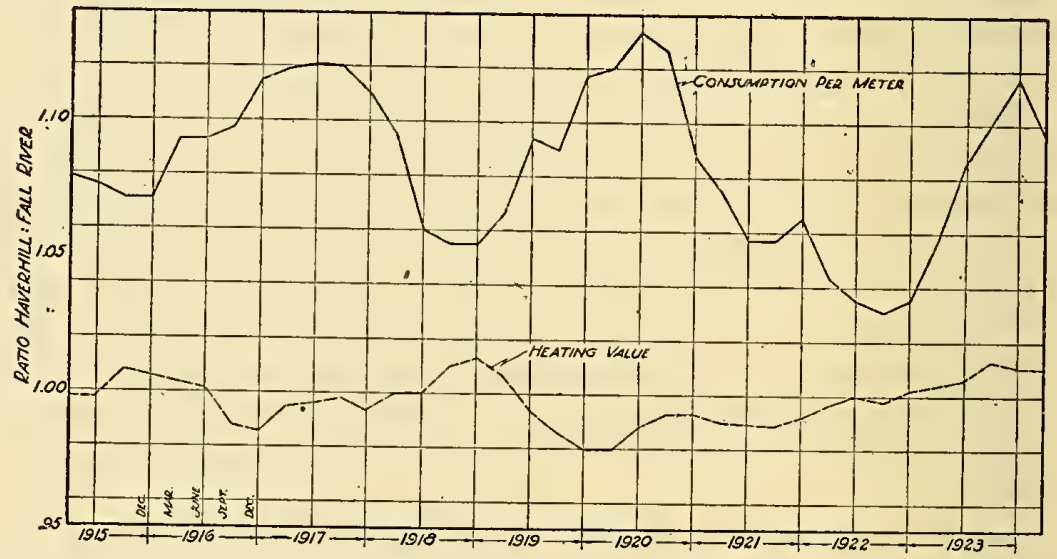

FIG. 18.--Relative heating values and volumes of gas used per meter in Haverhill and Fall River, Mass.

point at the right-hand side of the figure. This was done by drawing the diagonal broken line from end to end of the consumption curve and laying off from a horizontal line a distance equal to that from the diagonal line to each point of the curve. Figures 18, 19, and 20 show quite clearly the tendency, which we should expect, for the heating value and consumption curves to form distorted mirror images, at least during the earlier and more normal part of the period considered, when the changes of heating value were greatest and industrial changes least.

The same general effect of distorted mirror images at the start and large changes independent of heating value after the war is given by Figures 21 to 24, which employ the device illustrated in Figure 13 and represent for each of four cities the ratio of consumption and heating value for each quarter to the same quantities during the corresponding quarter of the preceding year. 
Considering these seven figures as a whole, it appears that the changes of consumption are generally relatively greater than the changes of heating value. The pockets of the consumption curves are generally deeper and their sides steeper than the corresponding portions of the heating value curves. We must not conclude from this that the changes of consumption have been caused entirely by relatively smaller changes of heating value; there are far too many complicating circumstances for that. All that we are justified in

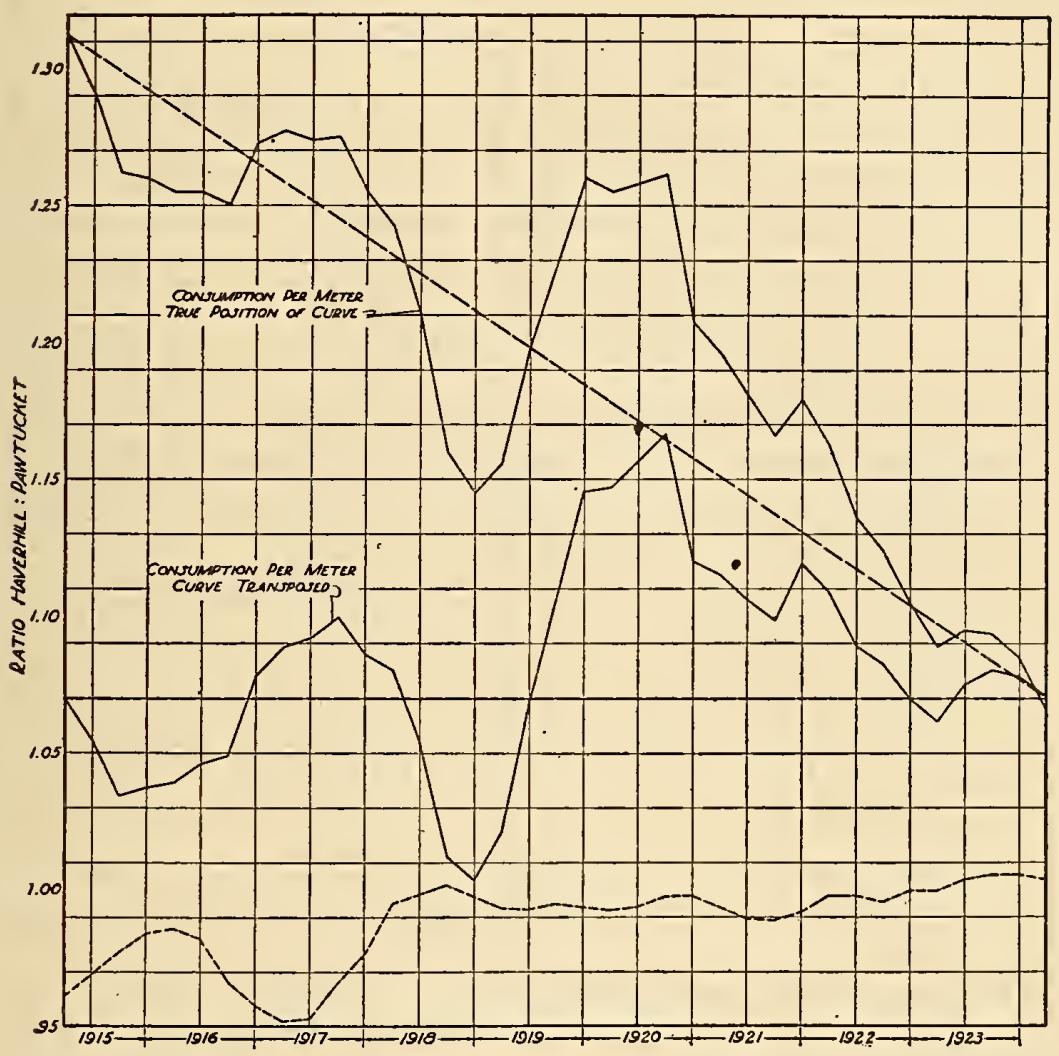

FIG. 19.-Relative heating values and volumes of gas used per meter in Haverhill, Mass., and Pawtucket, R. I.

concluding at this stage is that the occurrence of the reciprocal relation between heating value and consumption is too frequent to be entirely accidental, and that there is no evidence of importance that the consumption does not change in inverse proportion to the heating value, as all our direct evidence shows that it would if all consumers continued to get the same service.

Probably the most useful function which Figures 21 to 24 can serre is to show the utter futility of drawing any conclusion whaterer from a comparison made for one city or group of consumers for two differ- 


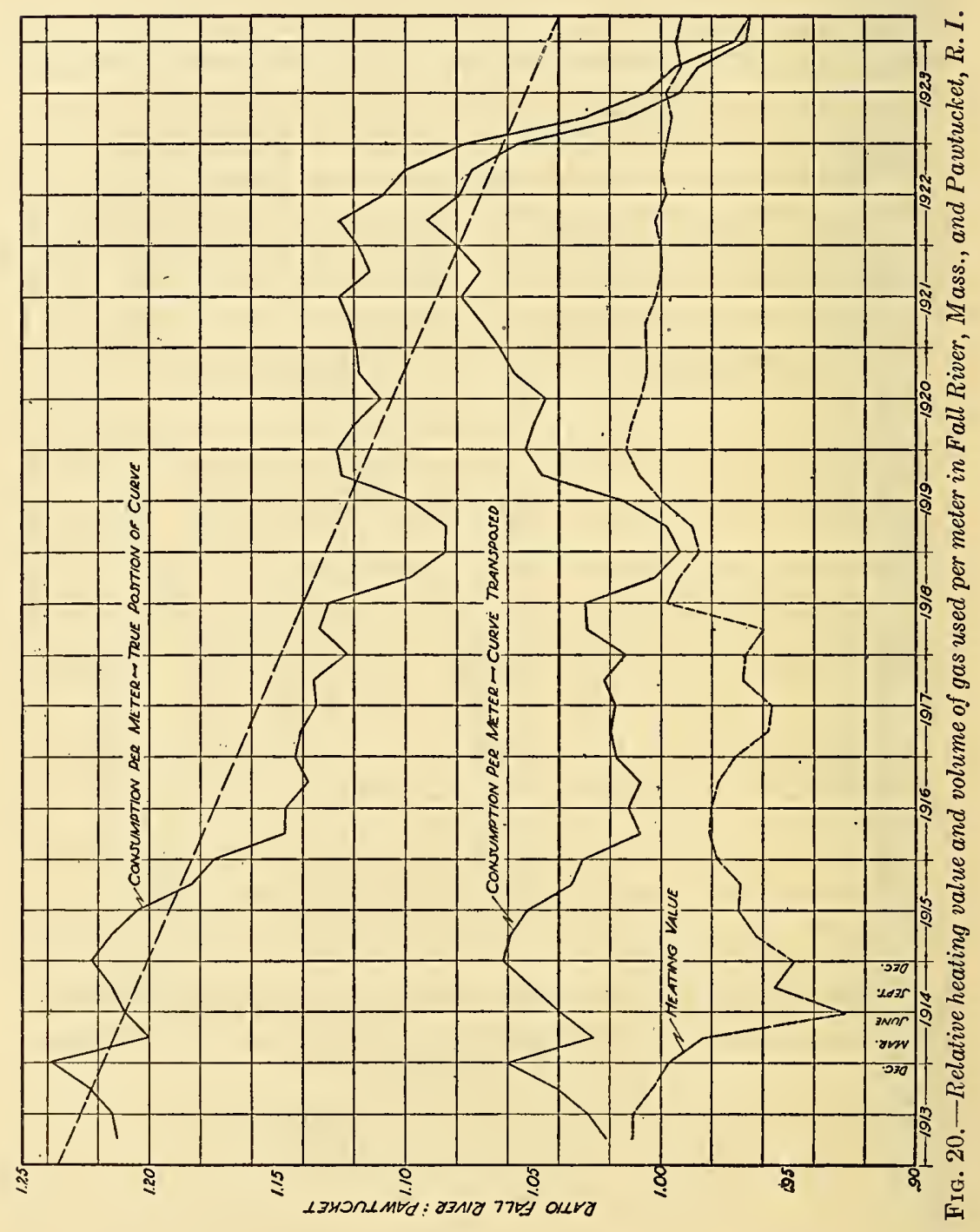


Wearer]

Relative Usefulness of Gases

407

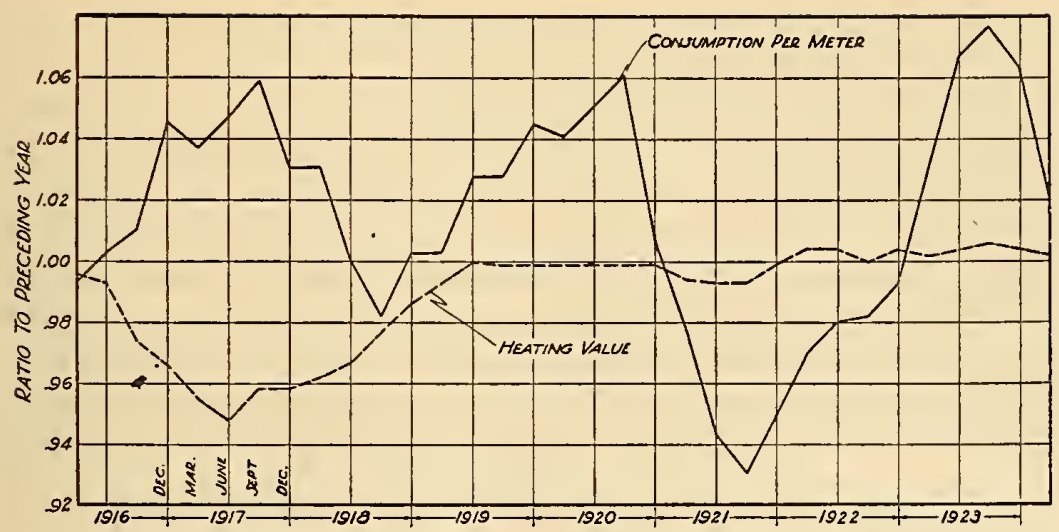

FIG. 21.-Relative heating value and volume of gas used per meter during consecutive years in Haverhill, Mass.

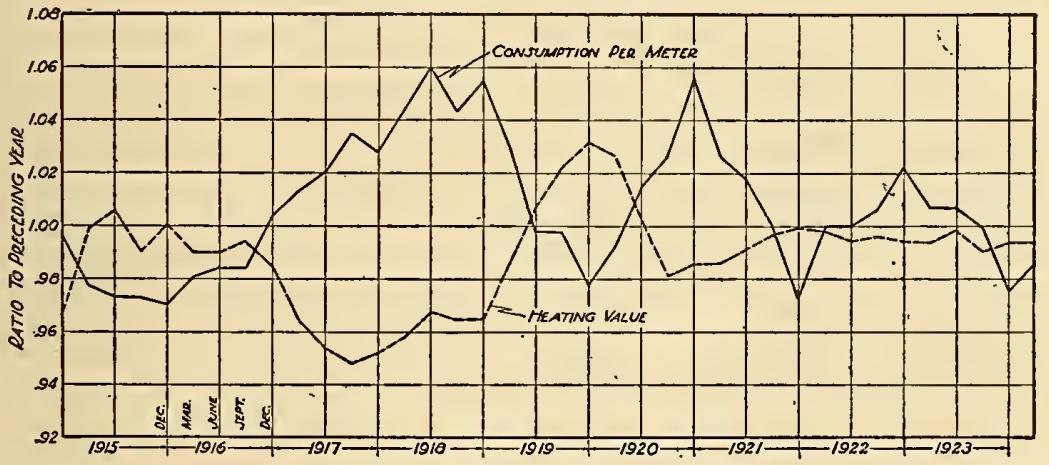

FIG. 22. -Relative heating value and volume of gas used per meter during consecutive years in Fall River, Mass.

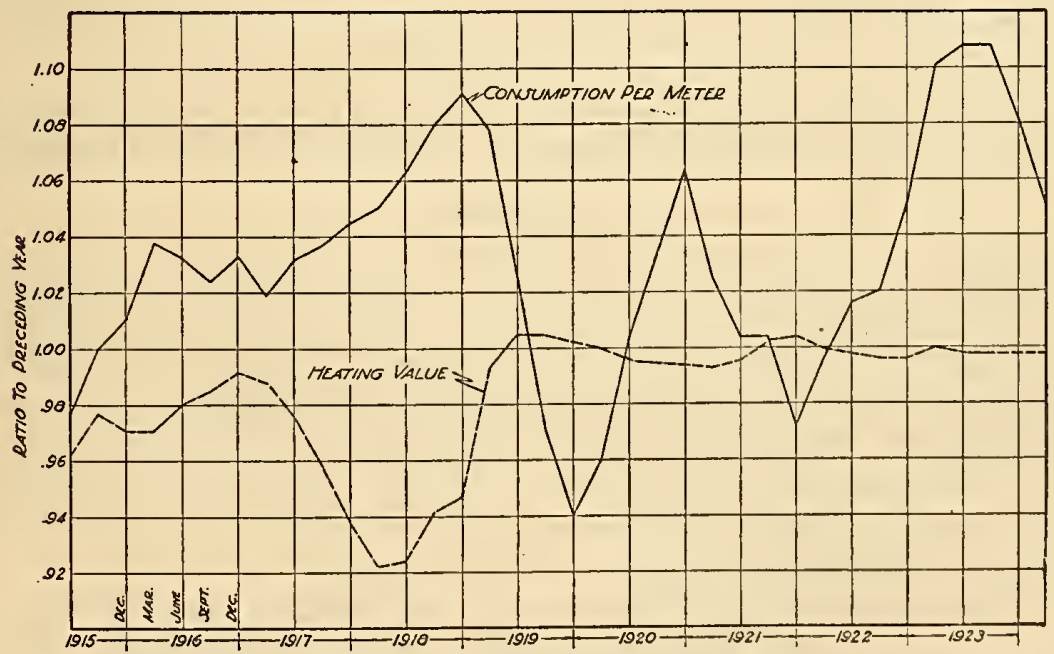

FIG. 23.-Relative heating value and volume of gas used per meter during consecutive years in Pawtucket, $R$. I. 
ent short lengths of time. Considering only periods of time during which there was no appreciable change of relative heating value, it is quite obvious that one can choose for comparison two quarters a year apart and get almost any relative change one wishes (in either direction or magnitude), and one can do this with the curves representing a single city or a comparison between cities. Much of the evidence on this subject which has been published or used in public hearings regarding standards has been of this character. A certain group or a certain locality has been selected and comparisons of relative consumption made over short lengths of time. The only way to treat such data is to get as complete additional data as possible

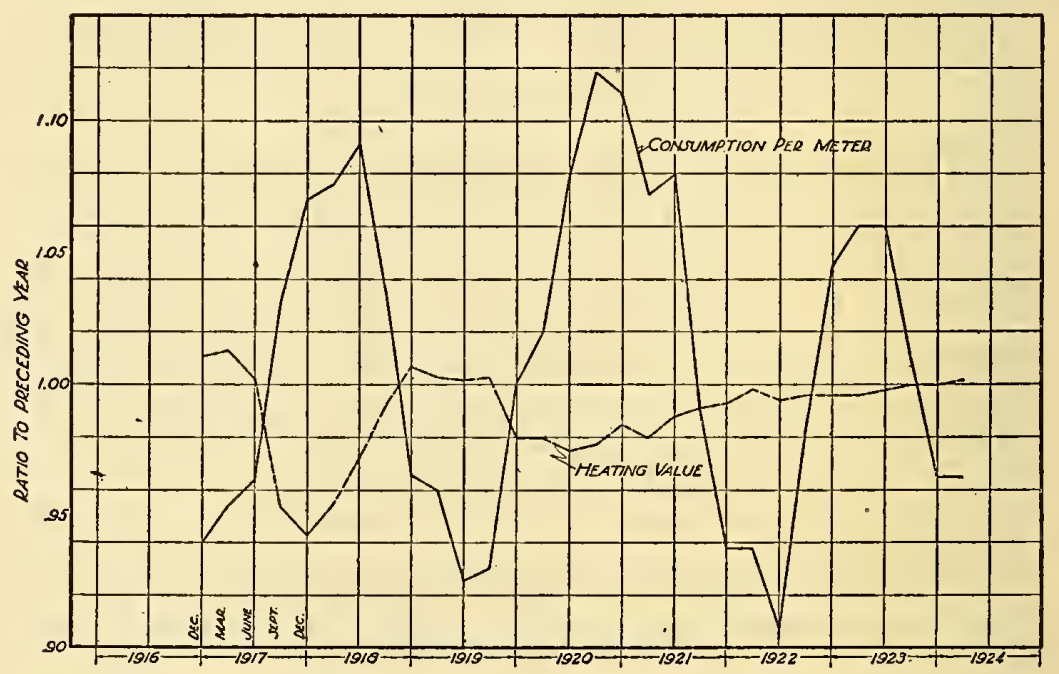

FIG. 2-1.-Relative heating value and volume of gas used per meter during consecutive years in Keokuk, lowa

to show whether those selected represented a general and permanent condition, and, if possible, to show what other effects were involved.

\section{CALIFORNIA}

The most valuable study that has been made of the effect of change of heating value upon the amount of gas used is that made by the joint committee on efficiency and economy of gas of the Railroad Commission of California, whose reports have already been referred to in connection with the direct determinations of the usefulness of gas. It is the most valuable study because it is the only extended one in which a real effort appears to have been made to determine and correct for the effects of the disturbing factors.

The effect of weather was studied with especial care, and many curves showing the relation between average temperature and the use of gas in three communities are given in the two reports. These 
curves have been consolidated in this review in the following manner: A number of points were taken on each curve given by the committee proportional to the number of points stated by the committee as having been averaged in the construction of the curve (or shown by plotted points). The ordinate of the $70^{\circ} \mathrm{F}$. point on each curve was arbitrarily considered as unity and the other points on the curve were plotted in the correct relative position. The result is shown in Figure 25. The rather close agreement of the numerous curves when plotted in this manner shows that the relation between average temperature and the amount of gas used is pretty well established for

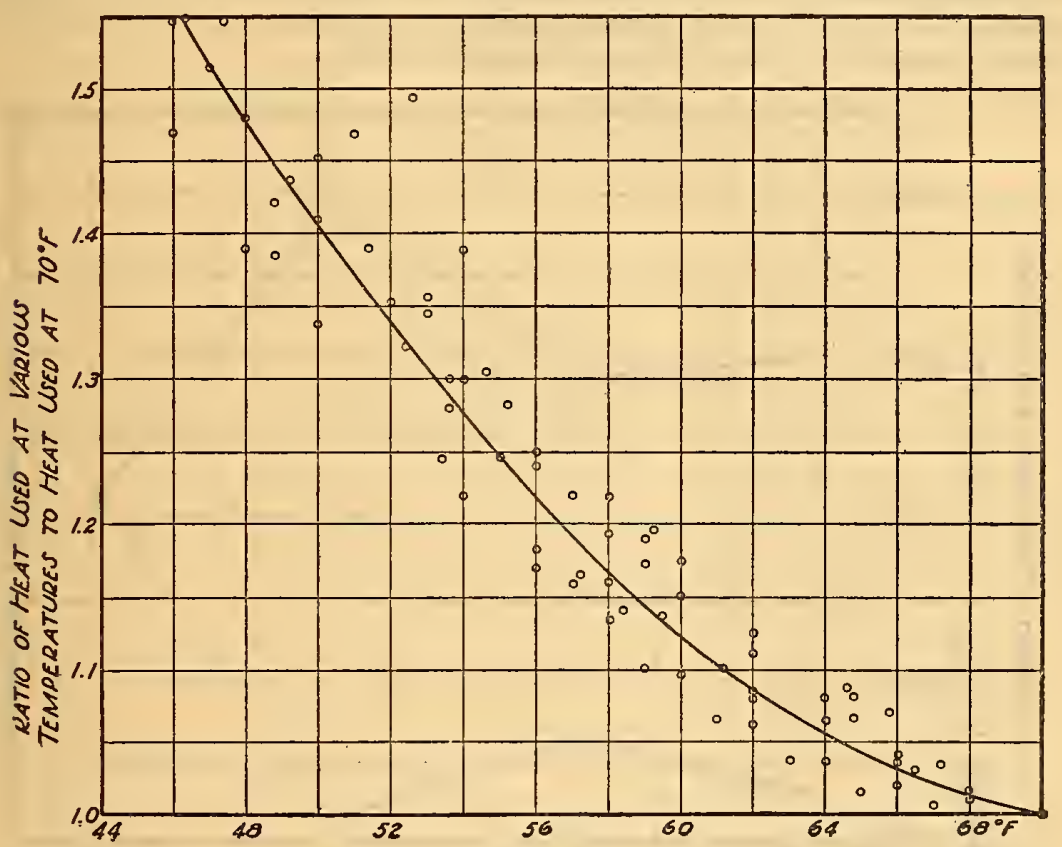

FIG. 25.-Ratio of heat used at various temperatures to heat used at $70^{\circ} \mathrm{F}$. in California

the California cities. It should be noted that the relation here shown is that for the total volume of gas used for all domestic purposes.

The curves showing the average daily consumption for each customer plotted against temperature ${ }^{52}$ need not be reproduced. They show clearly that decreasing the heating value of the gas increased the volume consumed but affected the total heat used very little, if at all.

The sales per customer are also shown by the committee for sixmonth periods for three cities-San Jose, Los Gatos, and Fresnoduring $1919,1920,1921$, and the first six months of $1922 .{ }^{53}$

32 First report, p. 38-40; second report, p. 39-44.

s3 Second report, p. 45-46; Appendix VI. $43360^{\circ}-25 \uparrow-5$ 
Regarding these comparisons the committee says (second report, p. 21-22):

San Jose and Fresno Comparison.-A comparison of the operations in San Jose and Fresno was made to determine whether any economic condition had affected the use of gas during the period of the tests. Table 1 in Appendix VI sets forth a comparison of the sales per consumer for the first six months and second six months of the years 1920 and 1921 and the first six months of 1922 for both Fresno and San Jose. These two communities are similar in size and in their dependence upon agriculture, although not located in the same part of California. It is to be noted, however, that both cities experienced an increase in sales of B.t. u. of between 11 and 12 per cent during the first six months of 1921 over the same period of time for the preceding year, and both experienced no increase in the first six months of 1922 over the similar period of 1921.

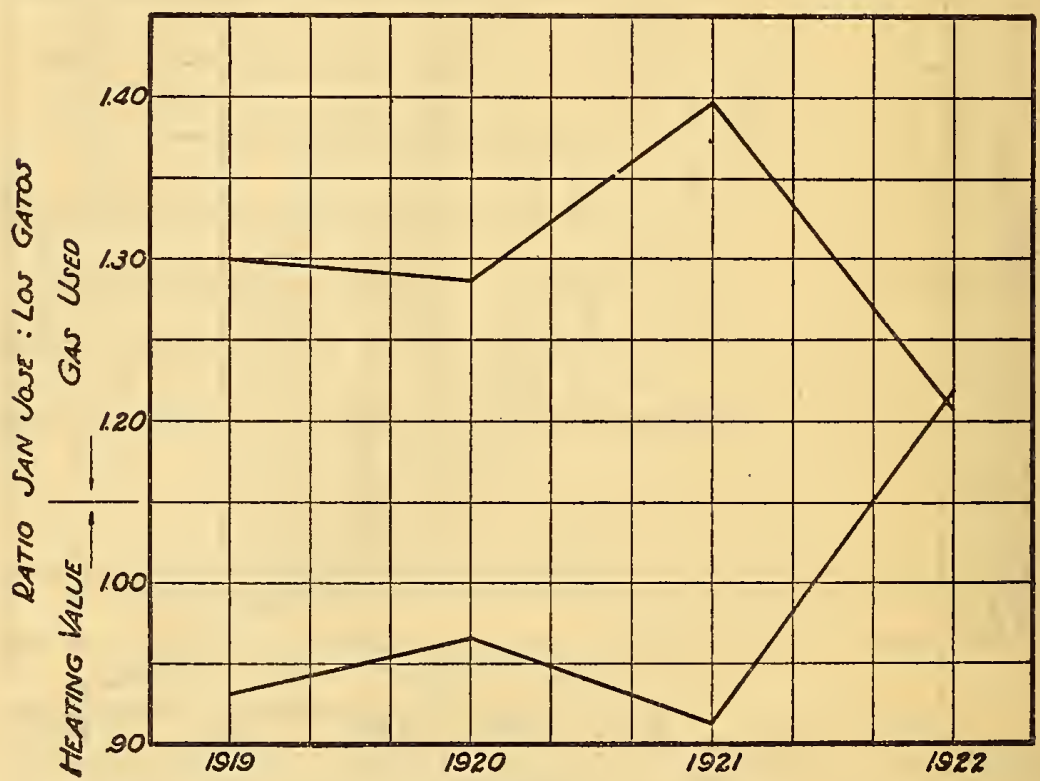

FIG. 26.-Relative heating value and volume of gas used per meter in San Jose and Los Gatos, Calif.

Los Gatos Test.-Commencing in November, 1921, the Pacific Gas \& Electric Co. has been supplying in Los Gatos from a high-pressure transmission line from San Jose, a distance of 10 miles. Prior to that time the city of Los Gatos was supplied with gas which tested somewhat in excess of $600 \mathrm{~B} . \mathrm{t} . \mathrm{u}$. With the introduction of gas transmitted from San Jose, the quality of the gas was reduced to approximately 525 B.t. u., being by test 10 B.t. u. less than that supplied in San Jose. Shortly after the San Jose gas was delivered the company adjusted all appliances in Los Gatos, as there were complaints received regarding poor quality of gas which were evidently caused from the material lowering in heat content.

It appeared to the committee that here was a chance to check the results which were obtained in San Jose as shown by the charts heretofore discussed. Analysis was made of the books of the company in order to determine the number of consumers and sales by months for the years 1918, 1919, 1920, and 1921. The results of this investigation are shown by Table 2 of Appendix VI. In this table it is 
assumed that the quality of gas supplied to consumers prior to November, 1921, was approximately $600 \mathrm{~B}$. t. u., this figure being based upon the weekly record of the analysis of the gas distributed.

Charts A and B set forth in per cent the change in sales, both in cubic feet and B.t. u. for the first six months of 1919, 1920, 1921, and 1922 and for the last six months of 1919, 1920, and 1921 for Los Gatos, Fresno, and San Jose. It is to be noted that both Fresno and San Jose indicate a reduction in both cubic feet and B.t. u. sales for the first six months of 1922 over 1921; that Los Gatos shows no increase in B.t.u. sales with the reduction in heat content, but a very marked increase in cubic foot sales.

This committee feels justified in concluding, in view of all of the investigations made and the evidence before it relative to the utilization of oil gas as manufactured in California, that within the limits of from 500 to 600 B. t. u., and with equal uniformity of quality and pressure, the consumers' use will vary in inverse proportion to the quality of gas delivered; and that from a utilization standpoint alone there is no benefit to be obtained with a reduction in heat content.

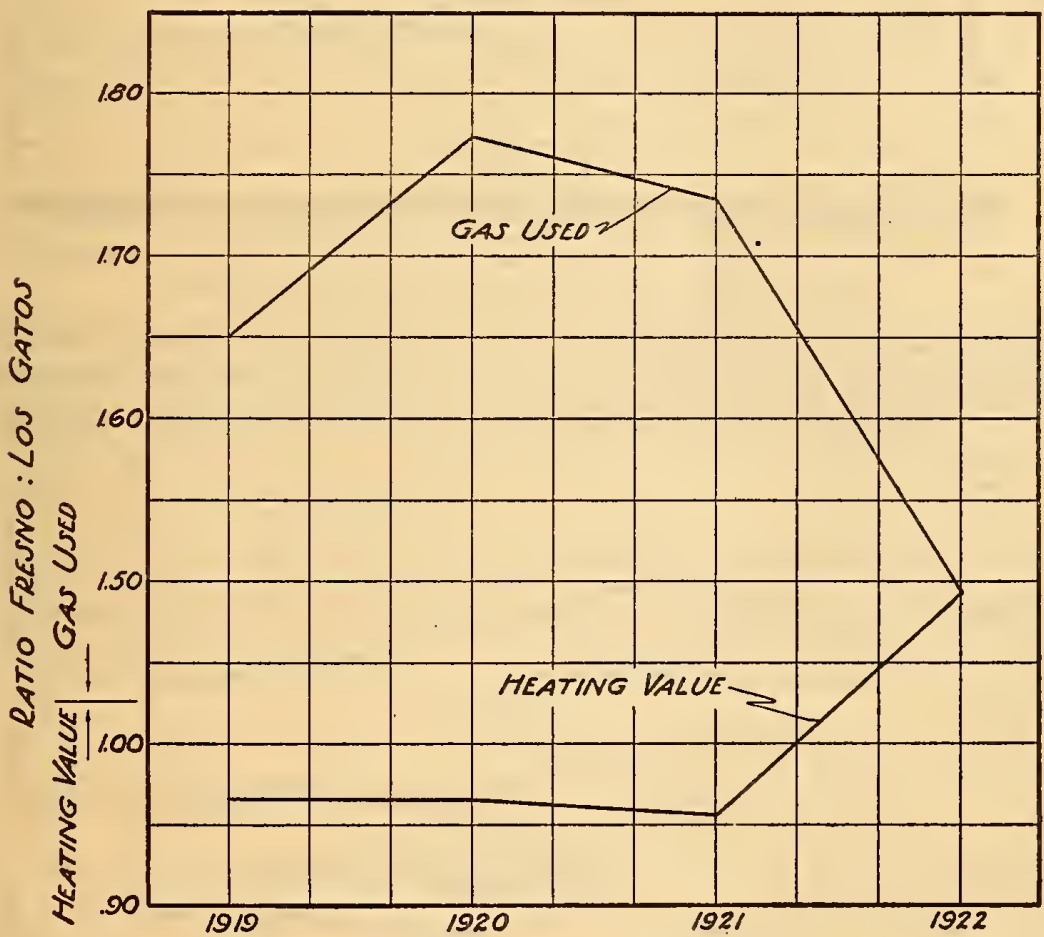

FIG. 27.-Relative heating value and volume of gas used per meter in Fresno and Los Gatos, Calif.

The relationships found in the comparison between the California cities are presented in a slightly different form than that used by the committee in Figures 26 to 29. The mirror image is very good in the comparison between Los Gatos and San Jose and as good as could be expected in the case of Los Gatos and Fresno. Comparing Fresno and San Jose by semiannual periods connected con- 
secutively, Figure 28, the relation between heating value and volume used is practically obscured by seasonal variations, but when cor-

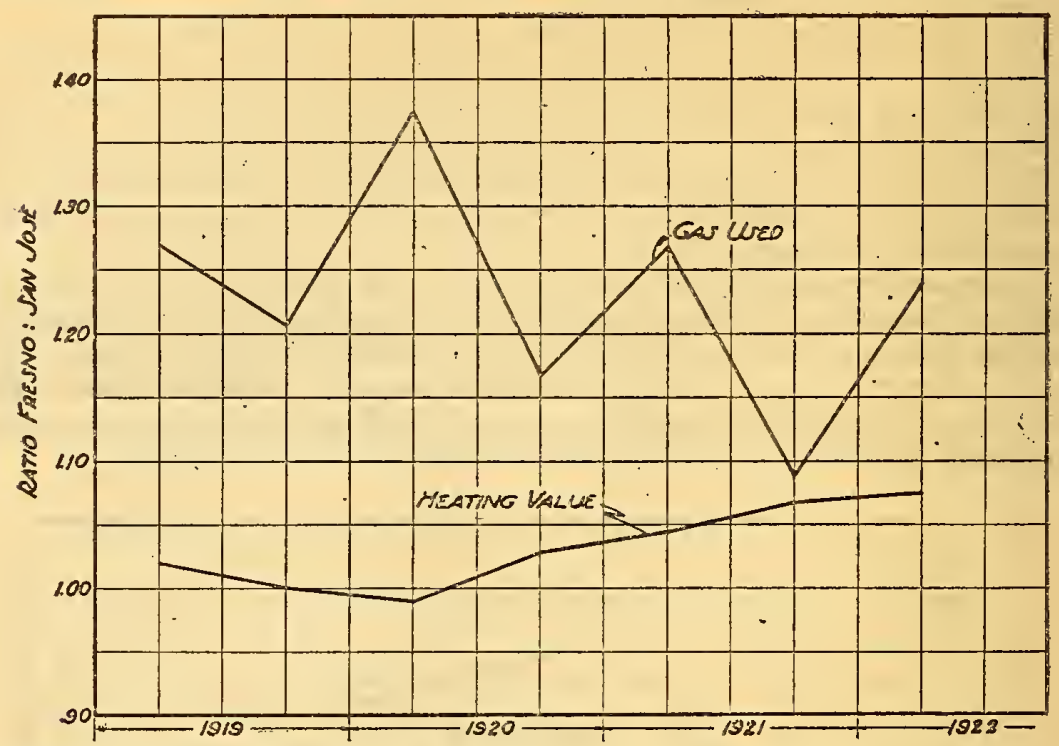

Fig. 28.-Relative heating value and volume of gas used per meter in Fresno and San Jose; six-month periods connected consecutively

responding periods of successive years are compared, by independently connecting the points representing the first half of each year and

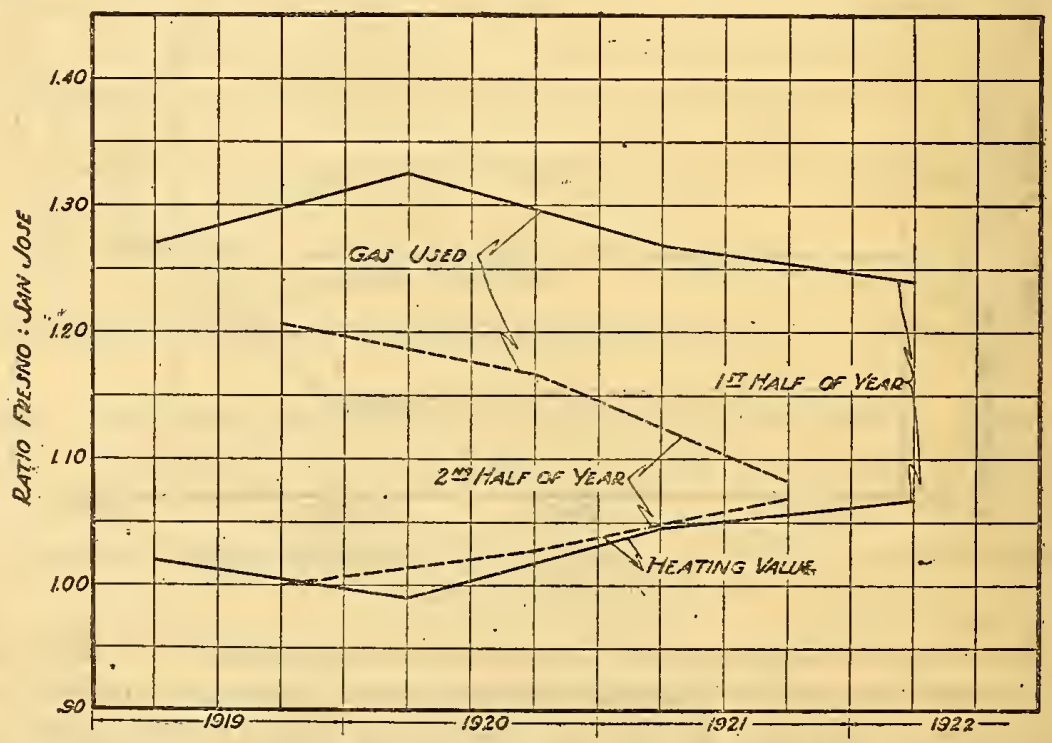

Fig. 29.-Relative heating value and volume of gas used per meter in Fresno and San Jose; corresponding periods of consecutive years connected

those representing the second half, the agreement with the reciprocal relation is seen to be almost perfect (fig. 29). 
A casual inspection of either these curves or of the figures published by the committee shows at once that when one city decreased its relative heating value with respect to another the amount of gas used in the first city increased relatively to the amount used in the second city. It would be interesting, however, to obtain a figure which would express quantitatively the relation between the two changes. Such a figure is easily obtained for the comparison between two cities for consecutive years. Let us compare, for example, Los Gatos with Fresno for the first six months of 1921 and the corresponding period of 1922. During the first half of 1921 the heating value of the gas sold in Los Gatos was $600 \mathrm{~B}$. t. u. and that in Fresno 573 B. t. u. The ratio of the first to the second, which we will designate as $a_{1}$, was, therefore,

$$
a_{1}=\frac{600}{573}=1.047
$$

During the first half of 1922 the corresponding ratio of heating values $a_{2}$ was

$$
a_{2}=\frac{524}{573}=0.915
$$

The:percentage change of relative heating values was, therefore,

$$
100 \times \frac{a_{2}-a_{1}}{a_{1}}=12.6 \text { per cent }
$$

That is to say, if two customers, one in Los Gatos and one in Fresno, used equal quantities of heat during both periods, and the Fresno customer used the same volume during the two periods, the Los Gatos customer had to burn a volume of gas 12.6 per cent greater during 1922 than during 1921.

The relative change in the volume of gas used can be computed in the same way. The average customer in Los Gatos burned 12,630 cubic feet during the first half of 1921 and the average customer in Fresno 21,940 cubic feet. The ratio $b_{1}$ between these numbers is

$$
b_{1}=\frac{12,630}{21,940}=0.576
$$

During the corresponding period of 1922 the ratio $b_{2}$ was

$$
b_{2}=\frac{14,440}{21,620}=0.667
$$

The relative consumption expressed in per cent had therefore increased

$$
100 \times \frac{0.667-0.576}{0.667}=13.6 \text { per cent }
$$

Comparing these two periods we therefore find that the increase in the relative volume of gas used in Los Gatos is 13.6 per cent instead of 12.6 per cent, as would have been the case had the heat used by the average customers in the two cities maintained a constant ratio. Using $R$ to designate the ratio $\frac{13.6}{12.6}$ as previously pro- 
posed, we find $R=1.08$; that is to say, in this case the increase in the use of gas of lower heating value was 108 per cent as great as would be computed from the theory that the amount of heat used was not affected by the heating value of the gas, and that all other influences were the same in both cities. Comparisons of the same kind may equally well be made between Los Gatos and San Jose and between San Jose and Fresno.

Table 5.-Comparison between Los Gatos, Fresno, and San Jose

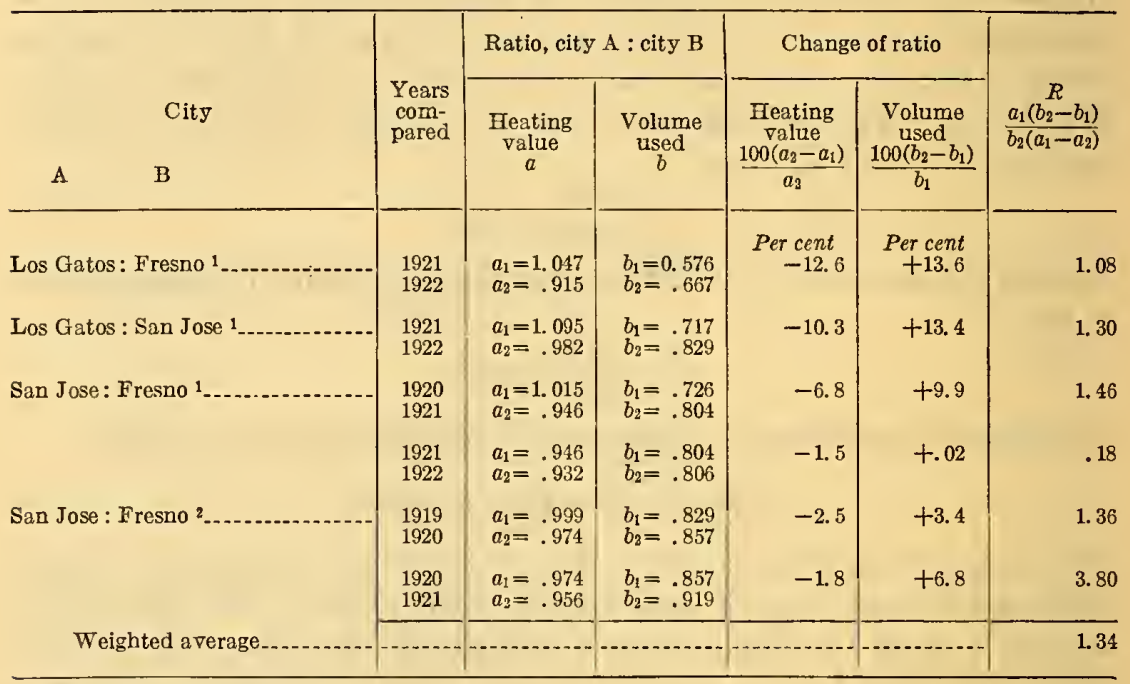

1 First six months of year.

2 Second six months of year.

Table 5 shows all such comparisons which may be made between these cities for corresponding halves of consecutive years between which the relative heating values changed appreciably. By reference to the example given the reader should have no difficulty in understanding the method of obtaining and the significance of each number in the table.

The several values obtained for $R$ are obviously not equally significant, because, the effect of factors other than a change of heating value will be much greater upon the result of a comparison between periods of little relative difference in heating value than upon the result obtained from periods of large relative difference. Hence, we will weight each value in direct proportion to the difference of heating value which it represents. The weighted average so obtained is 1.34, which is nearer unity than the arithmetical average, 1.53.

This means that, as far as these statistics are concerned, it appears necessary to use more heat when a gas of lower heating value is supplied. It is difficult to account for this on any ground except a more energetic development of the uses of gas in Los Gatos and San 
Jose than in Fresno. The fact that less gas was used per customer in a slightly colder region, and that the use of gas for space heating has been rapidly developed in recent years probably accounts for the expansion of sales in the San Jose district.

The variations in the value of $R$ obtained by the different comparisons is of the utmost significance in deciding upon the probable value of comparisons made in other localities in which generally only one short period before and one after the change of heating value were compared. It is again evident that any such comparison standing alone is almost valueless, especially if it represents the changes taking place in only one city, so that there is no cancellation of factors such as variations in climatic and economic conditions. Usually in such comparisons even the temperature is neglected. The result of such neglect is easily seen in the value of $R$ for San Jose and Fresno for 1921-22. The result is easily interpreted, however, when it is found that in San Jose the first half of 1922 was warmer, while in Fresno it was colder than in 1921.

Further data obtained by the California commission, together with a very good summary of the earlier data, are given by L. W. Ready, ${ }^{54}$ chief engineer of the California Railroad Commission. The following statement occurs under the heading "Some Recent Data":

The change in the use of gas resulting from the introduction of natural gas of $1,000 \mathrm{~B}$. t. u. or more in place of manufactured gas has uniformly shown a reduction in use very nearly equivalent to the increase in heat content. A recent change in gas quality at Santa Barbara of from 550 to 700 B. t. u. per cubic foot, an increase of 27.3 per cent, will, no doubt, produce some interesting figures. There has not been sufficient time to derive over-all figures for all consumers, but a tabulation has been made of some 14 down-town restaurants using gas for general top-burner and baking operations. During the last week of the $550 \mathrm{~B}$.t. u. gas, these restaurants had a combined use of 195,300 cubic feet, and in the first week of the $700 \mathrm{~B}$. t. u. gas a combined use of 152,400 cubic feet, a decrease of 21.9 per cent. The average weekly use for four weeks prior to the change in quality was 196,900 cubic feet, and for the four weeks following the change was 155,900 cubic feet, or a decrease of 20.8 per cent. The weather conditions during these periods were not noticeably different, nor were there any changes in activities that would affect the consumption of gas in the restaurants.

Ready's method of stating the relation does not quite make apparent the fact that the volume used varied almost exactly in inverse proportion to the heating value, and that the amount of heat used before and after the change was almost exactly the same.55 Taking the two-week period of comparison, $R=1.03$. For the eightweek period, $R=0.96$.

8. L. W. Ready, Gas Age-Reeord, 53, pp. 419-421; 1924.

ss The reason why the relation is not apparent is, of eourse, that the ratio $(100+a): 100$ is not equal to the ratio $100:(100-a)$. During the week before the ehange of heating value the amount of heat used was $195,300 \times 550=107,415,000$ B.t. $u$., and during the week following the change it was $152,400 \times 700=106,680,000$ B. t. u. 


\section{MASSACHUSETTS}

The publication most referred to in justification for the claim that a decrease of heating value does not increase consumption is the report of the committee on calorific standards of the American Gas Association. ${ }^{56}$ The report contains an argument and a considerable amount of data to prove that a reduction of calorific standards does not increase the consumption of gas appreciably.

The data presented with respect to Massachusetts are the most complete and, both because of the time and the number of companies they cover and because they are based upon official records, they must be regarded as of the greatest importance. Quoting from the report of the committee:

In 1916 the Board of Gas and Electric Light Commissioners of Massachusetts secured permission from the legislature to suspend temporarily the candlepower requirements with regard to 19 of the Massachusetts gas companies to allow said companies to reduce the B.t.u. content of the gas supplied down to a minimum of 500 B.t.u. This test, which finally covered a period of 18 months ***; was to enable the board to determine the calorific standard which would define the best gas for the consumer, considering the purposes for which it is used $* * *$.

One condition which makes these experiments peculiarly authoritative should be emphasized. In considering the effect on consumption in other States where reductions have been made in heating value standards it is necessary to take into account other consumption variables occurring at the same time of the change, such, for instance, as greatly increased consumption due to the shortage of coal, normal increases in consumption per meter occurring in years when no B. t. u. change was made, etc.

In Massachusetts experience such variables can be ignored, as the consumption of the two groups of companies are shown operating at the same time under absolutely comparable conditions during which one group reduced the calorific value of their gas and the balance of the companies maintained the former standard.

In Appendix B will be found a report prepared by L. J. Willien, of the C. H. Tenney Co., the statistical figures in which have been taken from the public records of the Department of Public Utilities of Massachusetts.

On this report are shown the annual average consumption per meter for the following groups of companies, together with reduction in B. t. u. made each year by the 19 companies participating in the test.

Group A represents the gas companies who lowered their B. t. u., Group B represents total gas companies who remained on the old standard, Group $\mathrm{C}$ represents a selected number of the Group B companies more comparable in size to the Group A companies.

Turning now to Willien's report, we find that the gas companies in group A were placed on the heating-value basis with a requirement of 500 B. t. u. on July 1, 1916, and that "as a result of this investigation a standard of 528 B. t. u. per cubic foot was finally adopted and became effective January 1, 1918." This new standard applied to all the companies in the State. 


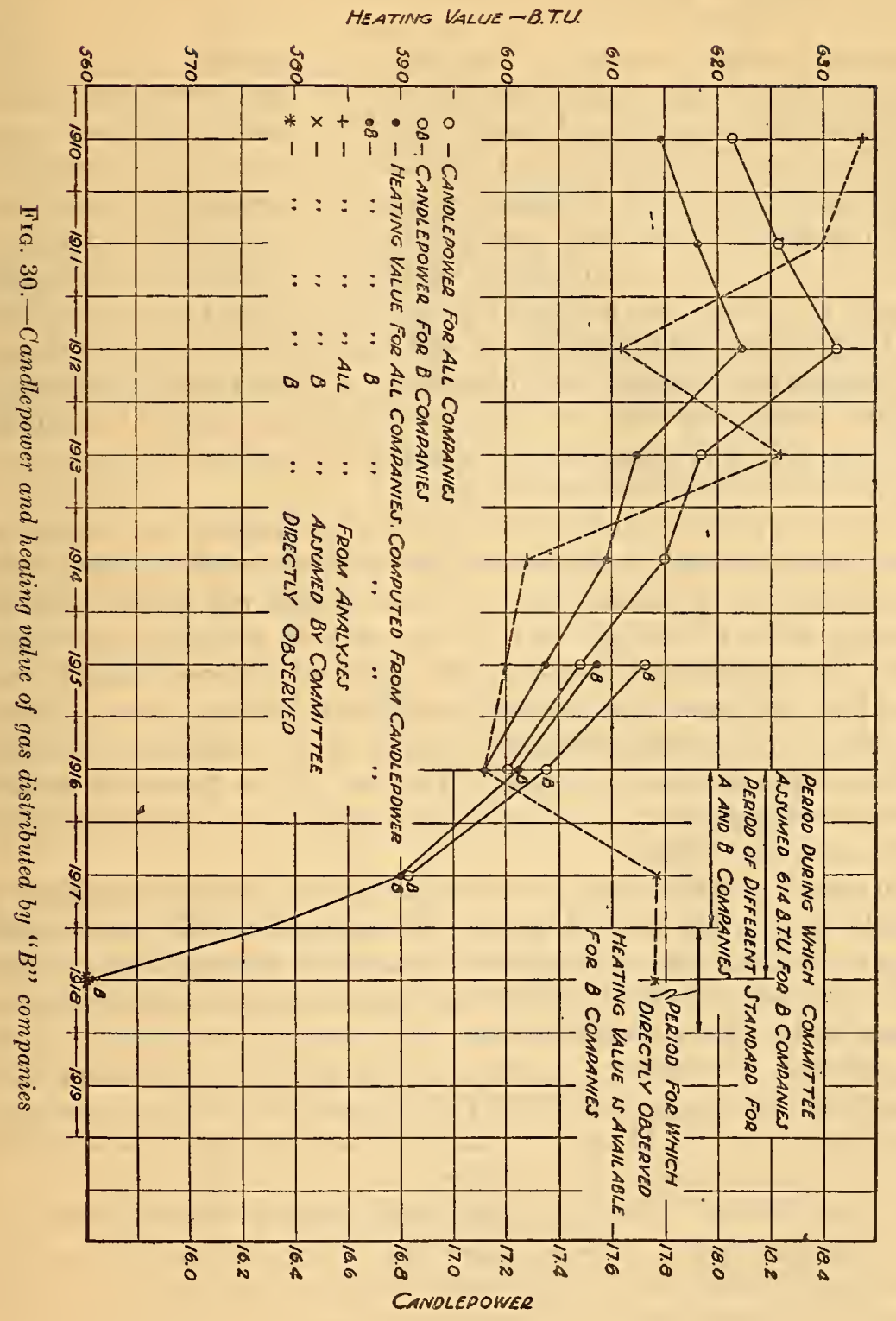


The heating value before the change of standard was computed by Willien from the somewhat infrequent volumetric analyses made. Since there were no analyses made during 1917, the heating value for B companies during 1917 was assumed to have been that for the State as a whole during the preceding seven years. By a curious mistake, probably caused by the fact that the tests of gas quality are reported by the board of gas and electric light commissioners for calendar years beginning January 1 and the consumption per meter for fiscal years beginning July 1, this assumption is extended through 1918 , during which the B companies were on a heating value standard and calorimetric tests were regularly made and officially recorded.

Even in the absence of official calorimetric tests we could hardly accept the seven-year average for the period 1910-1916 as applying to 1917-18, for both gas analyses and the much more numerous and systematic candlepower tests had shown a fairly regular decrease of quality during that time; and during the war, when gas oil was almost unobtainable, gas companies could hardly be expected to return to a higher standard of four years earlier.

We have, however, a fairly good means for judging the changes of heating value which took place in the numerous and regular official determinations of candlepower. It is, of course, well known that the heating value of a single mixture can not be accurately predicted from its candlepower, because two gases of different composition may have the same candlepower but different heating values. When, however, we are considering the average of 57 companies operating plants without radical change of process over a period of several years candlepower and heating value should have a pretty definite relation to each other.

In order to agree with the committee on calorific standards as closely as possible we will accept the average calorific value of 598 B. t. u. for the initial year of the study and the average heating value for the period 1910-1916, basing our relation between average candlepower and average heating value upon these figures chosen by the committee. The average candlepower for all companies during 1916 was 17.22 ; during the years 1910-1916 it was 17.88 . The corresponding averages for the heating values given by the committee were 598 and 614 , respectively. These figures lead to the ratio of $24 \mathrm{~B}$. t. u. per cubic foot for a change of one candlepower in the neighborhood of 17 candlepower. This is higher than the ratio usually found in the neighborhood of 17 candlepower, which is 17 to $20 \mathrm{~B}$. t. u. per candle. We will therefore be conservative and (as it works out) favor the gases of low heating value by adopting in round numbers 20 $B$. t. $u$. as the average change of heating value accompanying a change of one candle. It really makes a difference of only 1 or 2 B. t. u. in any important case, whether this value is taken as 20 or 
as $15 \mathrm{~B}$. t. u. As an example of the use of this relation, we will take Group A during the year 1912. The candlepower for that year was 17.97, which is 0.77 candle higher than the general average of 17.20 in 1916. The heating value for Group A in 1912 is therefore computed to be $598+20 \times 0.75=613 \mathrm{~B}$. t. u.

For the sake of making the difference between the assumptions of the committee on calorific standards and the reviewer perfectly clear Figure 30 shows the average candlepower maintained by all companies during the years 1910-1916, for B companies in 1915, 1916, and 1917 , the heating value maintained by the B companies during 1918 as actually determined, and the various heating values computed or assumed by the committee and the reviewer.

We must also distinguish between the heating values maintained by the companies in the different classes during the years of the common candlepower standard which are used for comparative purposes.

The average results of official candlepower tests during the years 1912-1917 were as shown by Table 6 .

TABLE 6.-Candlepower of gas supplied by Massachusetts companies

\begin{tabular}{|c|c|c|c|c|c|c|}
\hline \multirow{2}{*}{ Group } & \multicolumn{6}{|c|}{ Candlepower } \\
\hline & 1912 & 1913 & 1914 & 1915 & 1916 & 1917 \\
\hline 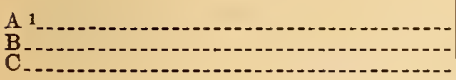 & $\begin{array}{l}17.97 \\
18.68 \\
19.10\end{array}$ & $\begin{array}{l}17.65 \\
18.05 \\
18.07\end{array}$ & $\begin{array}{l}17.20 \\
18.07 \\
17.85\end{array}$ & $\begin{array}{l}\mathbf{1 6 . 9 3} \\
17.72 \\
17.70\end{array}$ & $\begin{array}{l}16.89 \\
17.37 \\
17.32\end{array}$ & $\begin{array}{l}16.84 \\
16.87\end{array}$ \\
\hline
\end{tabular}

1 The candlepower for Group A in 1916 covers only the first six months of the year.

Using our assumed relation for determining the heating values of the gases supplied on the candlepower basis, we have for the several years the values given in Table 7 . The figures in parentheses are computed from candlepower, assuming that 17.22 candlepower gas had a heating value of $598 \mathrm{~B}$. t. u. and that the heating value varied at the rate of $20 \mathrm{~B}$. t. u. per candle from this number. The other figures are the average of official tests given in the gas commissioners' reports.

TABLE 7.-Heating value of gas supplied by Massachusetts companies during calendar years $1915-1919$

\begin{tabular}{|c|c|c|c|c|c|c|}
\hline \multirow{2}{*}{ Group } & \multirow{2}{*}{1915} & \multicolumn{2}{|c|}{1916} & \multirow{2}{*}{1917} & \multirow{2}{*}{1918} & \multirow{2}{*}{1919} \\
\hline & & $\begin{array}{l}\text { First } \\
\text { half }\end{array}$ & $\begin{array}{l}\text { Sccond } \\
\text { half }\end{array}$ & & & \\
\hline $\begin{array}{l}\mathrm{A} \\
\mathrm{B} \\
\mathrm{C}\end{array}$ & $\begin{array}{c}(592) \\
(608) \\
(608)\end{array}$ & $\begin{array}{r}(591) \\
(601) \\
(600)\end{array}$ & $\begin{array}{c}559 \\
(601) \\
(600)\end{array}$ & $\begin{array}{c}559 \\
(591) \\
(591)\end{array}$ & $\begin{array}{l}549 \\
560 \\
553\end{array}$ & $\begin{array}{l}545 \\
555 \\
551\end{array}$ \\
\hline
\end{tabular}


The data on the volume of gas used are given not for the calendar years, as are the data on quality, but for fiscal years ending June 30. Assuming that the quality during any fiscal year is the mean of the calendar years of which it is a part, we have the heating values for the sereral fiscal years shown in Table 8.

TABLE E.-Heating value of gas supplied by Massachusetts companies during fiscal years $1916-1919$

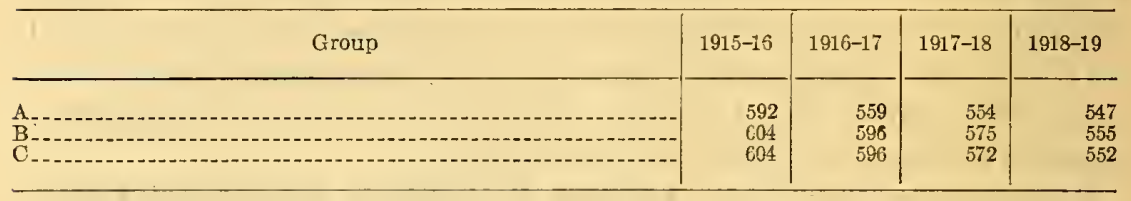

The figures taken by Willien from the commissioner's report showing the average consumption of gas per meter for each of the groups are given in Table 9.

TABLE 9.-Volume of gas used per meter by various groups

\begin{tabular}{|c|c|c|c|c|}
\hline Group & $1915-16$ & $1916-17$ & $1917-18$ & $1918-19$ \\
\hline $\begin{array}{l}\mathrm{A}-1 \\
\mathrm{~B}-1\end{array}$ & $\begin{array}{c}\text { Cubic feet } \\
23,431 \\
15,808 \\
19,637\end{array}$ & $\begin{array}{c}\text { Cubic feet } \\
24,819 \\
16,632 \\
20,598\end{array}$ & $\begin{array}{c}\text { Cubic feet } \\
26,103 \\
18,263 \\
22,645\end{array}$ & $\begin{array}{r}\text { Cubic feet } \\
25,296 \\
18,045 \\
22,774\end{array}$ \\
\hline
\end{tabular}

From these data the relative consumptions per meter and the relative, heating values for the different groups are as shown in Table 10.

TABLE 10.-Ratios between heating values and volumes of gas used by various groups

\begin{tabular}{|c|c|c|c|c|}
\hline Companies & $1915-16$ & $1916-17$ & $1917-18$ & $1918-19$ \\
\hline $\begin{array}{l}\text { Relative heating value: } \\
\text { Group A : Group B } \\
\text { Group A : Group C.... }\end{array}$ & $\begin{array}{r}0.980 \\
.980\end{array}$ & $\begin{array}{r}0.939 \\
.939\end{array}$ & $\begin{array}{r}0.964 \\
.969\end{array}$ & $\begin{array}{r}0.984 \\
.988\end{array}$ \\
\hline $\begin{array}{l}\text { Pelative consumption: } \\
\text { Group A : Group B } \\
\text { Group A : Group C }\end{array}$ & $\begin{array}{l}1.481 \\
1.191\end{array}$ & $\begin{array}{l}1.492 \\
1.206\end{array}$ & $\begin{array}{l}1.429 \\
1.146\end{array}$ & $\begin{array}{l}1.401 \\
1.110\end{array}$ \\
\hline
\end{tabular}

A glance at these ratios, which are plotted in Figures 31 and 32 , together with the corresponding ratios for 1912-1916, shows that, considering either pair of groups, the relative consumption of one group always increased when the relative heating value decreased materially; the agreement is as good as that in the California cities.

If the assumption of the committee is correct that the variables other than heating value "can be ignored * * * as the consumption of the two groups of companies are shown operating at the same time under absolutely comparable conditions," then a numerical comparison between the relative consumption in the different groups 
and the relative heating value should show quantitatively the relation between heating value and consumption.

Treating these data in the same way as those from the California cities, we find when we compare Groups A and B and A and C, respectively, as shown in Table 11, increases in the relative volumes of gas used amounting to 79.2 and 101.7 per cent of the relative changes which would correspond to independence between heating value and the amount of heat used.

It may be well, instead of considering in three steps the changes which take place, to consider them in only two-the change from the candlepower to the heating-value standard by class $A$ companies, while B companies maintained the old standard, and the change by

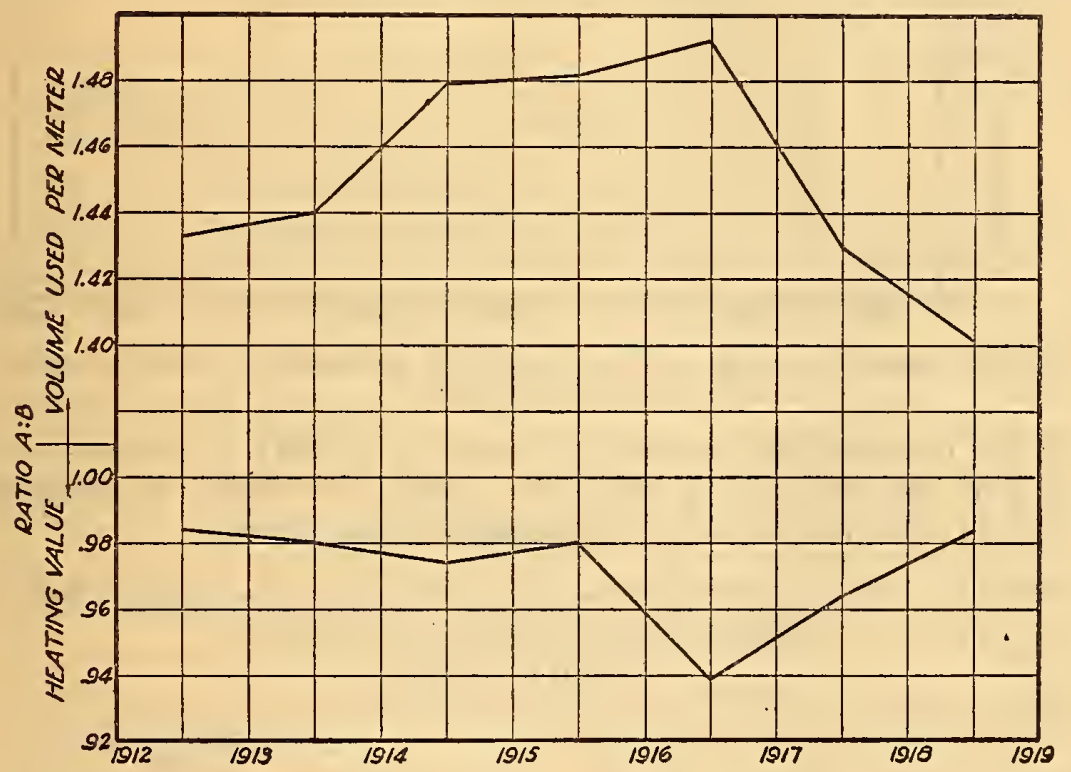

FIG. 31.-Relative heating value and volume of gas used per meter in cities of groups $A$ and $B$

B companies to the heating-value standard which once more put all the companies on the same basis. This has the advantage of eliminating from consideration the year 1917-18, during which the "candlepower companies" were changing to the new standard.

The comparison on this basis is given in Table 12. The weighted average of $R$ for $\mathrm{A}$ and $\mathrm{B}$ companies is 0.790 and for $\mathrm{A}$ and $\mathrm{C}$ companies 102.8 , in striking agreement with the weighted means from the three-period comparison. Taking weighted means for the annual changes which took place during the entire period from 1912 to 1919 , we get from the comparison between $\mathrm{A}$ and $\mathrm{C}$ companies, $R=1.19$ : from that between $\mathrm{A}$ and $\mathrm{B}$ companies, $R=0.97$. 
It should be noted that a change in the assumed relation between candlepower and heating value would affect oppositely the results obtained by the comparison over seven and that over four years.

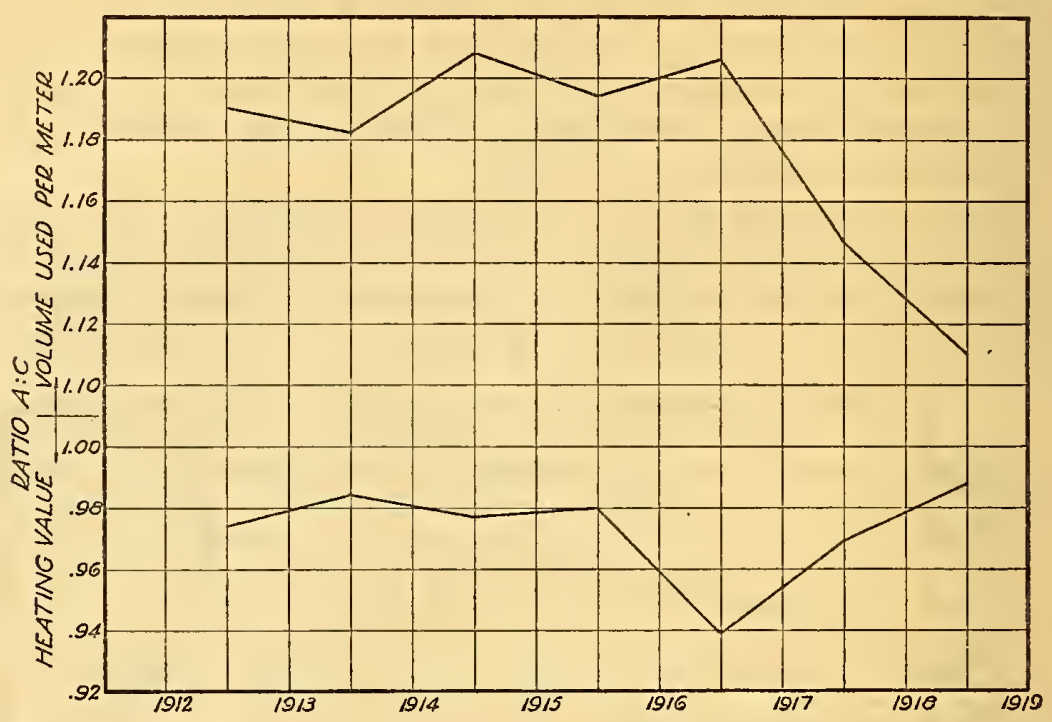

FIG. 32.-Relative heating value and volume of gas used per meter in cities of

If, for example, we assumed a change of $25 \mathrm{~B}$.t. u. instead of 20 B.t.u. per candle, the mean for 1916-1919 would be increased slightly, that for 1912-1919 diminished somewhat more.

TABLE 11.-Change of relative volume of gas used with change of heating value for different groups of Massachusetts companies

[Considered as three changes]

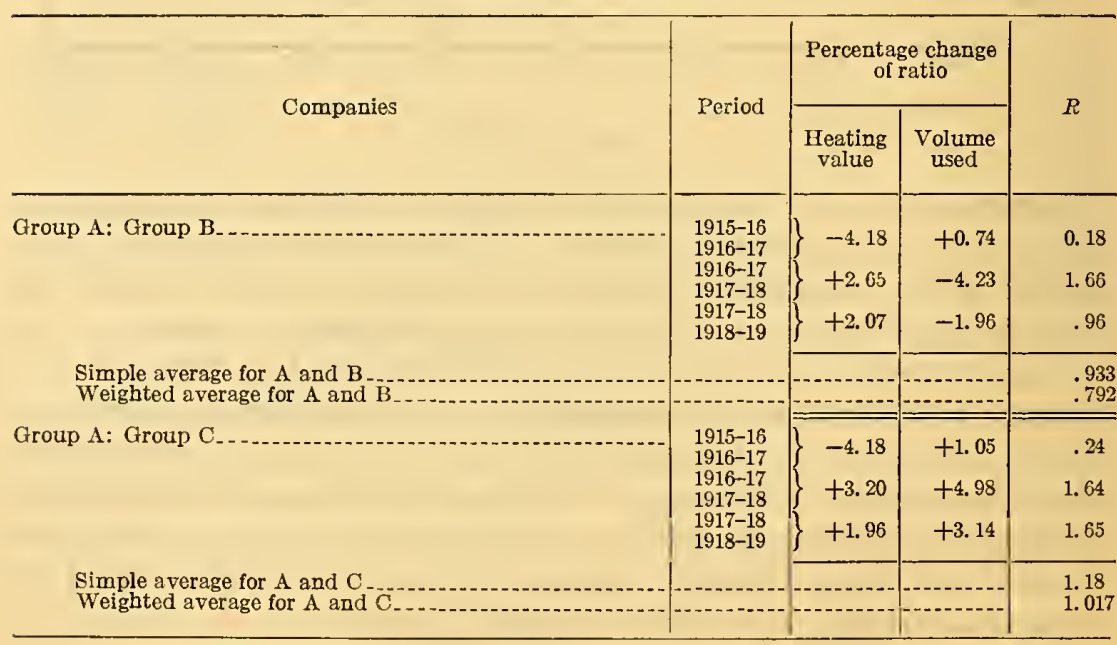


TABLE 12.-Change of relative volume of gas used with change of heating value for different groups of Massachusetts companies

[Considered es two changes]

\begin{tabular}{|c|c|c|c|c|}
\hline \multirow{2}{*}{ Companies } & \multirow{2}{*}{ Period } & \multicolumn{2}{|c|}{$\begin{array}{l}\text { Percentage change } \\
\text { of ratio }\end{array}$} & \multirow{2}{*}{$R$} \\
\hline & & $\begin{array}{c}\text { Heating } \\
\text { value }\end{array}$ & $\begin{array}{c}\text { Volume } \\
\text { used }\end{array}$ & \\
\hline Group _A: Group B.-. & \multirow[t]{2}{*}{$\begin{array}{l}1915-16 \\
1916-17 \\
1916-17 \\
1918-19\end{array}$} & $\left\{\begin{array}{l}-4.18 \\
+4.57\end{array}\right.$ & $\begin{array}{l}+0.74 \\
-6.10\end{array}$ & $\begin{array}{l}0.18 \\
1.35\end{array}$ \\
\hline $\begin{array}{l}\text { Weighted average for } \mathrm{A} \text { and } \mathrm{B} \\
\text { Simple arerage for } \mathrm{A} \text { and } \mathrm{B}\end{array}$ & & & 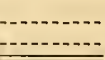 & $\begin{array}{r}.790 \\
.765 \\
\end{array}$ \\
\hline \multirow[t]{2}{*}{ Group A: Group C } & \multirow[t]{2}{*}{$\begin{array}{l}1915-16 \\
1916-17 \\
1916-17 \\
1918-19\end{array}$} & $\left\{\begin{array}{l}-4.18 \\
+5.22\end{array}\right.$ & $\begin{array}{l}+1.05 \\
-7.96\end{array}$ & $\begin{array}{r}.24 \\
1.66\end{array}$ \\
\hline & & & & $\begin{array}{r}1.028 \\
.950\end{array}$ \\
\hline
\end{tabular}

The fact that the ratio of consumption between the 18 companies of Group $\mathrm{C}$ and the remaining 21 companies of Group B is not constant at once brings into question another of the committee's assumptions. Indeed, the committee must have had a shade of doubt about the conditions of the two Groups A and B being "absolutely comparable," since they accepted Willien's selection of Group C, which is "more comparable" in size, at least, to Group A. (Group A averaged 22,300 consumers per company in 1919; Group B, 4,360, and Group C, 7,040, according to Brown's Directory of American Gas Companies for 1920.) Why the various groups are not accurately comparable is easily explained. The period under consideration was one of great changes in industrial conditions and in available fuel supply, and it included at least one unusual winter. It also marked the beginning of a considerable expansion in auxiliary house heating by gas. Changes in these important conditions would obviously affect differently such different classes of customers as factories, residences, and restaurants. Hence, we should not expect a large industrial city and a small residential district to be affected in the same way by changes in conditions other than the gas supply. The figures quoted by the committee are ample evidence that they were not. There is some reason to believe, too, that the possible market for gas in the smaller cities was not so well developed as in the large, and that the growth of business was different for that reason. If domestic consumers had much the same average consumption in all parts of the State and differences in consumption per meter represented industrial consumers, hotels, etc., the character of the load may be roughly judged by the consumption per meter. It can be seen as a mathematical relation that if the load in different cities 
were made up of industrial and domestic loads in different proportions, but all the industrial consumers were affected alike and all the domestic consumers were affected alike by a given change of conditions, then the effect of the change upon the sales of the gas company as a whole would be a linear relation of their consumption per meter. The same linear relation would hold if the development of business and the effect of economic and weather conditions were uniform for each of any other two classes of customers which made up the total business. Hence, by plotting the consumption per meter against the change of consumption of Groups B and $\mathrm{C}$ and extending the straight line connecting the two points to the consumption per meter of Group A, we should have a fairly close approxima-

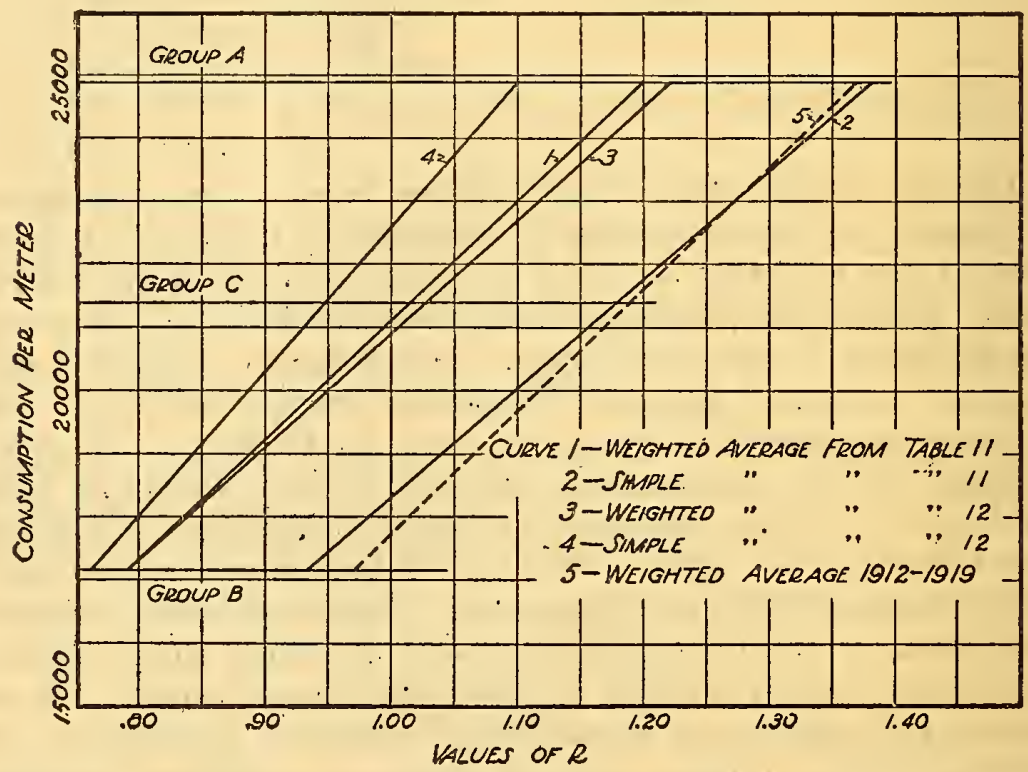

FIG. 33.-Values of $R$ (the ratio between relative change of volume used and heating value) from several methods of averaging

tion to the change of consumption which would have taken place in the cities of Group A had they kept the same standard as Groups $\mathrm{B}$ and $\mathrm{C}$. Comparing this with the actual consumption of Group A, we get the most probable relation between consumption and heating value in cities of the same character which it is possible to derive from the available data.

The cities of Group A had an average consumption per meter of 24,912 cubic feet; Group B, 17,187; and Group C, 21,413. Figure 33 shows the result of plotting the value of $R$, obtained by the four methods of averaging the data for 1915-1919, against consumption per meter. These give $1.10,1.20,1.22$, and 1.38, respectively, as the value for $R$. The weighted mean for 1912-1919 gives 1.37. 
It is interesting to compare this result with that of two cities that are actually as nearly alike as possible. The only city in Group B of more than 50,000 inhabitants, and consequently the only one for which details of industries are given in the census of manufactures, is Lawrence. Of the cities of Group A the one which appears to most resemble Lawrence is Lowell. These cities are only 10 or 15 miles apart; both are centers of textile manufacture; each city contains nine very large mills, employing about two-thirds of the working population, and both cities are far enough from Boston to be independent centers of population and industry and not merely manufacturing districts of the metropolis. A comparison between the two cities is given in Table 13. Each year the relative heating value of the gas supplied to Lowell decreased and the relative consumption in cubic feet increased. The relative demand for heat decreased the last year. The aggregate decrease of relative heating value during the period of comparison was 5 per cent and the increase of relative consumption was 7 per cent. Here $R=1.31$.

$\mathrm{T}_{\mathrm{ABLE}}$ 13.-Comparison between the cities of Lawrence and Lowell, Mass., i915-1919

\begin{tabular}{|c|c|c|c|}
\hline & Lawrence & Lowell & $\begin{array}{c}\text { Ratio, } \\
\text { Lowell: } \\
\text { Lawrence }\end{array}$ \\
\hline $\begin{array}{l}\text { Population of district supplied, } 1919 \text { (Brown's directory) } \\
\text { Number of factory employees, } 1919 \text { (census of manufacturers) }\end{array}$ & $\begin{array}{r}130,000 \\
30,319 \\
27,820\end{array}$ & $\begin{array}{r}135,000 \\
30,111 \\
27,054\end{array}$ & 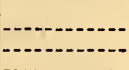 \\
\hline $\begin{array}{l}\text { Consumption per meter: } \\
1915-16 \text {. } \\
1916-17 \\
1917-18 \\
1918-19\end{array}$ & $\begin{array}{l}21,117 \\
21,196 \\
22,445 \\
22,120\end{array}$ & $\begin{array}{l}26,749 \\
28,384 \\
30,436 \\
29,983\end{array}$ & $\begin{array}{l}1.265 \\
1.338 \\
1.353 \\
1.355\end{array}$ \\
\hline 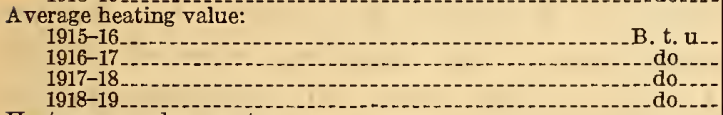 & $\begin{array}{l}598 \\
592 \\
591 \\
589\end{array}$ & $\begin{array}{l}588 \\
570 \\
567 \\
551\end{array}$ & $\begin{array}{l}.984 \\
.963 \\
.959 \\
.936\end{array}$ \\
\hline $\begin{array}{l}\text { Heat consumed per meter: } \\
1915-16 . \\
1916-17-18 \\
1918-18 \\
1918-19\end{array}$ & $\begin{array}{l}126.5 \\
125.4 \\
132.7 \\
130.4\end{array}$ & $\begin{array}{l}157.2 \\
161.5 \\
172.5 \\
165.1\end{array}$ & $\begin{array}{l}\text { 1. } 242 \\
1.287 \\
1.300 \\
1.267\end{array}$ \\
\hline
\end{tabular}

If the differences between the two cities are taken account of, the increase in consumption in Lowell is more remarkable, since it is the larger city and had the larger consumption per meter, and in the State as a whole these two factors appeared to reduce the tendency for the consumption of gas to increase.

It does not appear possible to select any other pair of cities which changed heating values at different times which are as closely comparable as these two.

\section{MONTREAL AND TORONTO}

One important fact that the data from the Massachusetts cities most clearly establish is that factors other than changes in heating $43360^{\circ}-25 \div-6$ 
value so affect the changes of consumption from time to time that in any individual case they completely obscure the effect of change of heating value. For example, we find among the cities of one group during the first year changes in consumption per meter ranging from a decrease of 1.7 per cent to an increase of 25.7 per cent. During the last year of the comparison the range is even greater-from a decrease of 33.1 per cent to an increase of 26.1 per cent. Obviously, with such relative differences occurring when there is no relative change of heating value, no conclusion which is drawn from changes of consumption in a single selected locality, especially over a brief period of time, can have much value in comparison with the average of all the companies in a State, 57 in number, over a period of four years.

Hence, the other exhibits used by the committee on calorific standards are insignificant in comparison with the data from Massachusetts. Certain facts should be noted in connection with them, however.

Two of the exhibits relate to the principal industrial cities of Canada, Montreal, and Toronto during the war. When the war began in 1914, it was followed by a panic in industrial and financial circles and by a memorable campaign for thrift and for contributions to support the Government, as well as such charities as the relief of Belgium. A great development of war industries followed, attended by prosperity and liberal expenditure among industrial workers. At the same time there was a fuel shortage. Gas was available and consequently in great demand. After the war there was not only a cessation of the manufacture of munitions, but a general industrial depression amounting almost to a panic. Beginning with the war we should, therefore, expect that in the industrial cities of Canada the demand for heat in the form of gas would fall off during the first depression, increase with the growth of the war industries, and fall off again during the second period of depression. Exhibit 2 of the committee shows the consumption of gas in Montreal during the first two phases of this cycle. The decided increase in consumption in 1917-18 is attributed by the committee, correctly no doubt, to the development of the war industries; but the decline of sales during the preceding depression is not attributed to the curtailment of normal industries upon the outbreak of the war, a curtailment which occurred even in the United States (as shown, for example, by considerable reduction in gas sales by each of the three groups of companies in Massachusetts).

Exhibit 3 shows data from Toronto, presented in the form of a table, of the number of customers who used certain volumes of gas per month expressed in percentages of the whole number of customers. The data are given only for customers using less than 5,000 cubic 
feet per month during April, 1918, at the height of the industrial activities connected with the war and the worst of the fuel shortage, and for April, 1920, when industrial activity, in the United States at least, was declining. The table shows a slight decline, about 0.5 per cent, in the number of customers using more than 5,000 cubic feet per month. On the other hand, it shows an increase of about 2.5 per cent in the volume of gas used per customer for all customers burning less than 5,000 cubic feet per month, which must include nearly all the domestic consumers. The reduction in heating value between the dates considered was from 538 to 492 B. t. u., 9.5 per cent. It is interesting to compare the increase of 2.5 per cent per customer for small consumers in Toronto with the decrease of 10 per cent per meter between 1918 and 1920 in the neighboring city of Buffalo, as shown by the annual sales and number of meters reported in Brown's directory.

The chief engineer of the Toronto company, Arthur Hewitt, ${ }^{57}$ said regarding the use of gas in Toronto "*** the increase in consumption per meter in 1917 [11.53 per cent] is absolutely and fully accounted for by the tremendous load put upon us in supplying gas for the manufacture of munitions of war, and I desire to point this out particularly." In the case of Montreal the committee does not hesitate to ascribe a sharp increase in gas consumption to the beginning of the manufacture of munitions. Why not give some weight, in the case of Toronto, to the cessation of this activity?

\section{READING, PA.}

Exhibit 4 contains only a statement of the policy of the Connecticut commission and presents no data on the relative usefulness of gases of different heating value. Exhibit 5 relates to Reading, $\mathrm{Pa}$., and the data presented are taken from a report by C. F. Elmes, of the firm of Sanderson \& Porter, regarding the change from a candlepower standard to $575 \mathrm{~B}$. t. u. The change in heating value, which was estimated by Elmes at 8 per cent, was made gradually during June, July, and August of 1915. The results are of more than usual interest because the Reading case has been made much of by the gas industry. Elmes's report was used by the Peoples Gas Light \& Coke Co., of Chicago, in a campaign to obtain a lower standard, and the data were also used by the committee on the heating value of artificial gas in the report to the United States Fuel Administrator dated August, 1918 (Appendix C, pp. 13-14). Appendix C is an argument to show that a decrease of heating value does not materially increase the volume of gas consumed. In each of the several reports

${ }^{87}$ Report of Committee on Heating Value of Artificial Gas to United States Fuel Administrator, Report of Conference on Conservation of Coal and Oil, p. 22. 
it is either stated or implied that the difference between the heating values during 1914 and 1915 was 8 per cent, although the 8 per cent change did not take place until after the middle of the year 1915, instead of on the 1st of January, from which the data on consumption are dated.

Assuming that during the two months of changing quality the rate of change was constant, the effect on consumers' bills must have been the same as though the whole change had taken place on July 15. Assuming the usual 15-day average lag between the time the gas is used and the meter is read, and taking Sanderson \& Porter's figures, the average heating value of the gas metered during 1914 was, therefore, about 3.3 per cent higher than during 1915 . The average changes in the amount of gas burned by the groups selected for comparison were as follows: Group 1 (10 hosiery mills) 2.6 per cent increase; Group 2 (9 printers) 2.3 per cent increase; Group 3 (9 candy makers) 2.5 per cent decrease; Group 4 (34 bakers, hospitals, and restaurants) 4.8 per cent increase; Group 5 (small customers having prepayment meters) 1.0 per cent increase. The average for the large customers in the first four groups weighted according to the amount of gas used was 2.7 per cent increase. If the percentage change of each customer is taken individually, the average of all is 10 per cent increase. Obviously, a more direct comparison of the effect of the change of gas quality can be made by considering the consumption after the change is completed with that of the corresponding months of the preceding year. Sanderson \& Porter state the volume consumed each month by each of 17 selected large consumers and state the appliances used by each and the date of installation. Eliminating the consumers who added to their equipment during the year and one hospital which was remodeled, we have 14 consumers who had not changed their gasburning equipment during the year. During the four months immediately following the change of gas quality these 14 customers burned $4,104,300$ cubic feet of gas with the same gas-burning equipment that consumed $3,906,600$ cubic feet during the same period of the preceding year, an increase of 5 per cent. The figures are also given for the monthly consumption of gas in prepayment meters. During the four months following the change the consumption per meter by this class of customers increased 3.5 per cent over the consumption during the same period of the preceding year, and during the nine months following the change it increased 5.9 per cent over the consumption during the corresponding nine months of the preceding year.

The consumption by the small consumers using prepayment meters is probably affected less than that of most other customers, because the prepayment meters, in general, serve the older installa- 
tions and the smaller consumers, and in both classes a larger proportion of the gas is probably used for lighting than in the larger or more modern installations. For reasons already pointed out, the lighting load could not be expected to increase with a change of heating value. The customers simply change their method of lighting or get less light.

At the time the change of heating value went into effect the use of gas was declining. In the case of the average Massachusetts company the use of gas was also declining during this period, and the loss of business was not made up until 1917. This may be worth noting because of the emphasis sometimes placed upon an increasing rate of consumption prior to a decrease of heating value.

\section{PROVIDENCE, R. I.}

Exhibit 6 of the committee on calorific standards relates to the total send out for Providence, R. I., during 24 weeks in 1920 (February 25 to August 10), and a corresponding period in 1919. At about the end of May, 1920, the heating value was reduced from about 580 to 510 B. t. u. Providence is an important industrial city, and again a period of rapid industrial changes was chosen for the comparison.

Through the courtesy of F. C. Freeman, engineer of the Providence Gas Co., the Bureau of Standards was supplied with data showing the weekly average heating value and weekly send out during the years 1919-1921 and a portion of 1922. These data are shown graphically in Figure 34, in which the arerage heating value and total send out are plotted for each week. The scales used are such that a given percentage change in heating value is represented by the same vertical distance as the same percentage change in volume of gas sent out, so that the two sets of curves may be easily and directly compared. Several points of interest appear from an inspection of these curves:

1. It may be clearly seen that there is a very large seasonal variation, most clearly shown by the abrupt increase in the use of gas which occurs every autumn. This is, of course, balanced by a change in the reverse direction which seems to occur rather gradually in late winter and spring.

2. The seasonal change in the spring is opposed to the change to be expected from the reduction of heating value which occurred in the spring of 1920 .

3. There are also irregular variations, which can not bc attributed to seasonal changes, of greater magnitude than any effect to be anticipated from the change of heating value in 1920.

4. These seasonal and irregular changes must have rendered it impossible to judge of the effect of a change of heating value by 


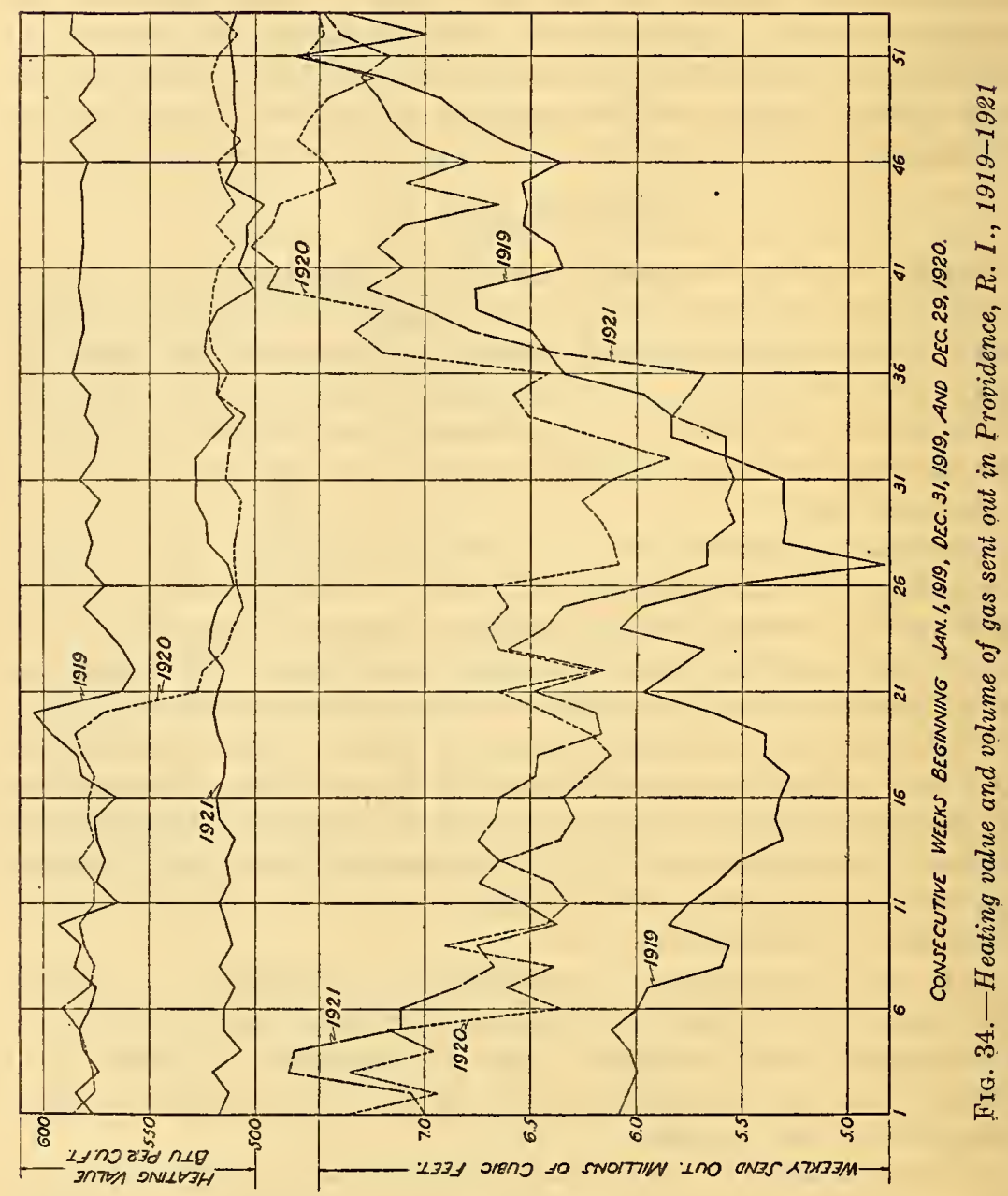


considering only the send out before and after the change without reference to other years in which no change of heating value took place (compare fig. 13).

5. The major change of heating value in 1920 was but little greater than a change of nearly equal magnitude in the same direction during the corresponding week of 1919. (The change in 1919 was not permanent.) Both for this reason and because of the many irregularities of unknown origin in the send out for both years it is not surprising that the effect of the change of standard in 1920 did not appear during the week of the change, even when compared with 1919. All that could have been reasonably expected was a general change in the tendency of the send-out curve for 1920 at the time of the reduction.

6. Such a change in general tendency certainly did occur. Before the reduction of heating value the send-out curves for 1920 and 1921 are closely interwoven. At about the date of the change the curve for 1920 becomes definitely higher than for 1921 and remains so during the remainder of the year. Similarly, both the curves for 1920 and 1921 are approaching the curve for 1919 until about the 1st of June. The curve for 1920 then breaks away for a time from that for 1919, after which it again approaches the 1919 curve. On the other hand, the 1921 curve, unaffected by a reduction of heating value, continues to approach and soon crosses that for 1919 .

The relations between the various years may be much more clearly seen by again employing ratios between corresponding weeks of two years. Ratios of heating values, volume sent out, and potential heat sent out for the years 1919,1920,1921, and 1922 are shown in Figure 35. When the method of ratios is employed for only two years it is, of course, impossible to judge whether irregularities in the ratio curve are caused by conditions peculiar to the first year or to the second. If, however, we plot ratios of one year, $A$, to each of several other years, $B, C, D$, etc., and find a corresponding irregularity in each of the resulting curves, it may be regarded as certain that the irregularity was caused by some condition peculiar to the year $A$. In Figure 35 we find that when each of the years 1920 , 1921 , and 1922 is compared with 1919 there was at about the end of May a decided falling off in the amount of potential heat sent out. This must, therefore, have been caused, at least in part, by an increase above normal in the amount of heat used during this period of 1919 .

On the other hand, the volume used in 1920, as compared with that used in 1919, 1921, and 1922, shows an increase at the time of the change of heating value in each case and must have resulted from a condition peculiar to 1920 , presumably the reduction of heating value. It is true that a comparison of potential heat scnt out in 1920 shows a decline in comparison with each of the other years, 


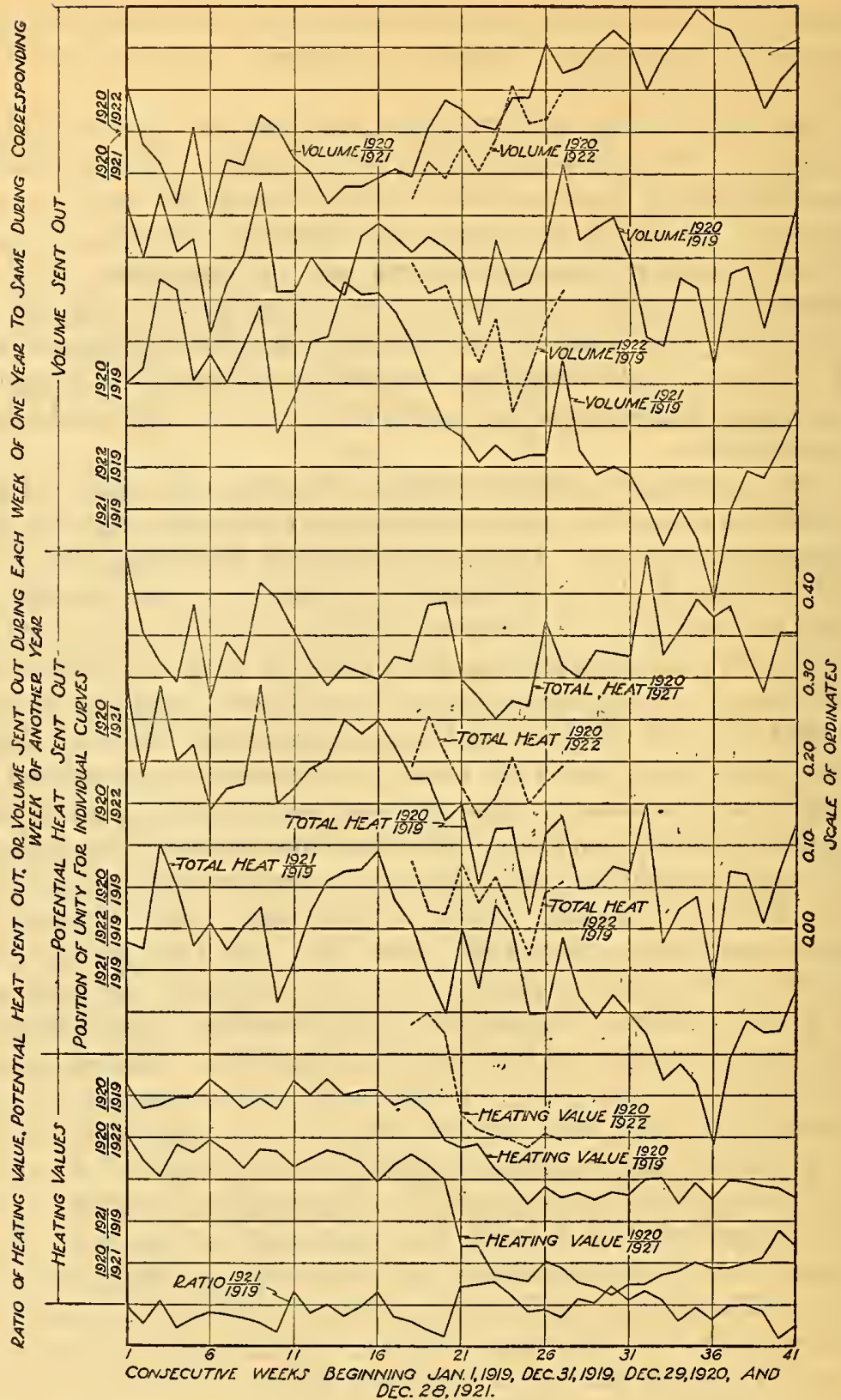

FIG. 35.-Data regarding heating value and gas sent out in Providence, R. I., expressed in the form of ratios

so that it appears probable that the change of heating value resulted in some increase in the volume of gas used and in some loss of market. (The prompt readjustment of appliances made in most 


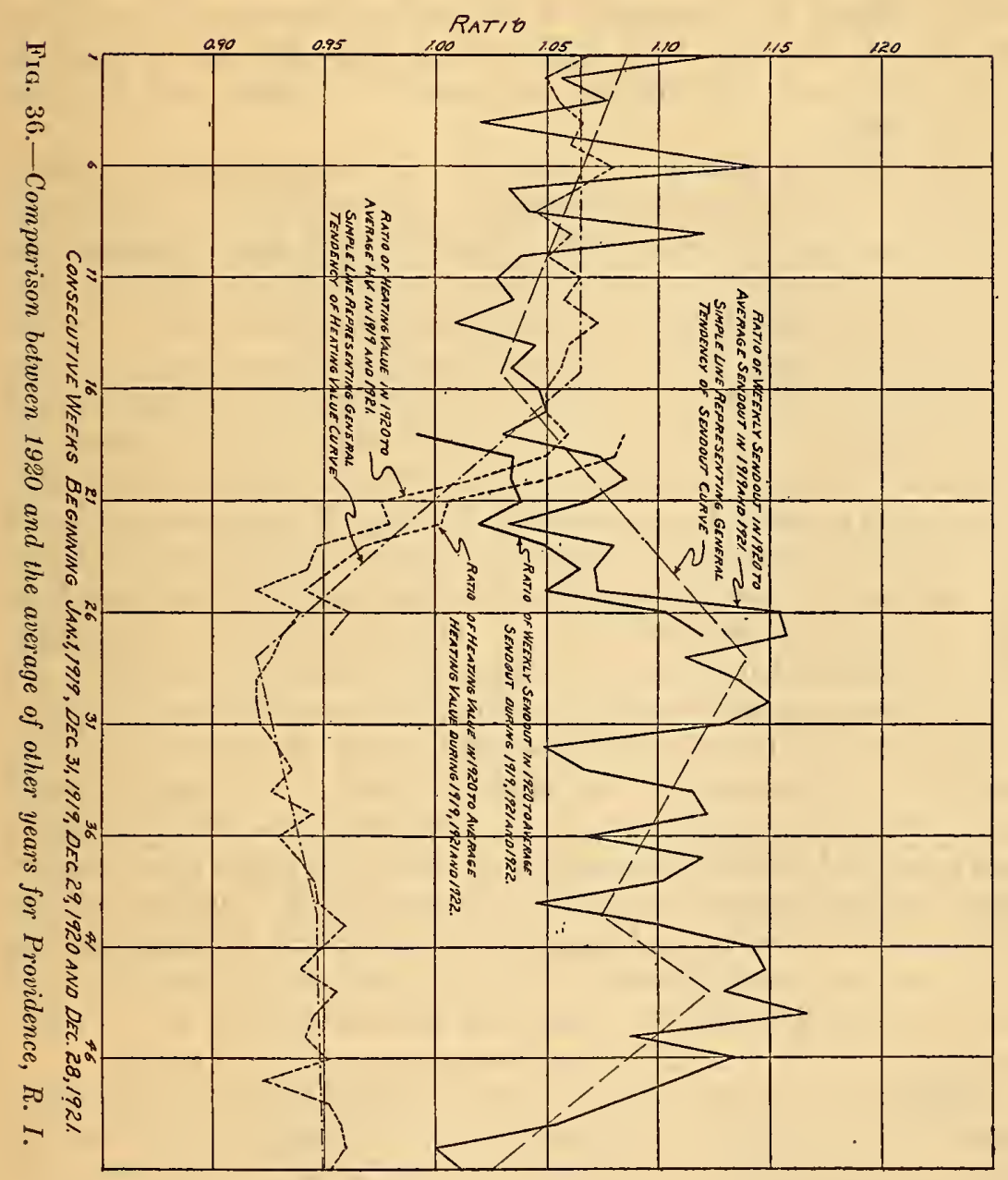


other communities when the heating value was reduced does not appear to have been made in Providence, hence, space heaters, water heaters, and some other appliances in addition to gas lights must, in general, have given less, or less rapid, service.)

Probably the best method available for forming a quantitative estimate of the effect of the change of heating value upon the volume of gas required is to compare 1920 with the average of the other years. Figure 36 shows such a comparison between 1920 and the average of 1919 and 1921 and between 1920 and the average of 1919, 1921, and 1922 during the period for which data for 1922 were available.

Light, broken lines have been drawn to approximate the general tendencies of the curves representing the comparison of 1920 with the average of 1919 and 1921. These broken lines represent the reviewer's judgment, and the reader should decide whether they represent the data shown by the actual curves satisfactorily. Assuming that they do so, we find that the relative send out during 1920 was declining with respect to the other two years until the reduction of heating value took place. The curve breaks upward during the period of change of relative heating value and declines again after that period at about the same rate as before. If we take as a measure of the effect of the change of heating value only the difference between the ordinates of the breaks in the send-out curve and compute $R$ by the usual method, we find $R=0.71$. This corresponds to the assumption that had there been no change of relative heating value the relative consumption would have remained constant during the period from the fifteenth to the twenty-eighth week. If we make the more probable assumption that the send out would have changed during that period at the same rate that it appeared to be changing before and afterwards (which may be done by extending to the twenty-eighth week the first segment of the line representing the general tendency of the send-out curve, and considering the vertical distance between this point and the beginning of the third segment) we find $R=1.00$. The value for $R$ found by considering the whole of the curves representing the ratio of 1920 to the other three years is $R=0.95$.

Whichever of these values of $R$ more nearly represents the actual effect of the change of heating value, it appears certain that the volume of gas used in Providence was affected by the change of heating value much more than was the amount of potential heat used.

\section{SHEBOYGAN, WIS.}

A paper by A. F. Davey ${ }^{58}$ describes a reduction of heating value which took place in Sheboygan, Wis., and the efforts of the company to make the change work as little hardship as possible to its customers.

${ }^{68}$ Wisconsin Gas Association; 1921. Gas Age, 47, pp. 303-304; 1921. 
As the reduction of heating value was begun, the company advertised for five weeks in the papers and on the consumers' bills urging thrift in the use of gas, calling attention to the company's service department, offering to aid in choosing the most efficient appliances and to "tell you how to avoid waste by using them intelligently." The advertisement was very effectively worded and must have attracted the attention of almost every gas consumer. This advertisement was followed by a house to house inspection and adjustment of appliances. It is significant that "in most cases it was necessary to ream the orifices."

The campaign to educate the consumers in the economical use of gas, the readjustment of their appliances, the reduction in heating value, and an increase in the price per thousand cubic feet of about 15 per cent (10 per cent, 17.5 per cent, and 20 per cent on different quantities) took place simultaneously. The figures given by Davey show that the volume of gas used per consumer was 10.1 per cent greater during the eight months following the change than during the corresponding months of the preceding year, during which the heating value of the gas was 10.3 per cent greater. Stated in another way, the average consumer used the same amount of heat after the change as before, in spite of a 25 per cent increase in the cost of heat and in spite of a readjustment of appliances and of an admirably conducted campaign to educate the public in the economical use of gas. Against these factors which would tend to decrease the consumption of gas, Mr. Davey sets an abnormally cold autumn (which may have resulted in earlier starting of house-heating furnaces with the elimination of room and hot-water heating by gas), a good fruit crop, daylight saving during 1919 (which affected only two of the eight months considered), prohibition, and the normal increase in the uses for gas. Who can tell which group of influences was predominant? Yet this paper has been repeatedly referred to by others as important evidence of the equivalence of gases of different heating value.

\section{SEATTLE, SPOKANE, AND TACOMA, WASH.}

In 1920 the three principal cities of Washington-Seattle, Spokane, and Tacoma-changed their heating-value standards. A large amount of information regarding these cities was collccted by H. J. Flagg, ${ }^{59}$ chief engineer of the Public Service Commission of Washington, and J. W. Carey, ${ }^{60}$ his successor as chief engineer of the commission (now the Division of Public Utilities, Department of Public Works). The heating values of the gas distributed are given in tabular form, daily determinations being given by Flagg and weekly

\footnotetext{
69 Study of relation of thermal quality of gas to consumption Octoher-December, 1020.

${ }^{80}$ Report of the chief engineer in relation to the heating value of gas in Seattle, Trcoma, and Spokane, May, 1924.
} 
averages by Carey. Data regarding consumption are given in the form of curves. The most important of these are in Carey's report and show the volume of gas sold per meter for each of the cities as a whole and for certain subdivisions or selected groups. Most of these data are given in monthly quarterly means; that is, for each month the figure given is the average consumption for that month and the months immediately preceding and following it. In this review it has been assumed, following Flagg's report, that the heating value of the gas distributed in Seattle and Spokane was 600 B.t. u. per cubic foot until the date of the first heating value determination given by him; the heating value of the gas sold in Tacoma before the beginning of the regular tests is assumed by G. E. Whitwell, ${ }^{\text {e1 }}$ superintendent of the Tacoma plant, to have been $565 \mathrm{~B}$. t. u. In making up monthly averages from the weekly averages given by Carey, the heating value during each day of the month was assumed to have been that of the average of the week in which the day occurred.

In general, it may be said that in the case of these cities the reduction of heating value was made at a time when its effect upon consumption was opposed by both weather and economic conditions. The autumn of 1920 was abnormally warm. Weather conditions and a strike in the plant of the Seattle Lighting Co. in September of 1919 doubtless affected the shape of the curves showing the relation of gas sales to those of the preceding year during the four months between the beginning of the reduction of heating value and the preparation of Flagg's report; they therefore affected Flagg's conclusions. In a reasonably complete study of the available data over a number of years the effect of these accidental variables is probably not very important, but the effect of changing economic conditions can not be disregarded.

As we should expect from the fact that monthly meter readings will, on the average, represent gas burned 15 days previously, the strike in the early part of September, 1919, affected the "volume of gas used" as determined from meter readings for both September and October. Since the volume of gas sent out from the plant is measured at the time it is used, it seemed possible to correct for this difficulty by considering the total "send out" rather than the volume sold. The volume sent out should, in general, bear a constant relation to the volume sold, since the gas "unaccounted for" is a small and nearly constant fraction of the whole. The monthly send out for 1919 and 1920 was kindly supplied by F. K. Lane, manager of the Seattle Lighting Co.

These data and the consumption taken from Flagg's curres are shown in Figure 37. It will be noted that the send out for 1919 appears normal as compared with the average sales for 1915-1918 
except during September. In the years 1915-1918 the volume of gas used during September was the average of that used during August and October; hence it is probable that the same would have been the case in 1919 had conditions at the gas plant been normal.

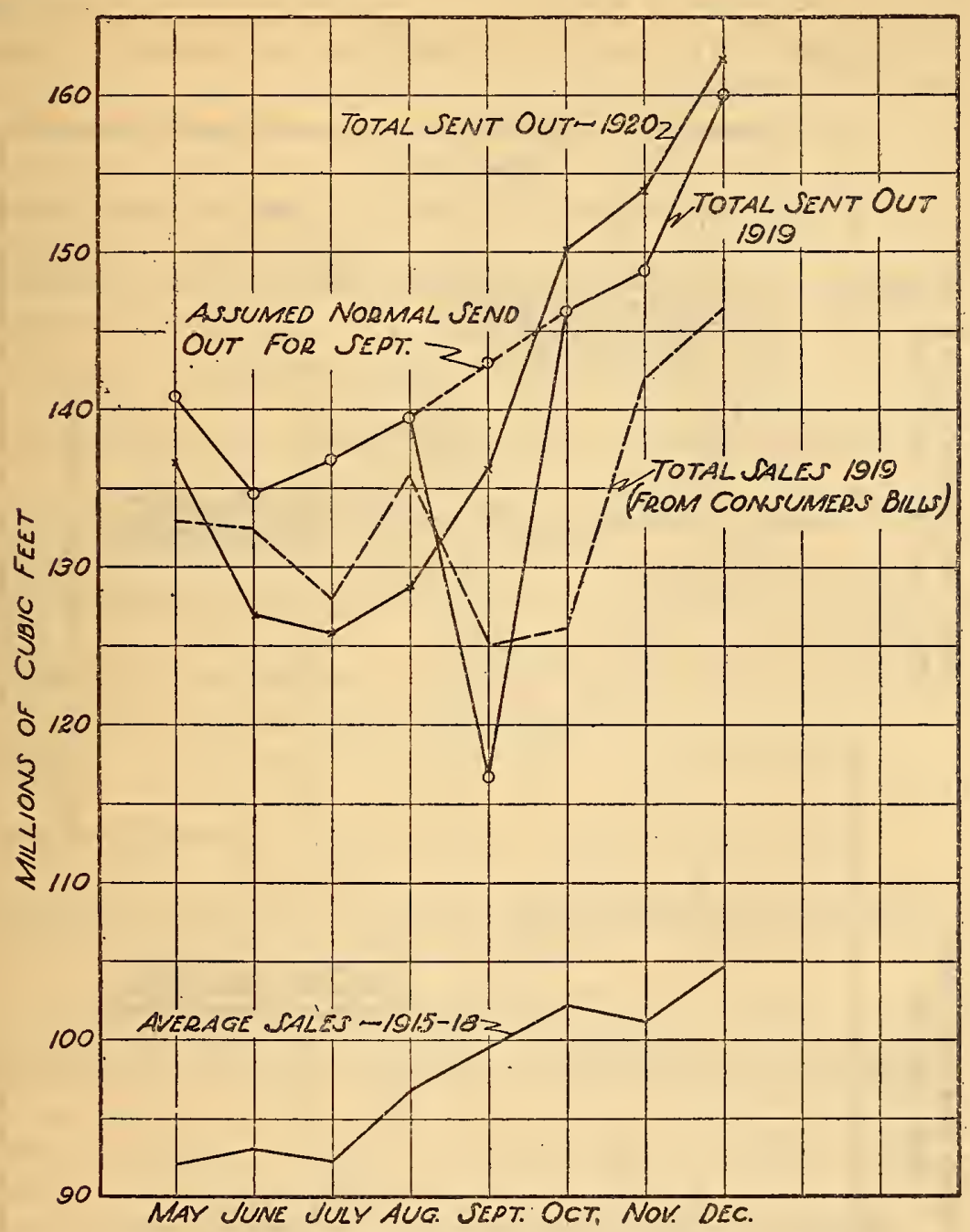

Fig. 37.-Total send out and total sales, Seattle, Wash., 1919

It should be noted in Figure 37 how well the shape of the curve representing the volume of gas sold indicates that this number is the average of the gas used during the month in which the meter is read and the preceding month. This is to be expected, of course; and since we are interested in the heating value of the gas supply at the time the gas is used, not when the meter is read, we will have to use the average heating value for the two months when the volume used is 
based on the customer's meter readings. This correction is, of course, unnecessary when considering the volume of gas metered at the works.

Since 1919 was an abnormal year on account of the strike, a comparison of total send out and total sales for 1920 with total sales for 1915-1918 is given in Figure 38. A reasonably close agreement with the relation of inverse proportionality between heating value and demand is indicated.

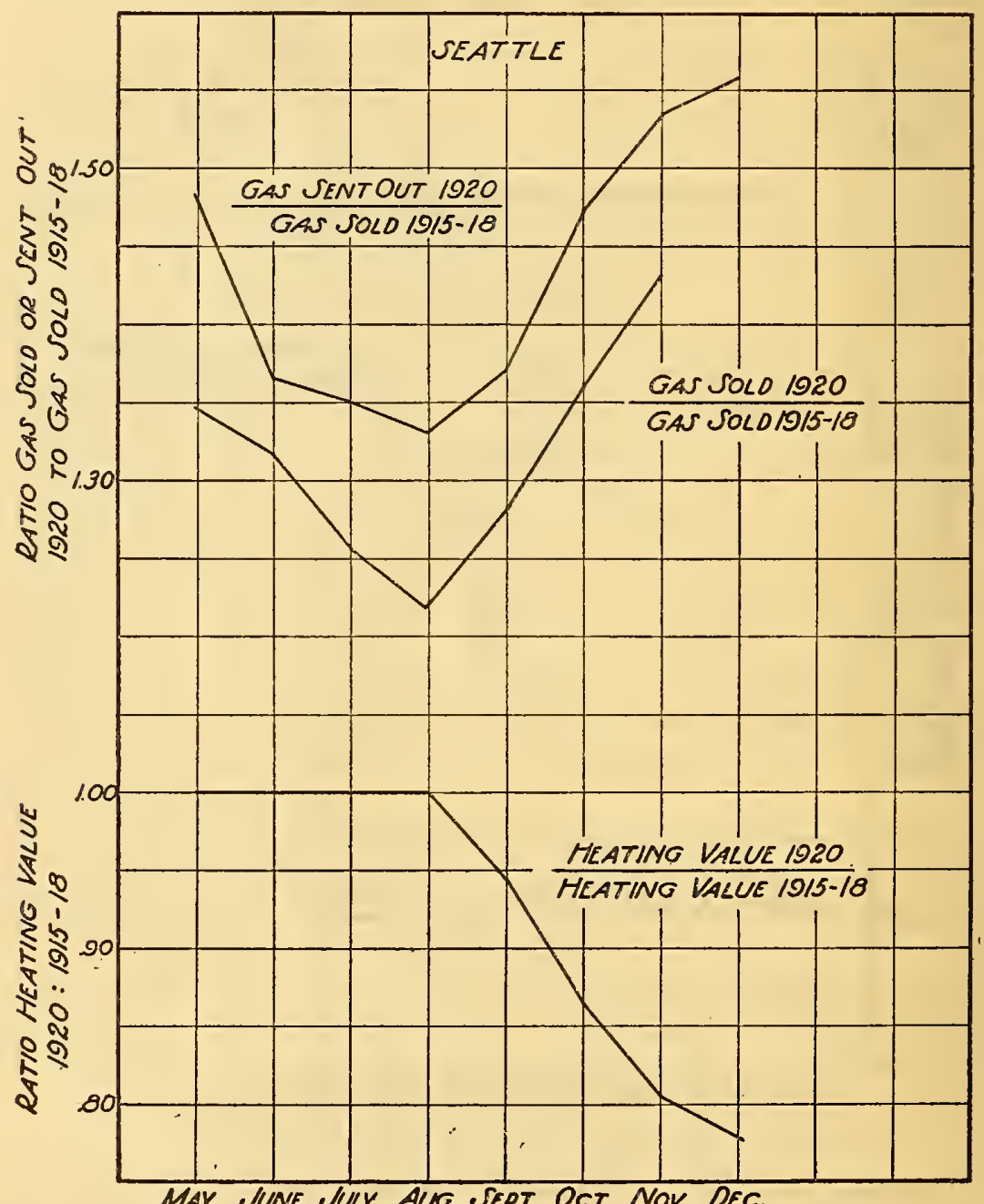

FIG. 38.-Comparison between 1920 and 1915-1918, Seattle, Wash.

It may be seen that the consumption does not increase quite in proportion to the decrease of heating value, and this may be explained in part by the weather. In order to determine whether this variable would account for much of the difference, the relative 
amount of heat required in 1919 and 1920 was computed, using the relation found by the California committee as shown in Figure 21. The result is shown in Figure 39 and indicates that the high autumn temperature of 1920 would just about account for the total observed effect if as much heating equipment were used as in the California cities. Carey's data showing by quarterly means the volume of gas used per meter have been put in the usual form showing the ratio for each period to the corresponding period of the preceding year. They are given in Figure 40, together with the corresponding ratios for heating values and bank clearings. The relation between volume of gas used and business activity as indicated by bank clearings is unmistakable, especially during the five or six months preceding the change of heating value. Yet the decline in the volume of gas used

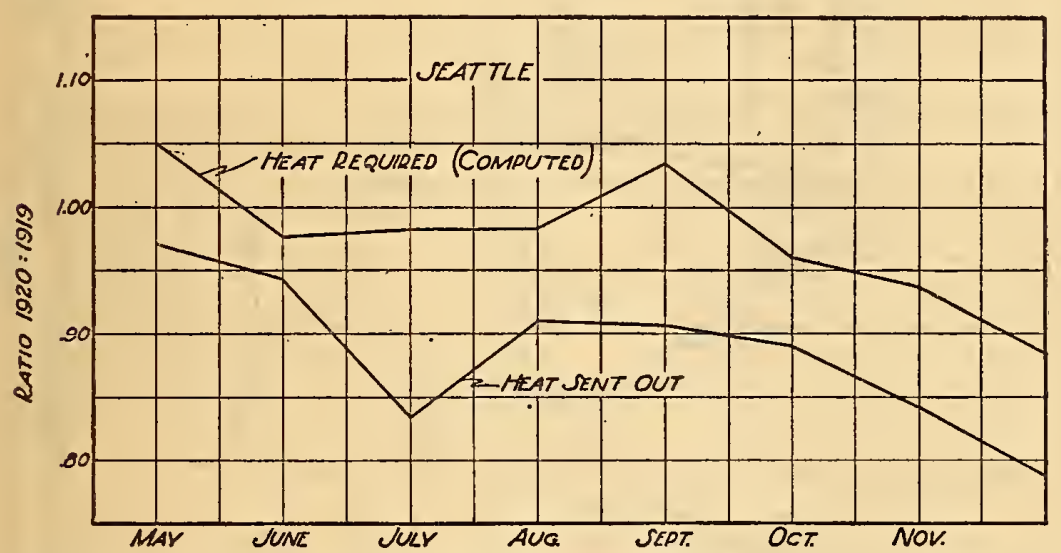

FIG. 39.-Possible effect of temperature on relative amount of heat required in Seattle, Wash., in 1919 and 1920 . Computed on the assumption that temperature has the same effect upon sales as in California

is abruptly reversed as soon as the heating value begins to change in spite of the fact that relative bank clearings are still falling rapidly. When the heating-value curve rises (during the comparison between 1921 and 1920), the relative volume of gas used falls practically in proportion, in spite of the fact that the change is again opposed by economic conditions. Hence we have once more a very striking mirror image between curves representing consumption and heating value. The image is distorted, it is true, but the cause of the principal distortion is very apparent.

Since these curves represent ratios of one year to another, the portions representing a period of important change are no more affected by unknown variations in the year of the change than in the year with which it is compared. Thus the steep decline of the curve representing bank clearings in 1920 is caused as much by business expansion in 1919 as by depression in 1920. Hence it is of interest to 


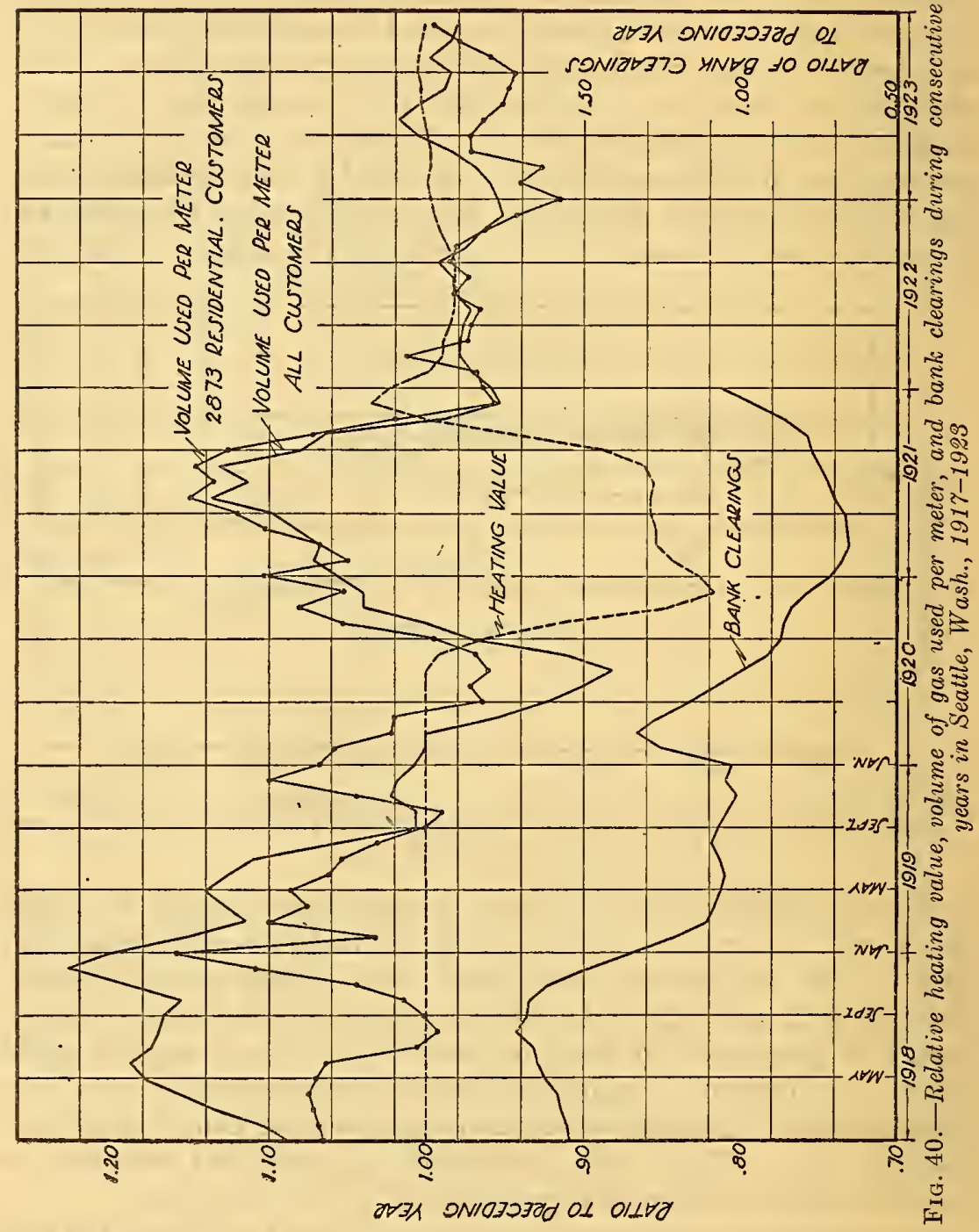




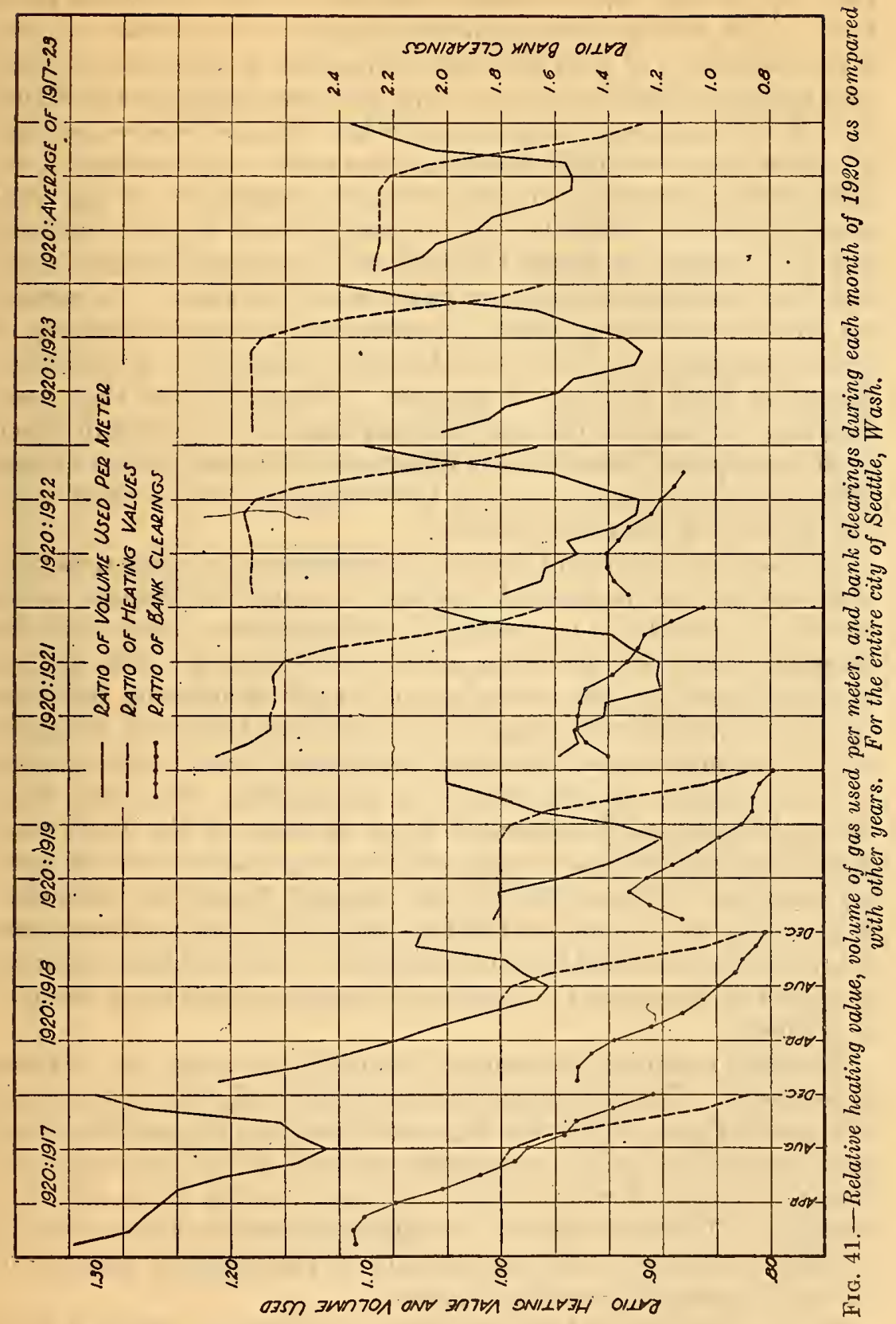

$43360^{\circ}-25 \div$ 
compare the year of the important change of heating value not with 1919 and 1921 only but with each of a number of other years. In this way we may hope to largely eliminate variable conditions peculiar to 1919, although we can never eliminate those peculiar to 1920 . This comparison of 1920 with successive years is shown for the city as a whole in Figure 41 and for 2,873 residential customers in Figure 42. We at once have additional evidence that the relative increase of volume used was opposed by the same causes that produced a decline of bank clearings. In 28 of the 31 comparisons of this kind made in the case of Seattle, Tacoma, and Spokane we have declining relative consumption during the portion of the year when bank clearings were declining and heating value nearly stationary. In general we find the increase of relative consumption during the decrease of relative heating value to be least for those comparisons in which the decline of bank clearings is greatest. Always we find that bank. clearings decreased in 1920 more rapidly than in the year with which 1920 is compared; hence we should expect to find that the use of heat diminished in the last months of 1920 more than in any other year, just as it did in the earlier months.

The best we can do in the way of determining the numerical relation between the decrease of heating value and the increase in the volume of gas used is to average the comparisons of 1920 with the six other years, three preceding and three following it. This method of comparison has the advantage of largely eliminating both the conditions peculiar to a single year (other than 1920) and the effect of any continuous development of the industry, such as the growth of space heating and the decline of gas lighting which may have been taking place. The value of $R$ can be taken by the direct comparison between the total change of the average ratio curves for heating value and volume used for the months August to December. For the city as a whole, $R=0.86$; for the 2,873 residential customers it is 0.95 . As we should expect, the effect of the decline of business in 1920 was less upon the residential customers than upon the city as a whole.

The data regarding Spokane are treated in the same way as those from Seattle. The continuous curves of Figure 43, which correspond to those of Figure 39 for Seattle, again show that the amount of gas used responds to the same economic effects as do bank clearings and that the reciprocal relation exists between heating value and consumption. The large distortion of the mirror image in the winter of 1920-21 is obviously caused principally by the abnormal quantity of gas used during the preceding winter.

The comparisons of 1920 with each of the other years from 1917 to 1923, which are represented in Figures 44 and 45, show the same characteristics as do the curves for Seattle; diminishing bank clear- 


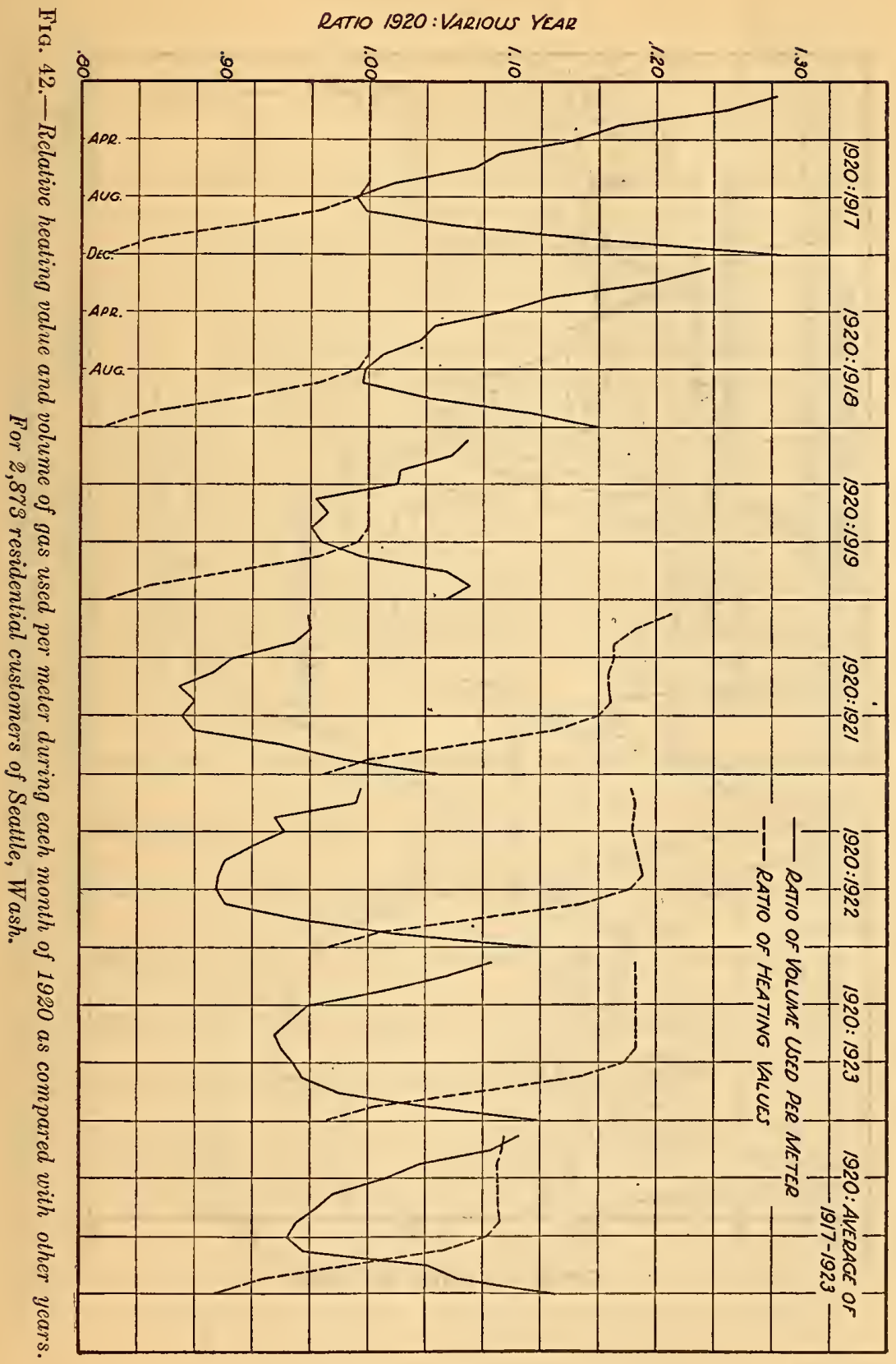




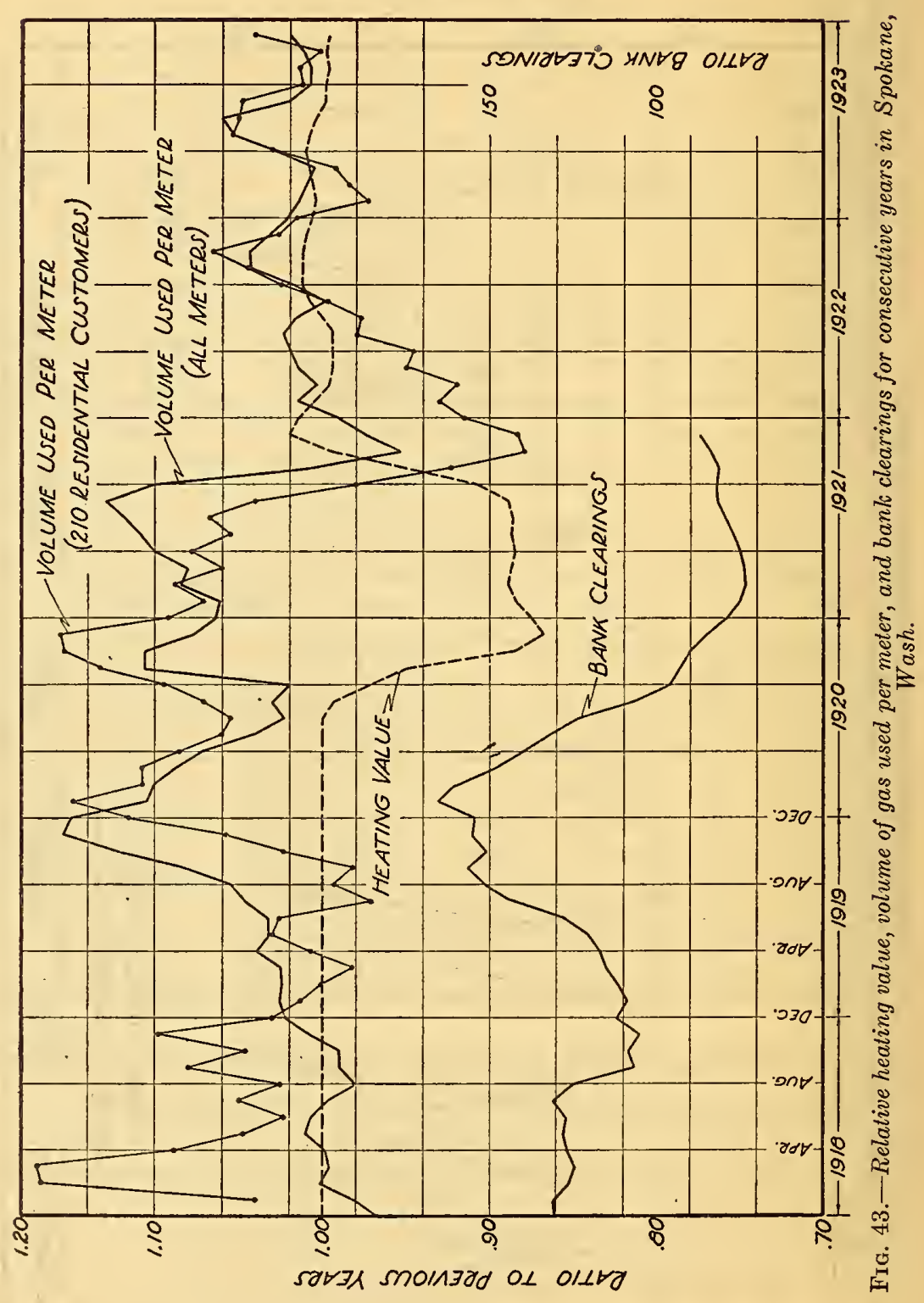




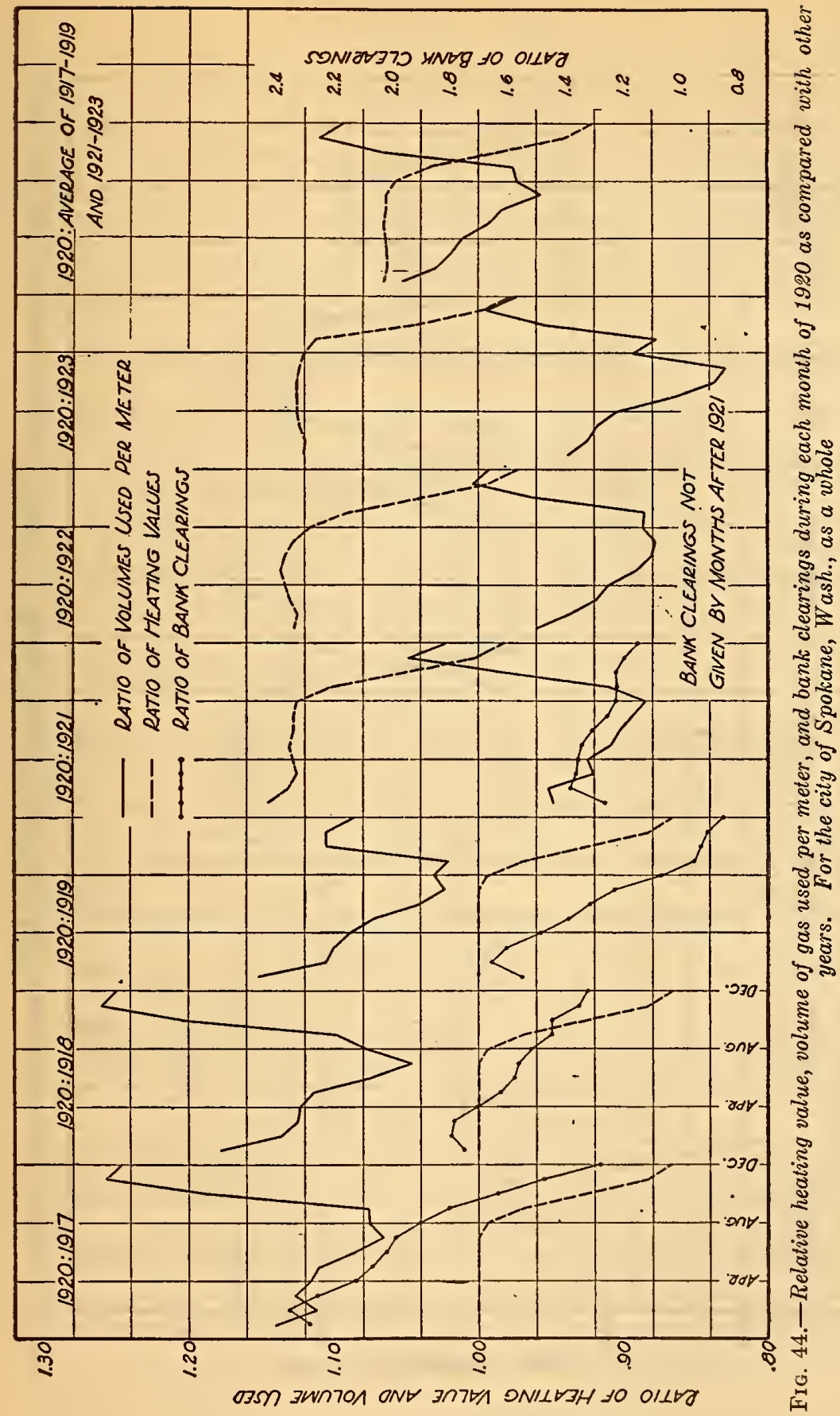




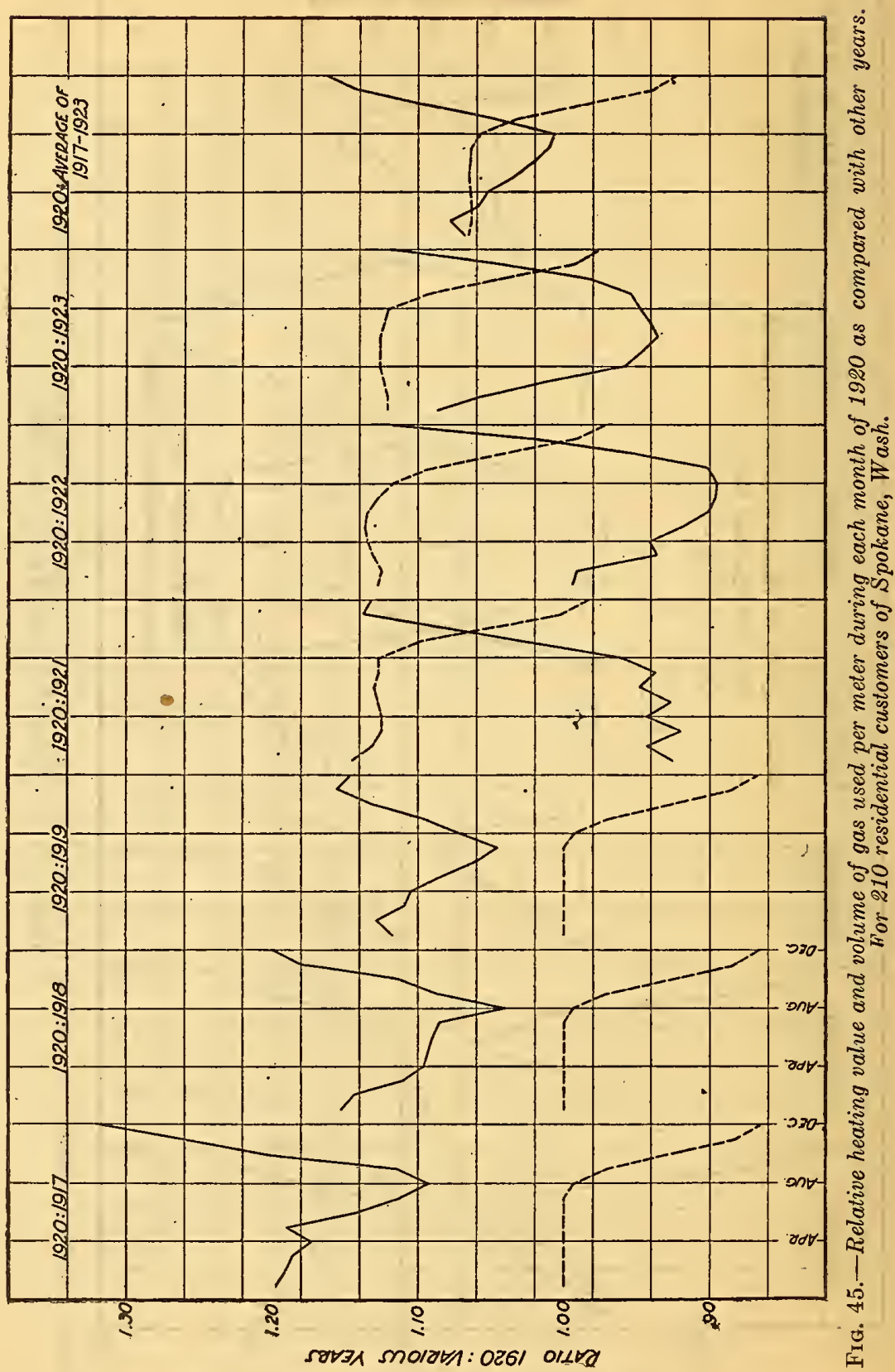


ings are accompanied by a diminishing use of gas until the heating value is changed. Any characteristic common to the six curves of one figure necessarily represents an effect peculiar to 1920 . The hook at the end of each of the consumption curves for the city as a whole, therefore, shows definitely that either the consumption in Norember of 1920 was abnormally large or that in December abnormally small. Our only evidence from which to judge which month was abnormal is the further downward break of bank clearings

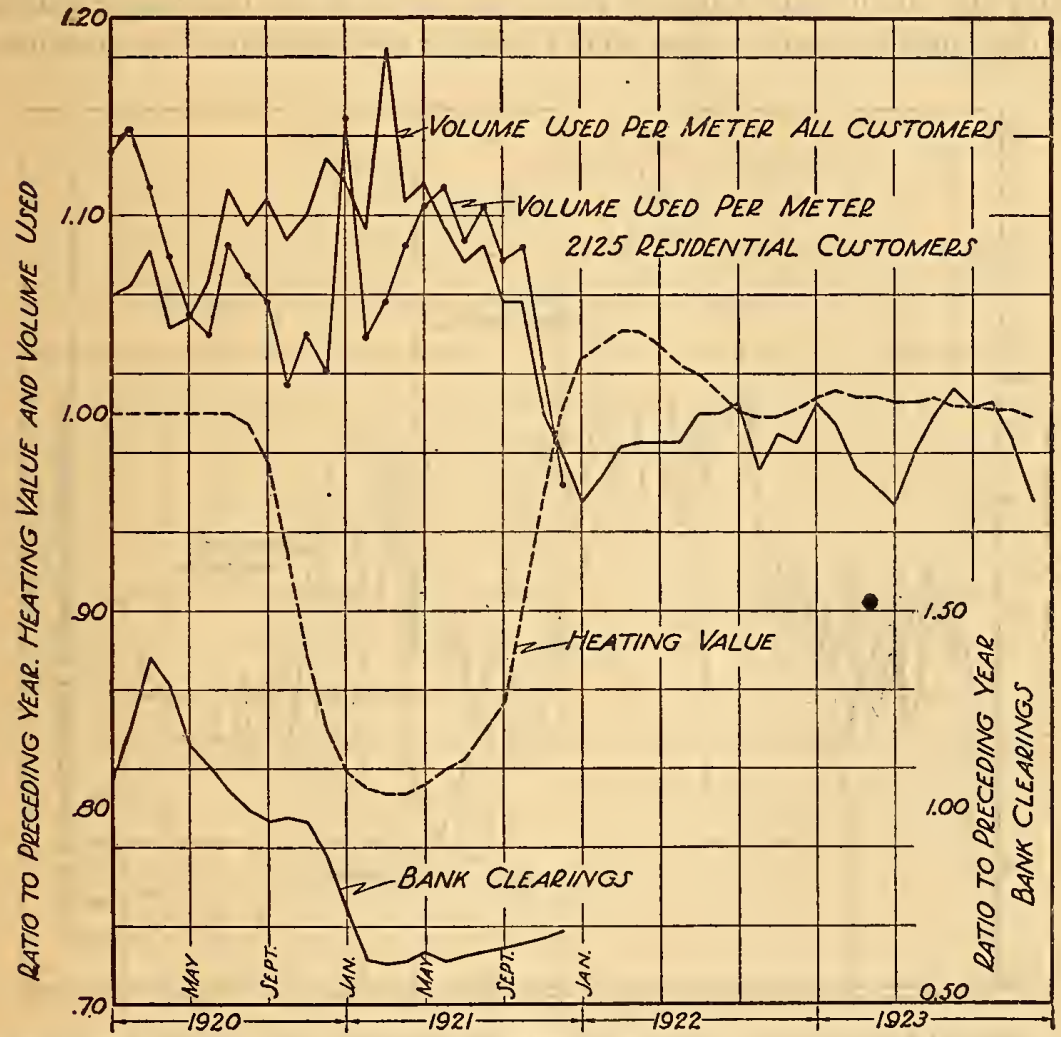

FIG. 46.-Relative heating value, volume of gas used per meter, and bank clearings for consecutive years in Tacoma, Wash.

at about the same time and the fact that the residential customers, who appear to be less (or less promptly) affected by industrial conditions, show no such consistent break. If we take $R$ for the city as a whole from the average curves from August to December, we get the value $R=0.85$. If we take the equal interval from July to November, we find $R=1.19$. The curves representing domestic customers give $R=1.05$ for August to December, and $R=1.02$ for July to November.

The data from Tacoma (fig. 46) at first glance indicate an exception to the general rule that the consumption changes in inverse propor- 
tion to the heating value. But little, if any, increase is apparent when comparing 1919 with 1920; but the large reduction in bank clearings indicates the reason. Tacoma has the same climate as Seattle, and the possible effect of temperature noted in the case of the latter city no doubt applied equally to Tacoma. An explanation of the trend of the curves relating to Tacoma must be looked for in the economic situation, however.

Unfortunately, Carey's data regarding the consumption per meter do not extend back of 1919; hence we must use Flagg's data on the total volume of gas sold in order to determine the previous

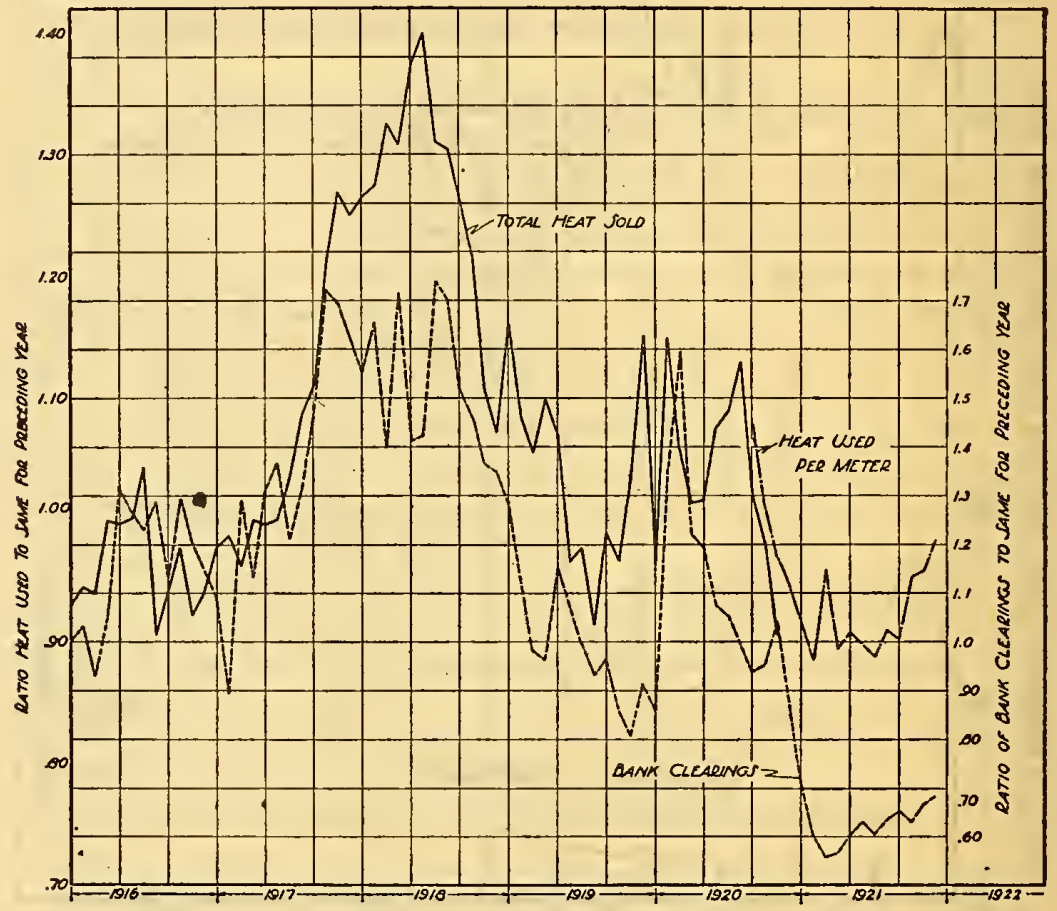

Frg. 47.-Relative bank clearings and amounts of heat in gas used during consecutive years in Tacoma, Wash.

trend of gas consumption. Figure 47 shows the relative amount of heat in the gas sold from year to year and the simultaneous changes in the volume of business indicated by bank clearings until the last date for which monthly clearings are available. It is at once apparent that the amount of heat used does not drop off more in the autumn and winter of 1920 than we would expect from the previous trend of the two curves. On comparing 1920 with the years 1921-23 (fig. 48) we find once more an approach to the reciprocal relation between heating value and consumption. The fact that these three curves are quite similar to each other, but very unlike that for 1920-1919 


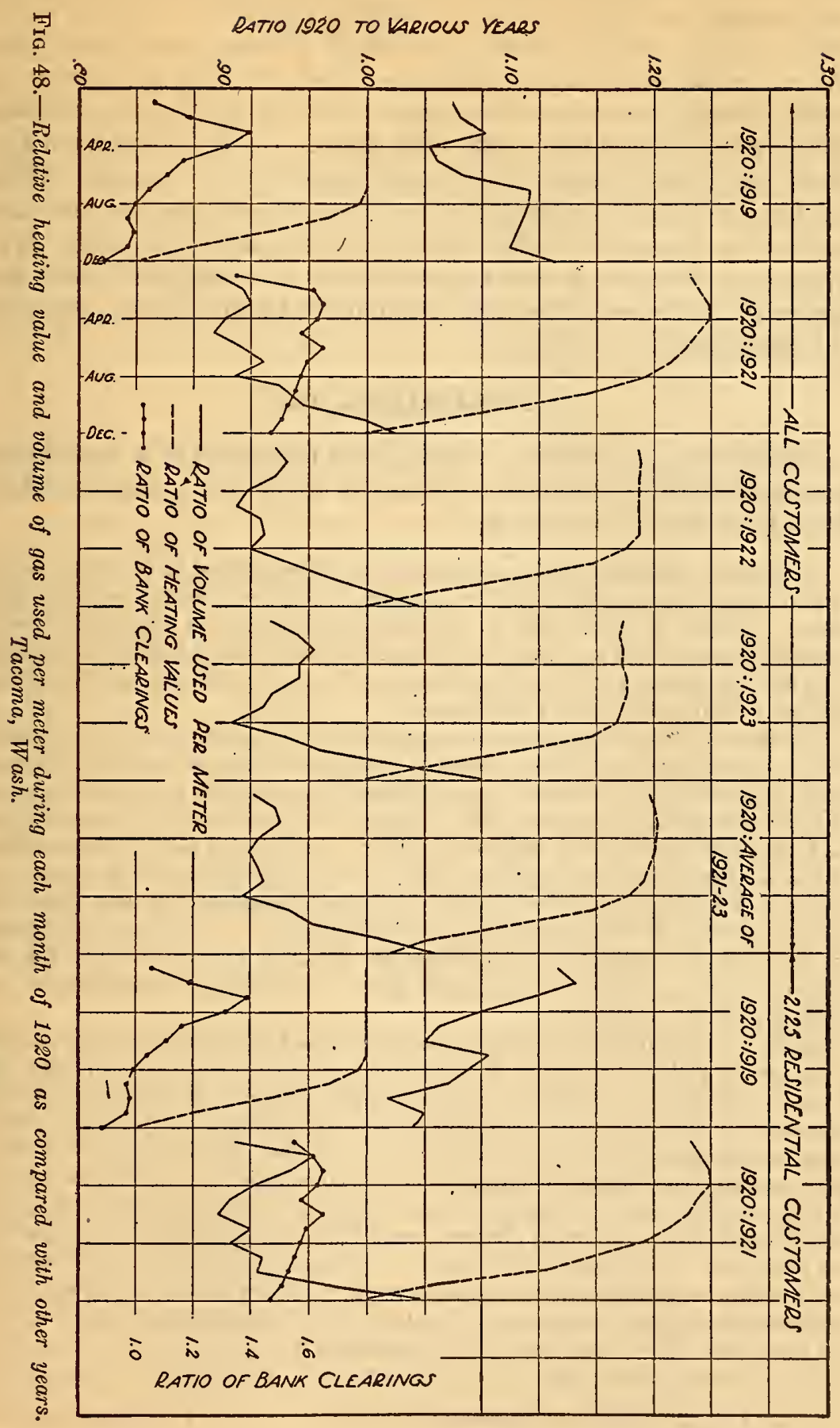


shows at once that 1919 was not normal; both business activity and the consumption of gas were increasing rapidly during the latter portion of the year. Hence, a value of $R$ based upon 1921-1923 will represent much more nearly the true effect of the change of heating value than a value based upon the average of the four years. The value of $R$ based upon $1920-1923$ is 0.82 . It is evident from Figure 47 that the changes of economic conditions in Tacoma during and after the war were greater than in Seattle or Spokane and that they had a more direct effect upon the amount of gas used. The explanation for this is not apparent, but it is suggested that the proximity to Tacoma of a big cantonment (Camp Lewis) may have had something to do with it.

\section{PHILADELPHIA, PA.}

The following quotation ${ }^{62}$ is made from the report of a commission appointed in 1921 "to make a survey of the property and operation of the Philadelphia Gas Works."

The various statistical analyses, including those submitted to this commission purporting to demonstrate that consumption does not increase, are not conclusive. Usually a partial list of consumers is taken and a comparison made between the amount of gas consumed under a candlepower or high B. t. u. standard with that under a low heating standard. Quite the reverse can be and has been proven by other lists of consumers.

The figures purporting to show comparisons for large numbers of consumers are also not conclusive. Widely different results are obtained in different places, and the most that can be said for such studies is that they do not prove that lowering the standard has increased bills. We have seen no study in which allowance has been made for one very important factor. In order to answer the question with some degree of conclusiveness comparison should be made between consumption through appliances adjusted to burn 22-candlepower gas most efficiently and through those adjusted to burn 530 and 550 B. t. u. gas most efficiently. No comparison is valid unless appliances are adjusted in both cases to the gas being consumed. Otherwise, any result may be obtained, depending upon the condition of the appliances.

Generally, appliances have not been examined and adjusted to burn 22-candlepower or high B. t. u. gas most efficiently before the quality of the gas was changed. Now, it is well known that consumers often change the adjustment of appliances themselves, and, not knowing just what should be done, they often make the situation worse rather than better. Further, appliances become dirty and corroded, the efficiency decreases, and gas consumption is thereby increased. But when the standard is changed the gas company, in order to avoid complaint, sends inspectors to examine appliances, clean them, make necessary adjustments, and even alter the appliances if necessary. Then a comparison is made between consumption when appliances are not in good condition and consumption when appliances have been overhauled. Would it not be surprising if consumption had increased? But what would have happened if all this work had been done and the character of the gas had not been changed? Would not the consumption

62 Report of the gas commission to the mayor and council of the city of Philadelphia, May, 1921; pp. 40-44. 
have decreased? If the same work had been done before the change in standard and none afterwards, what would then have been the result?

The futility of most comparisons is due to the difficulty of eliminating all factors affecting consumption except a change in standard. The amount of gas consumed is determined by many things-for example, temperature and weather conditions, price of food (roasts and cheap cuts require considerable gas for cooking, and when other foods are substituted consumption is affected), industrial conditions, wages, unemployment, price of electricity, cost of other fuel, etc. None of them has anything to do with candlepower $\mathrm{v}$. heating standard and yet they are so important that they easily submerge and obliterate the effect of a 10 or 15 per cent reduction in heating value.

Although believing that too great weight should not be attached to "before and after" comparisons of gas sales, the commission has caused a study to be made of the consumption of gas per meter during the last few vrears in Philadelphia, compared with the heating value of the gas supplied. This study indicates that consumption has increased as the heating value of the gas has decreased. The facts in detail appear in Tables 6 and 7. A graphic representation appears in the accompanying Chart $\mathrm{A}$, which shows that the amount of gas sold per meter in one month as compared with the same month of the preceding year generally increases and decreases inversely with the change in heating value. In other words, when the heating value of gas goes down the consumption of gas as compared with the same month in the preceding year goes up and vice versa. The only distinctive exception is in the spring of 1921, and this may be due in part to the recent extensive overhauling of appliances by the company.

The commission is of the opinion that for the great majority of purposes the amount of useful work which can be done with a given amount of gas is dependent upon its heating value, and that, other things being equal, the a mount of gas used will generally be inversely proportional to the heating value. Appliances can be adjusted to burn 22-candlepower or high-heating value gas just as efficiently as $530 \mathrm{~B}$. t. u. or low-heating value gas, and experiments have shown that with properly adjusted mantle burners the light produced varies approximately with the heating value. If the heating value is not a proper measure of the utility of gas, why should a heating standard be specified? It should be noted that even the witnesses produced by the company admitted that for water heating and for industrial purposes the amount of gas required would vary almost in exact inverse proportion with heating value.

All in all, it is our opinion that when a change is made from 22-candlepower gas to $535 \mathrm{~B}$. t. u., or a reduction in heating value of 17 per cent, the amount of gas required to do a given amount of work under conditions permitting each gas to be burned as efficiently as normal practice will allow will not be increased 17 per cent but a somewhat smaller amount, probably from 10 to 15 per cent. If these conclusions are sound, it follows that any reduction in the number of heat units supplied without a corresponding change in the price per thousand cubic feet will cause consumers to pay larger bills for the same amount of work performed. Consequently, any change in standard without consideration of the price and of the cost of making the lower-quality gas would be extremely unjust and wholly unwarranted, especially as the consumer using gas most efficiently is the one most adversely affected.

All that has been said is on the assumption that consideration is given to all other factors and that no change will be made in quality without decision as to the reasonable price which should be charged for the new gas. These factors are elsewhere considered in this report, and the price that should be charged for 530 B. t. u. gas is, and always should be, based upon the cost of the gas, which is relatively lower per heat unit for $530 \mathrm{~B}$. t. u. than for 22-candlepower gas. 
If consumers did not use more cubic feet of the low-heating value gas than the high-heating value gas, it is obvious that the-heating content should be reduced to the lowest possible point, for the cost of making the former is much less than the cost of the latter, and the price charged consumers per thousand cubic feet could be reduced materially. Consumers' bills would then be much less, because if they used no more gas to do the work required and if a lower price was charged per thousand cubic feet bills would be greatly reduced. The great economy of such a program would make it very attractive, and if quality can be reduced to $575 \mathrm{~B}$. t. u. without increasing the amount of gas consumed, why not reduce it to 500 or to 450 , or even to 300 , the B. t. u. content of blue gas? The foregoing discussion clearly indicates the fallacy of the broad assumption that the amount of gas consumed will not increase with a decline in heating values.

The data regarding the volume of gas used in Philadelphia, given in the report of the commission, are plotted in Figure 49. The discussion given by the commission is adequate.

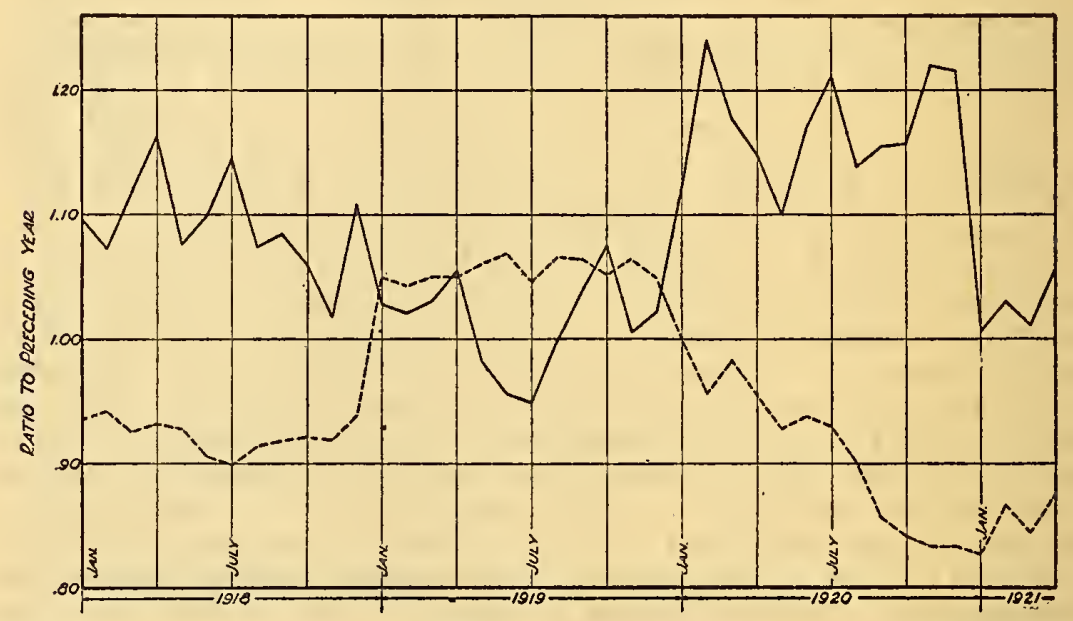

FIG. 49.-Heating value and volume of gas used per meter in Philadelphia, Pa., $1917-1920$

\section{NEW JERSEY}

Appendix 4 of the Report of Conference on Conservation of Coal and Oil by the Reduction of the Heating Value of Artificial Gas, August 28, 1918, which forms a portion of the Report of Committee on Heating Value of Artificial Gas to the United States Fuel Administrator, contains data for a short period of time during a reduction of heating value by the Public Service Co., which operates 12 plants in New Jersey. The State was divided into a northern and a southern section. The table gives the heating value and the change in send out as compared with the corresponding month of the preceding year. The data, converted into the form of ratios to the preceding year for both heating value and send out, are given in Table 14. 
It may be seen that the northern companies which reduced their heating value 2.6 per cent increased their sales 10.1 per cent, and that the southern companies, with a decrease of heating value of 5.6 per cent, increased their sales 12.0 per cent. With the disturbed conditions of industry at this time it is, of course, impossible to say how much of each of the increases was caused by the reduction of heating value. Perhaps the most significant thing about the table is the relatively greater increase of send out by the group of companies that reduced their heating value most.

TABLE 14.- - Heating value and send out of New Jersey gas companies in 1917 and 1918

\begin{tabular}{|c|c|c|c|c|}
\hline & \multicolumn{2}{|c|}{$\begin{array}{l}\text { Northern } \\
\text { companies }\end{array}$} & \multicolumn{2}{|c|}{$\begin{array}{l}\text { Southern } \\
\text { companies }\end{array}$} \\
\hline Month & \multicolumn{4}{|c|}{ Ratio to preceding year } \\
\hline & $\begin{array}{c}\text { Heating } \\
\text { value }\end{array}$ & $\begin{array}{c}\text { Send } \\
\text { out }\end{array}$ & $\begin{array}{c}\text { Heating } \\
\text { value }\end{array}$ & $\begin{array}{l}\text { Send } \\
\text { out }\end{array}$ \\
\hline $\begin{array}{l}\text { January } \\
\text { February } \\
\text { March } \\
\text { April } \\
\text { May } \\
\text { June } \\
\text { July }\end{array}$ & $\begin{array}{r}0.980 \\
.945 \\
.952 \\
.984 \\
.990 \\
.985 \\
.982 \\
\end{array}$ & $\begin{array}{l}1.114 \\
1.119 \\
1.159 \\
1.114 \\
1.114 \\
1.036 \\
1.049 \\
\end{array}$ & $\begin{array}{l}0.951 \\
.932 \\
.947 \\
.948 \\
.940 \\
.946 \\
.947 \\
\end{array}$ & $\begin{array}{l}\text { 1. } 156 \\
1.101 \\
1.104 \\
1.117 \\
1.159 \\
1.087 \\
1.114 \\
\end{array}$ \\
\hline Average........ & .974 & 1. 101 & .944 & 1. 120 \\
\hline
\end{tabular}

11. ROCHESTER, N. Y.

Appendix 3 of the Report of Conference on Conservation, etc., referred to under the preceding heading, gives data showing the heating value of the gas supplied in Rochester during 1916, 1917, and a part of 1918, together with the average of the "residence gas bills," including "approximately 70,000 accounts." Nearly the same data in a slightly different form are given in part C of Appendix GP of the Report of the Committee on Heating Value of Artificial Gas. In this tabulation the accounts of "some 60,000 domestic and residence gas customers" are divided into "straight gas customers" and "combined gas and electric customers."

The data from these two tabulations are plotted in Figures 50 and 51. Figure 50 shows by months the heating value of the gas, the average bills of the two classes of customers, and the ratio of the average bill of the combined gas and electric customers to the average bills of the straight gas customers. It is seen at once that not only the changes of consumption for both classes of customers but the relative changes of one class as compared with another so far exceed the change of heating value that we should not expect the latter to have a noticeable effect. We find large seasonal rariations 
in both the consumption and ratio curves, as well as irregular variations of unknown origin. Taking the heating value and ratio curves from this figure and the average bills for the city as a whole from Appendix 3, and comparing each month with the corresponding month of the preceding year, we obtain Figure 51. It is now seen that, while it would again be rash to say how much of the change of consumption resulted from change of heating value, five of the six periods of change of relative heating value which amount to more than 1 per cent show changes of consumption in the direction we should expect.

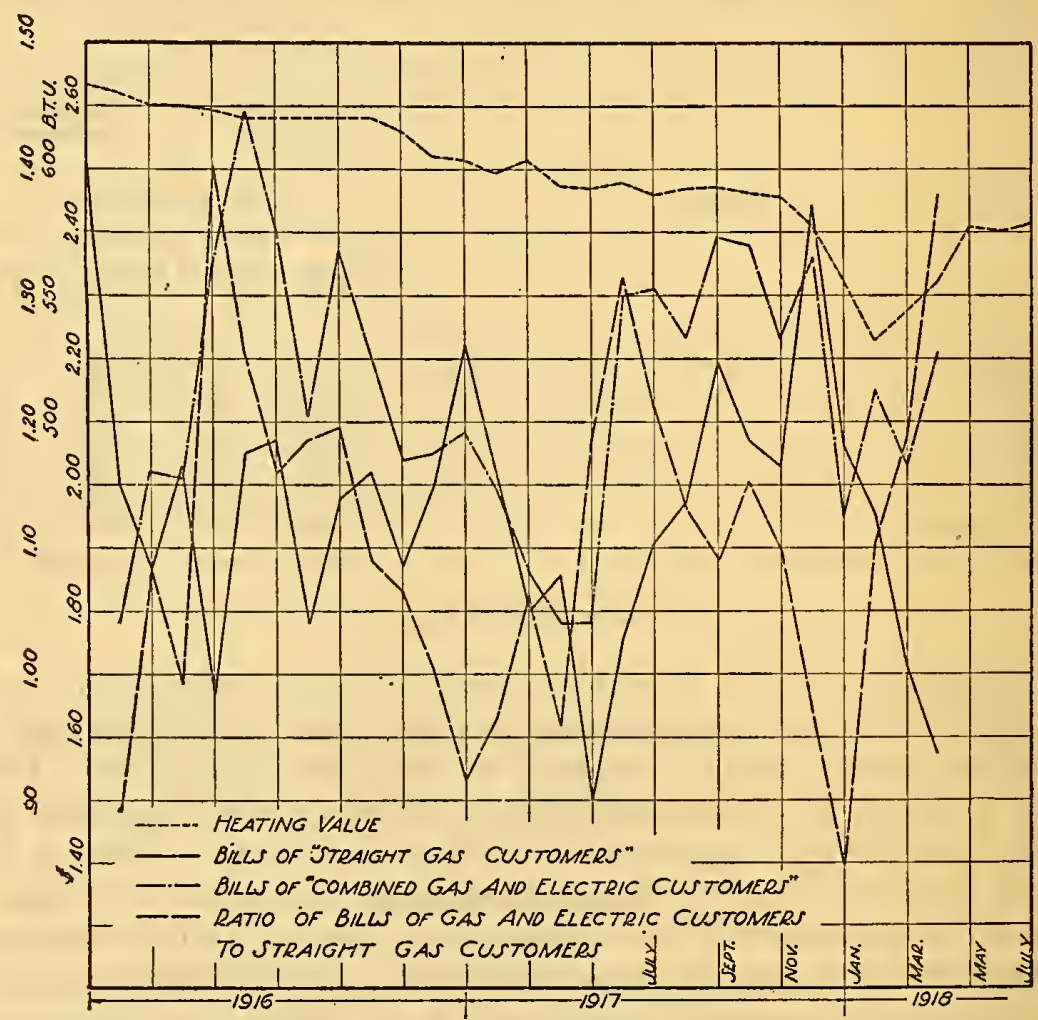

Frg. 50.-Heating value and consumers' bills in Rochester, N. Y.

The scale of ordinates at extreme left is for the ratio of bills of "gas and electric customers " to "bills of straight gas custonters"; the second scale at left is for the heating value; the third scale is for the average consumer's bill

These data from Rochester serve better, perhaps, than any other we have encountered to show how little reliance can be placed upon conclusions drawn from a limited time or a limited number of customers. Here we have 60,000 domestic consumers divided into two groups. The groups are supplied with the same gas; they form part of the same city and are therefore subject to the same conditions of weather and industry; they are compared in a manner which elimi- 


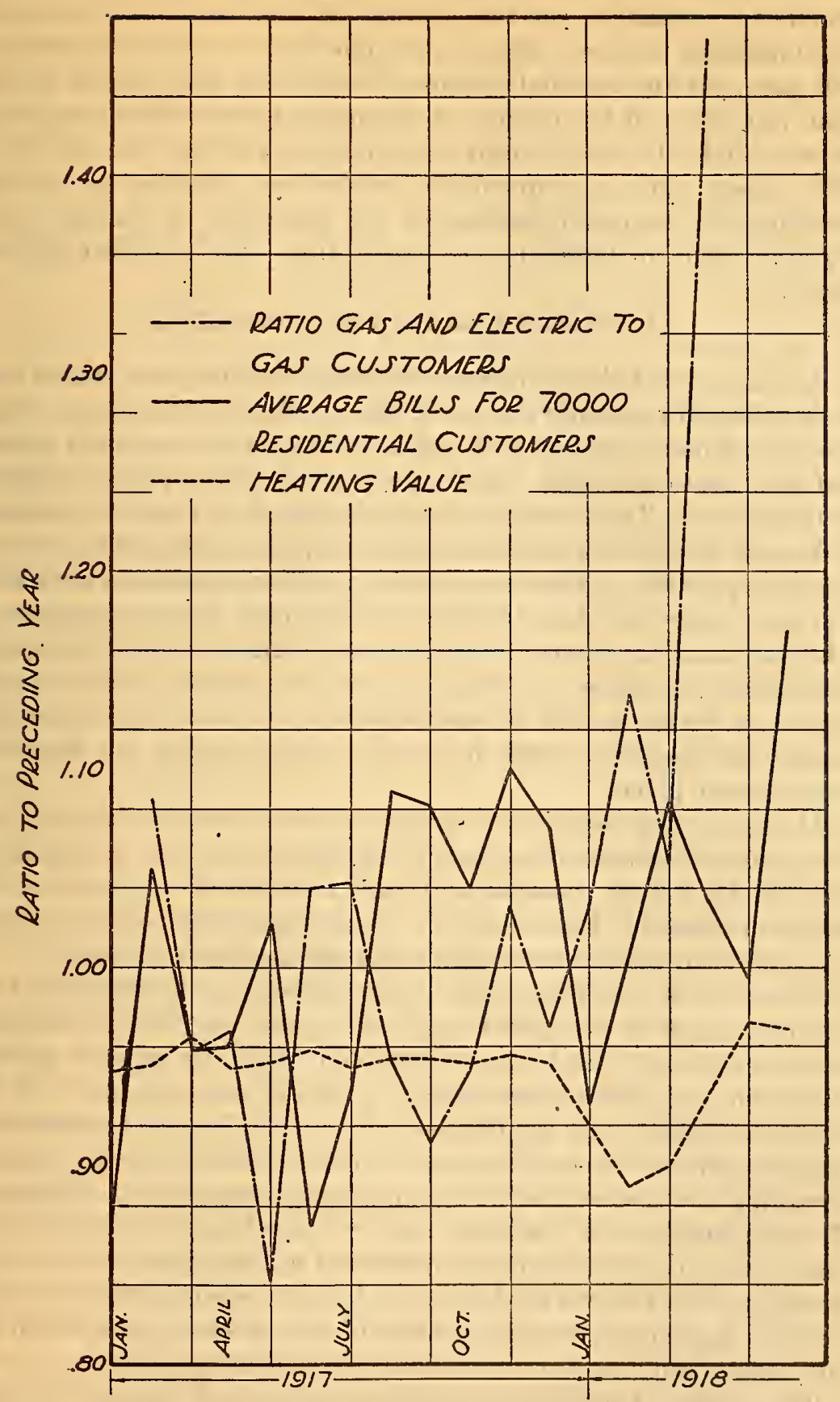

FIG. 51.-Relative heating value, average customer's bill, and ratio of different groups of customers for consecutive years in Rochester, N. Y. 
nates the effect of regular development and seasonal variations, and all effects common to the two classes. If there were any possibility of eliminating unknown effects, it should have been accomplished in this case; yet the residual irregular variation is many times greater than any effect of the change of heating value we could reasonably hope to find. It hardly needs to be pointed out that the data from New Jersey and from Rochester, while they may not prove that consumption increased because of the reduction of heating value, certainly give no indication whatever that such an effect did not occur.

\section{SELECTED GROUPS OF CUSTOMERS}

A further word should perhaps be said about the data which have been collected regarding the use of gas by selected customers. There are a good many references in the literature to such selected groups, but with few exceptions their importance does not justify inclusion in this review. The selection of such a group always involves personal judgment which, in a matter of this kind, it is desirable to avoid as much as possible. After the selection has been made it is impossible to check up on the data to determine whether they are accurate or whether some important factor has been overlooked; and it is equally impossible to extend the study in case the results for the period originally given should be inconclusive. It is believed that the reader will recognize these limitations after reading the statistical data already given.

Moreover, the selection of groups of customers in this way is a compromise between the direct determination of the usefulness of the gas by actual measurement and the statistical study of the apparent effect of changes upon a whole population, which does not possess in full the merits of either and has the faults of both.

If one wishes to know what useful effect can be obtained from different gases in any given appliance under any set of conditions whatever, the easy and only reasonable or accurate thing to do is to determine the information sought by actual measurement. If this could be applied to all appliances under all conditions of service with all gases, the results would give a complete answer to every question regarding the use of gas by any consumer or group of consumers. The only limitation of the direct method is the fact that it is physically impossible to make so large a number of actual observations as this would require, and we are left in doubt as to whether there may not be some appliances, come conditions of use, or some gases which will give results differing from the results we find in other cases.

The statistical study of the whole population of a large State over a period of seven years, such as we now have in the case of Massachusetts, pretty well eliminates the possibility of overlooking any of the important conditions of use of the gas, and this is the sole ad- 
vantage of the statistical method, whether applied to a State or a single consumer. The disadvantage of the broad statistical method is that there are numerous factors other than heating value which greatly affect consumption and most of these we have no way of eliminating or evaluating.

When a small group of consumers is selected for study we at once impose the limitation of the direct method of attack. How do we know that the customers selected are representative of the whole or that we have included all kinds of gas-burning equipment or all the conditions of use any more than when we use direct measurement? We have sacrificed all possibility of determining the useful service actually obtained by burning the gas and we have not eliminated with any degree of certainty the only objection to an actual observation of the facts desired. We have still most of the numerous and unknown effects of varying conditions within the city as a whole, with the possibility of having introduced others peculiar to the group or locality studied. Usually these groups are chosen to eliminate one variable among the many which affect the statistical method. The variable most frequently eliminated is the purchase of new appliances. Sometimes the additional requirement for selection is that the appliances in use shall not have been readjusted. This latter requirement is peculiarly unfair because it leaves out all the appliances in which it has been necessary to change the orifice and all those in which the change of gas renders the existing adjustment for any reason less suitable.

The other condition, that customers shall not have "changed their appliances," is probably equally misleading for the following reasons: The use of gas is constantly changing in almost every household; water heaters once used for a continuous supply are used only intermittently or are replaced entirely by coal-burning heaters; once popular space heaters get out of repair and are relegated to the attic; families break up or discontinue home baking or even home cooking; fireless cookers or electric appliances replace the use of gas for some purposes. In a community as a whole, such changes are more than counterbalanced by changes in domestic practice which increase the use of gas, but when a radical increase in the use of gas takes place it is usually accompanied by the purchase of a new appliance. When an appliance falls into disuse it is not likely to be immediately disconnected; still less likely is it that the appliance will be disposed of in a manner to bring to the attention of the gas company the fact of its removal. On the other hand, the gas company can very easily check up on the purchase of new appliances. Hence statistics based upon any reasonable number of consumers who are not known by the gas company to have changed their appliances must inevitably show a decrease in the use of gas. 


\section{DISCUSSION OF CHANGES IN VOLUME OF GAS USED BEFORE AND AFTER A CHANGE OF HEATING VALUE}

The individual cases of change of heating value have been discussed in sufficient detail in connection with their description. It remains to summarize them and to comment upon a few of the common errors which occur in the discussion of data of this class.

The general statement appears to be entirely justified that, in spite of the many complicating factors which affect consumption, every locality which has been studied in sufficient detail or over a sufficiently long time to permit a reliable conclusion has shown a change in the volume of gas used substantially equal to or greater than the change in heating value.

The data of outstanding importance appear to be those obtained in Massachusetts, California, and the cities of Washington--Massachusetts because of the great length of time and large number of companies studied and because two groups changed their heating value at different times offering unusual opportunities for a comparison; California because the committee on efficiency and economy appear to have made the most serious and intelligent effort on record to determine and eliminate disturbing influences; Seattle, Spokane, and Tacoma because we have detailed records regarding large populations over long periods of time and because the economic factors are for the first time easily traced.

In both California and Massachusetts the average effect of lowering the heating value appears to have been to increase the amount of gas used more than in proportion.

In most of the comparisons involving the several Stone \& Webster companies the irregularity of the curves does not permit us to judge what the quantitative relation between the changes of heating value and consumption is, but it does not appear from an inspection to be less than unity. In Providence, Spokane, and Sheboygan the ratio of the two changes appears to have been unity. Seattle and Tacoma show a little less than unity, and here the explanation is clearly one of rapidly changing economic conditions. The same is, no doubt, true for Montreal during the early part of the war. The curves for Philadelphia unquestionably indicate increases in the volume used when the heating value is decreased, but it is a little hard to fix the amount because of the irregularity of the curves. The data from New Jersey, Reading, Rochester, and Toronto are too fragmentary to be of much value, but they all indicate an increase in the volume of gas used when heating value is reduced. The increase is sometimes more and sometimes less than we should expect from the change of heating value alone; but in all these cities the effects of economic and weather conditions are obscure, and we have seen the very large part which such conditions play in the use of gas. 
In no case for which we have reasonably complete information is there any evidence whatever that a reduction of heating value actually caused the average customers to use less heat; this is a little hard to explain, in view of the fact that many appliances with fixed orifices certainly give less service after such a change.

We have defined a symbol $R$ to represent the ratio of the percentage of change in the volume of gas used (when corrected as far as possible to eliminate disturbing factors) to the percentage of change of heating value of the gas. $R$ was defined by the equation $R=\frac{-H v}{h(V+v)}$, in which $H$ represents the heating value of the gas before the change, $h$ the change of heating value, $V$ the volume of gas used by the community or group under consideration, and $v$ the change of volume used which appears to have been caused by the change of heating value.

The derivation and meaning of $R$ will be again illustrated by an example. The heating value of the gas distributed in Seattle in August, 1920, was 1.082 times the average heating value of the gas distributed during August of 1917, 1918, 1919, 1921, 1922, and 1923. The average heating value of the gas distributed in December of 1920 was 0.894 times the average heating value during December of the other six years. The average volume used per meter within the city in August, 1920, was 0.947 times the average volume used per meter during August of the other years. The average volume used during December of 1920 was 1.113 times the average for the other six years. In our formula for $R$

$$
\begin{aligned}
H & =1.082 \\
h & =0.894-1.082=-0.188 \\
V & =0.947 \\
v & =1.113-0.947=+0.166 \\
R & =\frac{1.082 \times 0.176}{0.188 \times 1.113}=0.86
\end{aligned}
$$

The meaning of $R$ will become clear from the following considerations: The amount of potential heat used by the average customer in August of 1920 was $1.082 \times 0.947=1.024$ times that used by the average customer during the same month of the other six years; the amount of potential heat used in December of 1920 was $0.894 \times$ $1.113=0.996$ times that used in other years. Had the change of heating value (or other unusual circumstances occurring during the months August to December) had no effect upon the amount of heat used, the ratio would have been 1.024 for December as well as for August; but had there been no effect upon the volume used, the ratio of rolumes would have remained 0.947 instead of increasing to 1.113. The increase, $1.113-0.947=0.166$, is 86 per cent $(R=0.86)$ of the increase which would have been necessary to maintain the constant ratio 1.024 for the potential heat used. 
It should be noted that the value of $R$ is unaffected by the general increase in the use of gas (13 per cent) taking place during the period studied or by seasonal variations in so far as these changes were regular and repeated themselves from year to year. The actual increase in the volume of gas used per meter per month from August to December was about 24 per cent, but only about half of this increase is peculiar to 1920 and occurs in the computation of $R$.

Table 15 gives the values of $R$ obtained in every case in which it seemed possible to arrive at a definite figure.

TABLe 15.-Values of $R$

[ $R$ is the ratio of percentage charge of consumption apparently caused hy change of heating value to the percentage change of heating value involved]

\begin{tabular}{|c|c|c|c|c|c|}
\hline \multirow[b]{2}{*}{ Case considered } & \multirow{2}{*}{$\begin{array}{l}\text { Approxi- } \\
\text { mate } \\
\text { number } \\
\text { of cus- } \\
\text { tomers }\end{array}$} & \multirow[b]{2}{*}{$\begin{array}{l}\text { Time con- } \\
\text { sidered }\end{array}$} & \multicolumn{2}{|c|}{$\begin{array}{c}\text { Changes of } \\
\text { heating value }\end{array}$} & \multirow{2}{*}{$\begin{array}{l}\text { Value } \\
\text { of } R\end{array}$} \\
\hline & & & Num- & $\begin{array}{l}\text { Magni- } \\
\text { tude of } \\
\text { largest } \\
\text { per cent }\end{array}$ & \\
\hline $\begin{array}{l}\text { Intercomparison between Fresno, Ios Gatos, and San } \\
\text { Jose. }\end{array}$ & 32,000 & 3 years & 6 & -12.6 & 1. 3 \\
\hline 14 restaurants in Santa Barbara 1 & 14 & 8 weeks & 1 & +27.3 & 1. 0 \\
\hline $\begin{array}{l}\text { Intercomparison of } 57 \text { companies of Massachusetts in } \\
\text { three groups. }\end{array}$ & 620,000 & 4 years. & 3 & -4.2 & 1. 2 \\
\hline $\begin{array}{l}\text { Intercomparison of } 57 \text { companies of Massachusetts in } \\
\text { three groups. }\end{array}$ & 620,000 & 7 year & 6 & -4.2 & 1. 4 \\
\hline $\begin{array}{l}\text { Comparison of Law rence and Lowell . - } \\
62 \text { industrial customers of Reading }\end{array}$ & 55,000 & 4 years & 1 & $\begin{array}{l}-4.8 \\
-3.3\end{array}$ & 1. 3 \\
\hline $\begin{array}{l}14 \text { industrial customers of Reading who did not change } \\
\text { their equipment. }\end{array}$ & 14 & 8 inonths. & 1 & -8.0 & .0 \\
\hline Prepayment meters in Reading.- & & 18 months... & 1 & -8.0 & 8 \\
\hline Shehoygan, Wis .- & 5,000 & 16 months.. & 1 & -10.0 & 1.0 \\
\hline Providence, R. I & 67,000 & 4 years... & 1 & -12.0 & 1.0 \\
\hline Seattle, all customers ${ }^{2}$ & 50,000 & 7 years.. & 1 & -19.0 & .9 \\
\hline Seattle, residential customers ${ }^{2}-$ & 2,873 & ......do_... & 1 & -19.0 & 1.0 \\
\hline Spokane, all customers ${ }^{3}$ & 9,000 & ...... do & 1 & -14.0 & 1.0 \\
\hline Spokane, residential customers & 210 & ......do.. & 1 & -14.0 & 1.0 \\
\hline Tacoma, all customers ${ }^{2}$ & 12,000 & 4 years & 1 & -19.0 & \\
\hline Philadelphia $4 . . . . . .$. & 417,000 & .....do_. & 2 & -20.0 & $0.6-0.9$ \\
\hline
\end{tabular}

1 Santa Barhara is interesting as our only case of a large increase of heating value.

2 Economic conditions known to have heen unfavorable to the change of volume used which the change of heating value would produce.

3 A verage of figures including and ornitting December, which appeared to he ahnormal. (See discussion.) 4 This value for $R$, which is difficult to determine because the change was made gradually at a time when other conditions were changing rapidly is the estimate of the Philadelphia Gas Commission.

Considering the fact that it is the groups which have been most thoroughly studied that have given the highest values for $R$, one who considered only the statistical data without prejudice in favor of any result would probably conclude that consumption changes a little more than in inverse proportion to a change of heating value. We must not lose sight, however, of the fact that, because of the great number of other factors affecting consumption, the statistical method is a very indirect, uncertain, and highly theoretical method of determining the relative usefulness of the different gases to the consumer, and can never have more than a small fraction of the value of the direct and simple observation of the actual performance of appliances. 


\section{RELATION OF DECREASED HEATING VALUE TO COMPLAINTS}

One of the most important arguments made in favor of a lower heating value standard is that experience has shown that the number of complaints received by the gas company (or public service commission) is not increased but rather reduced at the time of the change of heating value. This seems to apply only in those cities in which the consumers' appliances have been generally readjusted for gas of the new standard, however. Many writers speak of "floods of complaints," or use terms of similar meaning, when heating value was first reduced without readjustment of appliances. Several speak of the necessity of generally enlarging orifices, and a few of materially increasing pressures on the distributing systems in order to meet these complaints. When, however, a house to house canvass is made and every appliance correctly adjusted for the new quality of gas, complaints decrease. Surely there is nothing strange in this. All experience shows that gas of low heating value, even down to 300 B. t. u., can be burned satisfactorily in properly constructed and adjusted appliances. If adjustments are well made at the time of the house to house inspection of the appliances, many of which had probably not beem cleaned or adjusted for years, the appliances should be in far better condition to give service than before the change of heating value. The inspectors in this house to house canvass necessarily receive, and have opportunity to answer, a multitude of complaints which the customers have not yet taken the trouble to register; and they must discover and remedy many conditions which might lead to complaint in the future. It is not to the credit of the new standard that complaints are reduced, therefore. The same thing would happen in the case of any general inspection and adjustment of appliances and conditions of service in the homes of the consumers.

\section{RELATION OF RELATIVE USEFULNESS OF DIFFERENT GASES TO STANDARDS AND RATES}

This paper is not concerned with the general problems of determining the best standards or rates for gas service. Both problems involve many factors besides the relative usefulness to the consumer of the gas distributed. The conclusive evidence which we have found, showing that the customer is really concerned only with the amount of heat delivered and not with the volume, composition, or any other property of the gas which he buys, greatly simplifies the consideration of both rates and standards, and its relation to them should be pointed out.

Since it makes no difference in the use of gas how many cubic feet are required to deliver a million B. t. u., the consumer is not really 
concerned with the cost per thousand cubic feet. The users of gas are concerned only in receiving a continuous supply of gas at satisfactory pressure and at the lowest possible cost per $B . t$. $u$.

It directly follows from this that the heating value standard which is best in any locality is that which will permit the distribution of the quantity of potential heat required by the community served at the lowest total cost to the gas company. If a greater cost is incurred, either it must be paid by the public, or it must be paid by the gas company from its profits. Sometimes the second alternative is of greater disadvantage to the public than the first because, in order to provide extensions and maintain good service in other ways, the gas company must be able to attract capital.

The determination of what heating value will permit the distribution of potential heat at the least total cost is a complicated engineering and business problem involving a consideration of the manufacturing plant available; the relative cost of different fuels; the probable market for by-products, especially coke; the relation between manufacturing costs and the total cost of the service rendered by the company, etc. Some of these important conditions are subject to change, and the most economical heating value one year may not be the most economical five years later.

For this reason it is usually not desirable to prescribe heating value standards to remain in force for a long period of time. When there is no authority, such as a State public utility commission, which is competent to determine both rates and standards, it has been customary to grant franchises for a period of years specifying the price of gas (per thousand cubic feet) and the heating value. This in reality amounts to fixing the price of potential heat by contract but without leaving any easy method for the gas company to adjust its practice to meet changing economic conditions and engineering progress. The Bureau of Standards has long favored the inclusion in such a franchise of a provision allowing the gas company the option of changing the heating value at will, provided it does not change the essential part of the contract, which is the price of potential heat to the user. There are several good reasons for leaving this freedom to the gas company; the company's engineers will usually be the first to recognize the possibility of saving by the adoption of a new standard, and the fact that the saving is immediately added to their profits gives an incentive to develop improved methods, which will eventually result in benefit to the public.

One point that should never be lost sight of in the consideration of both rates and standards is that the effect of a change of heating value upon the service received by the public and the return made to the gas company for such service is the same as the effect of an inversely proportional change in the price of gas per thousand cubic feet. 


\section{SUMMARY}

This paper contains a critical review of available data regarding the relative usefulness of gases of different heating value. The sources of material have been limited to published data, official reports, and material which has been submitted as evidence to National, State, or municipal bodies in connection with hearings on rates or standards.

The review has been confined almost exclusively to facts expressed in definite figures; scant attention has been given to opinions and practically none to theory. In several cases, it is true, only the brief conclusions drawn from masses of data are given, usually in the authors' own words. This has been necessary to keep the length of the review within reasonable limits. Full references are given which permit anyone sufficiently interested to verify the correctness of all the data and conclusions.

The available data have been divided into two classes: (1) The direct determination of the useful effects actually obtained by burning gas in various appliances, and (2) statistics regarding the relative amount of gas used before and after changes of heating value.

The data in the second group have been treated in various ways to eliminate disturbing factors so far as possible and to bring out any relationship which exists between heating value and consumption.

With the exception of one or two minor investigations containing only a few observations each, the data of the first class are in remarkable accord and show definitely that for any of the common uses of gas the same amount of potential heat is equally useful regardless of the volume, composition, or other properties of the gas in which the potential heat is conveyed. The reviewer has attempted an explanation for this general relation in section 3 of the paper.

The data of the second class are also surprisingly consistent, considering the number and variety of other influences to which they are subject. They show definitely that the volume of gas consumed by a community under conditions otherwise reasonably constant is substantially inversely proportional to the heating value; or, what amounts to the same thing, that the amount of heat used by the community is not affected materially by a change of heating value of the gas supplied. The two classes of data thus lead to the same conclusion - that the usefulness to the consumer of a given volume of gas is accurately proportional to its heating value. The important consequences of this conclusion as applied to rates and standards are pointed out in the last section of the review.

Washington, April 6, 1925. 